GABRIEL DO NASCIMENTO GUIMARÃES

A ALTIMETRIA E O MODELO GEOIDAL NO ESTADO DE SÃO PAULO 
GABRIEL DO NASCIMENTO GUIMARÃES

\section{A ALTIMETRIA E O MODELO GEOIDAL NO ESTADO DE SÃO PAULO}

Dissertação apresentada à Escola Politécnica da Universidade de São Paulo para obtenção do título de Mestre em Engenharia

Área de Concentração:

Engenharia de Transportes

Ênfase:

Informações Espaciais

Orientador:

Prof. Dr. Denizar Blitzkow 
Este exemplar foi revisado e alterado em relação à versão original, sob responsabilidade única do autor e com a anuência de seu orientador.

São Paulo, de agosto de 2010.

Assinatura do autor

Assinatura do orientador

FICHA CATALOGRÁFICA

Guimarães, Gabriel do Nascimento

A altimetria e o modelo geoidal no Estado de São Paulo / G.

N. Guimarães. -- ed.rev. -- São Paulo, 2010.

$119 \mathrm{p}$.

Dissertação (Mestrado) - Escola Politécnica da Universidade de São Paulo. Departamento de Engenharia de Transportes.

1. Geodésia física 2. Gravidade 3. Satélites artificiais I. Uni versidade de São Paulo. Escola Politécnica. Departamento de Engenharia de Transportes II. t. 
Aos meus adoráveis e amados pais Odair e Raquel e a minha incomparável avó Aparecida (in memorian). 


\section{AGRADECIMENTOS}

Agradeço acima de tudo a Deus, pelo discernimento, sabedoria e saúde a mim concedido, para solucionar, contornar e superar todas as dificuldades encontradas ao longo deste percurso.

Ao professor, orientador e amigo Dr. Denizar Blitzkow pela oportunidade, confiança e incentivo em todas as etapas deste trabalho. Pela amizade adquirida ao longo do tempo, pelo convívio quase que diariamente e também pelas longas, prazerosas e sorridentes conversas.

À minha família pelo apoio, dedicação e orientação em todos os momentos.

Aos professores Dr. Edvaldo Simões da Fonseca Junior e Dra. Ana Paula Larocca, pelo apoio e sugestões de grande valia oferecidas. Ao professor Jorge Alves Trabanco pela amizade e o convívio nos trabalhos de campo.

À colega e talentosa pesquisadora Dra. Ana Cristina de Oliveira Cancoro Matos, que tanto me auxiliou ao longo deste trabalho.

Aos colegas de turma, em especial aos amigos Augusto César Barros Barbosa, Flávio Guilherme Vaz de Almeida Filho e Wagner Carrupt Machado.

Aos profissionais do Instituto Brasileiro de Geografia e Estatística (IBGE) pelos trabalhos de campo, em especial ao amigo e incomparável engenheiro de levantamentos Carlos Alberto Corrêa e Castro Junior.

Aos meus amigos que sempre me incentivaram e vibraram em todas as conquistas.

Aos técnicos de laboratório Adalberto Mariano e Arildo pelo suporte e ajuda. A todos os funcionários do Departamento de Engenharia de Transportes da Escola Politécnica da Universidade de São Paulo. 
À Escola Politécnica da Universidade de São Paulo pelo fornecimento de toda infraestrutura.

Finalmente, ao Conselho Nacional de Desenvolvimento Científico e Tecnológico CAPES pela concessão da bolsa de mestrado. 
A imaginação é mais importante que a ciência, porque a ciência é limitada, ao passo que a imaginação abrange o mundo inteiro. 


\section{RESUMO}

Esta dissertação tem como objetivo o estudo da altimetria e do modelo geoidal no estado de São Paulo. Para isso, uma abordagem detalhada do Problema de Valor de Contorno da Geodésia foi realizada. Além disso, são apresentados conceitos relacionados ao sistema de altitudes e a determinação das ondulações geoidais. Uma investigação do movimento e deslocamento vertical da crosta terrestre por meio do processamento preciso por ponto de duas estações de monitoramento contínuo (Cananeia - NEIA e Ubatuba - UBAT), localizadas no litoral paulista, foi efetuada. Constatou-se uma similaridade nos resultados por meio da comparação com o processamento feito pelo IBGE. A comparação envolvendo o Nível Médio dos Mares de duas estações maregráficas com relação ao nivelamento advindo de Imbituba foi outro estudo executado, onde a diferença após algumas correções foi de 0,34 cm. Uma análise a partir de 199 estações GPS sobre nivelamento foi realizada para comparação da ondulação geoidal com as anomalias de altura. As anomalias foram calculadas a partir dos modelos do geopotencial (EIGEN-GL04, EIGEN-5C e EGM08 para diferentes valores de grau e ordem). Os modelos que apresentaram melhor consistência com as estações GPS sobre nivelamento foram o EIGEN-GL04C e EIGEN-5C grau e ordem 360 e o EGM08 grau e ordem 360 e 2160. O modelo geoidal do estado de São Paulo foi gerado para um modelo digital de 5'. Utilizou-se a integral modificada de Stokes a partir do pacote computacional canadense SHGEO para o cálculo da componente de curto comprimento de onda. Foram empregados dados gravimétricos já existentes e dados advindos dos trabalhos de campo referentes ao Projeto Temático da FAPESP. No cálculo da componente de médio e longo comprimento de onda foi utilizado o modelo do geopotencial EGM08 (grau e ordem 150). A comparação com os dados GPS sobre nivelamento apresentou média de -0,22 m e RMSD 0,21 m. A escolha do estado de São Paulo está relacionada à grande quantidade de trabalhos geodésicos e atividades na área da engenharia e que necessitam da utilização de um sistema altimétrico. Além disso, a grande quantidade de dados gravimétricos e de estações GPS/RN é mais uma justificativa para a realização do trabalho no estado.

Palavras chaves: Geodésia. Altimetria. Geoide. 


\begin{abstract}
The investigation of the altimetry and the geoid model in São Paulo state is the aim of this dissertation. A detailed study concerning the Geodetic Boundary Value Problem was carried out. Moreover, the concepts related to the height system are presented. The analysis of the crust vertical displacement involving two continuous monitoring GPS stations (Cananeia - NEIA and Ubatuba - UBAT) in the coast of the state was performed. It was detected similar results between the comparison involved IBGE processing. A comparison involving the mean sea level of two tide gauge stations with respect to levelling from Imbituba was carried out. After some corrections the difference found was $0.34 \mathrm{~m}$. A comparison between height anomalies by the Global Geopotential Models (EIGEN-GL04, EIGEN-5C and EGM08 for different degree and order) and 199 GPS observations on Bench Marks of the spirit leveling network was performed. The Global Geopotential Models that presented consistency with GPS on Bench Marks were: EIGEN-GL04C and EIGEN5C degree and order 360 and EGM08 degree and order 2160. São Paulo state geoid model was computed in 5' digital model. The modified Stokes integral by the Canadian package SHGEO to compute the short wavelength component was used, from Helmert gravity anomalies derived. Existing gravity data and data from FAPESP Thematic Project was processed. EGM08 model was used as a reference field restricted to degree and order 150 to obtain the long and medium wavelength components. The comparison with GPS on Bench Marks presented mean $-0.22 \mathrm{~m}$ and RMSD $0.21 \mathrm{~m}$. The reason for the choice of São Paulo state is that there are a lot of geodetic activities and important engineering works that require the use of a height system. Furthermore, there are a lot of gravimetric and GPS/BM data all around the state.
\end{abstract}

Keywords: Geodesy. Height system. Geoid. 


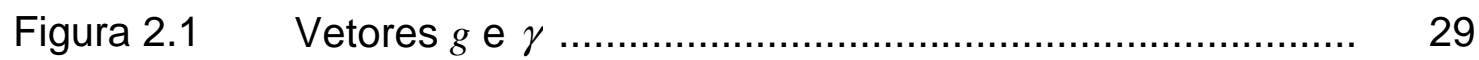

Figura 2.2 Quantidades envolvidas no problema de Molodenskii ....... 32

Figura 2.3 Determinação da altitude elipsoidal e correções aplicadas 39

Figura 2.4 Altitude dinâmica ...................................................... 43

Figura $2.5 \quad$ Altitude ortométrica …………………......................... 43

Figura 2.6 Altitude normal ....................................................... 45

Figura $2.7 \quad$ Altitudes niveladas ................................................... 46

Figura $2.8 \quad$ Elementos da altitude geodésica .................................... 47

Figura 2.9 Rede Altimétrica de Alta Precisão do Sistema Geodésico Brasileiro ................................................................... 48

Figura 2.10 Nivelamento de Precisão do estado de São Paulo ............ 49

Figura 2.11 Rede Maregráfica Permanente para Geodésia ................ 50

Figura 2.12 Discrepância entre o datum de Imbituba e o NMM local em algumas estações maregráficas ................................ 51

Figura 2.13 Gravímetro de mola ................................................... 54

Figura 2.14a Gravímetro LaCoste \& Romberg ………………........... 55

Figura 2.14b Gravímetro SCINTREX ……………........................... 55

Figura 2.14c Gravímetro absoluto FG5 ……………….................. 55

Figura 3.1a Satélite GRACE ……................................................ 61

Figura 3.1b Satélite LAGEOS ………………............................ 61

Figura 3.2 Distribuição dos dados de superfície ................................ 62

Figura 3.3 Anomalia de gravidade para um modelo digital de 30 ' $x$ 30 
Figura $3.4 \quad$ Fonte de dados de $\Delta g$ para um modelo digital de $5^{\prime} \times 5^{\prime} \ldots$

Figura $3.5 \quad$ Disponibilidade dos dados de $\Delta \mathrm{g}$ para um modelo digital

de $5^{\prime} \times 5^{\prime}$

Figura 4.1 Componentes da ondulação geoidal

Figura 4.2 Reduções gravimétricas 76

Figura 5.1 Estações GNSS no estado de São Paulo 79

Figura 5.2 Latitude (estação NEIA) 84

Figura 5.3 Longitude (estação NEIA) 84

Figura 5.4 Altitude geodésica (estação NEIA) 85

Figura 5.5 Altitude filtrada e sem tendência (estação NEIA) 85

Figura 5.6 Deslocamento planimétrico da estação NEIA 85

Figura 5.7 Coordenadas da estação NEIA processadas pelo IBGE ... 85

Figura 5.8 Latitude (estação UBAT) 88

Figura 5.9 Longitude (estação UBAT) 88

Figura 5.10 Altitude geodésica (estação UBAT) .... 88

Figura 5.11 Altitude filtrada e sem tendência (estação UBAT) 89

Figura 5.12 Deslocamento planimétrico da estação UBAT 90

Figura 5.13 Coordenadas da estação UBAT processadas pelo IBGE .. 90

Figura 5.14 Maregráfos da base Dr. João Paiva de Carvalho 91

Figura 5.15 Comparação do NMM 92

Figura 5.16 Desvio padrão da altitude ajustada 93

Figura 5.17 Estações GPS/RN 94

Figura 5.18 Discrepâncias entre GPS/RN e GGMs - EIGEN-GL04 ..... 95

Figura 5.19 Diferença entre GPS/RN e GGMs - EIGEN-GL04 96

Figura 5.20 Discrepâncias entre GPS/RN e GGMs - EIGEN-5C 98 
Figura 5.21 Diferença entre GPS/RN e GGMs - EIGEN-5C .............. 99

Figura 5.22 Discrepâncias entre GPS/RN e GGMs - EGM08 ............. 100

Figura 5.23 Diferença entre GPS/RN e GGMs - EGM08 ….............. 101

Figura 5.24 Distribuição dos dados gravimétricos no estado de São

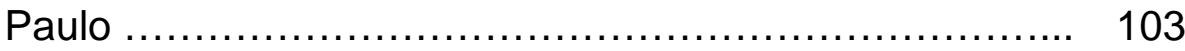

Figura 5.25 Anomalia de gravidade de Helmert ......................... 104

Figura 5.26 Modelo geoidal do estado de São Paulo ..................... 105

Figura 5.27 Discrepância entre GPS/RN e GEOIDSP2010 ............ 107

Figura 5.28 Diferença entre o GPS/RN e GEOIDSP2010 ............... 107

Figura 5.29 Interpolação da diferença entre o GPS/RN e

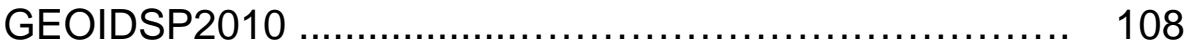

Figura 5.30 Pares de pontos selecionados …......................... 109

Figura 5.31 Diferença relativa entre o GPS/RN e GEOIDSP2010 ....... 110 


\section{LISTA DE TABELAS}

Tabela 2.1 Grandezas do PVCG …............................................ 40

Tabela $2.2 \quad$ Unidades de medidas de $\mathrm{g}$............................................ 53

Tabela 3.1 RMS da média dos dados GPS/RN menos o modelo do campo de gravidade derivada das ondulações geoidais EIGEN-GL04C

Tabela 3.2 RMS da média dos dados GPS/RN menos o modelo do campo de gravidade derivada das ondulações geoidais EIGEN-5C

Tabela 3.3 Comparativo entre o EGM96 e o EGM08

Tabela 3.4 Desvio padrão da ondulação geoidal dos dados de GPS/RN

Tabela 5.1 Coordenadas da estação NEIA

Tabela 5.2 Coordenadas da estação UBAT .

Tabela 5.3 Estatística entre GPS/RN e GGMs - EIGEN-GL04

Tabela 5.4 Estatística entre GPS/RN e GGMs - EIGEN-5C

Tabela 5.5 Estatística entre GPS/RN e GGMs - EGM08 102

Tabela 5.6 Estatística da diferença absoluta 107

Tabela 5.7 Estatística da diferença relativa 


\section{LISTA DE SIGLAS E ABREVIATURAS}

ANP

ANU

ArcGP

CHAMP

CNES

CSRS

DGPS

DNSC

DORIS

EESC

EGM08

EINGEN

Emplasa

ENVISAT

EPUSP

FAPESP

FFT

GAPS

GFZ

GGM

GLONASS
Agência Nacional de Petróleo

Australian National University

Arctic Gravity Project

CHAllenging Minisatellite Payload for Geophysical Research and Application

Centre National D'Etudies Spatiales

Canadian Spatial Reference System

Differential GPS

Danish National Space Center

Doppler Orbit Determination and Radiopositioning Integrated on Satellite

Escola de Engenharia de São Carlos

Earth Gravity Model 2008

European Improved Gravity Model of the Earth by New Techniques

Empresa Metropolitana de Planejamento da Grande São Paulo S.A.

Environmental Satellite

Escola Politécnica da Universidade de São Paulo

Fundação de Amparo à Pesquisa do Estado de São Paulo

Fast Fourier Transform

GPS Analysis and Positioning Software

GeoForschungsZentrum Potsdam

Global Geopotential Model

Global'naya Navigatision-naya Sputnikovaya Sistema 


\begin{tabular}{|c|c|}
\hline GNSS & Global Navigation Satellite System \\
\hline GOCE & Gravity field and steady-state Ocean Circulation Explorer \\
\hline GPS & Global Positioning System \\
\hline GRACE & Gravity Recovery And Climate Experiment \\
\hline GSFC & Goddard Space Flight Center \\
\hline IAG & Instituto de Astronomia, Geofísica e Ciências Atmosféricas \\
\hline IAG & International Association of Geodesy \\
\hline IBGE & Fundação Instituto Brasileiro de Geografia e Estatística \\
\hline IERS & International Earth Rotation and Reference Systems Service \\
\hline IGC & Instituto Geográfico e Cartográfico \\
\hline IGG & Instituto Geográfico e Geológico \\
\hline IGS & International GNNS Service \\
\hline ITRF & International Terrestrial Reference Frame \\
\hline JPL & Jet Propulsion Laboratory \\
\hline LAGEOS & Laser Geodynamics Satellite \\
\hline LTG & Laboratório de Topografia e Geodésia \\
\hline LLR & Lunar Laser Range \\
\hline Metrô & Companhia do Metropolitano de São Paulo \\
\hline NAD83 & North American Datum 1983 \\
\hline NGA & National Geo-spatial Intelligence Agency \\
\hline NIMA & National Imagery and Mapping Agency \\
\hline NMM & Nível Médio dos Mares \\
\hline NRCan & Natural Resources Canada \\
\hline ON & Observatório Nacional \\
\hline PETROBRAS & Petróleo do Brasil S.A. \\
\hline
\end{tabular}




\begin{tabular}{ll} 
PIB & Produto Interno Bruto \\
PPP & Posicionamento Preciso por Ponto \\
PVC & Problema de Valor de Contorno \\
PVCG & Problema de Valor de Contorno da Geodésia \\
RAAP & Rede Altimétrica de Alta Precisão \\
RBMC & Rede Brasileira de Monitoramento Contínuo \\
RMPG & Rede Maregráfica Permanente para Geodésia \\
RN & Referência de Nível \\
RTK & Real Time Kinematic \\
Sabesp & Companhia de Saneamento Básico do Estado de São Paulo \\
SGB & Sistema Geodésico Brasileiro \\
SI & Sistema Internacional \\
SIRGAS2000 & Sistema de Referência Geocêntrico para as Américas \\
SLR & Satellite Laser Range \\
SRTM & Shuttle Radar Topographic Mission \\
TSO & Topografia da Superfície Oceânica \\
UFPR & Universidade Federal do Paraná \\
UFSCAR & Universidade Federal de São Carlos \\
UNB & Universidade de Brasília \\
UNESP & Universidade Estadual Paulista \\
UNICAMP & Universidade de Campinas \\
USP & Universidade de São Paulo \\
WGS 84 & World Geodetic System 1984 \\
\hline
\end{tabular}




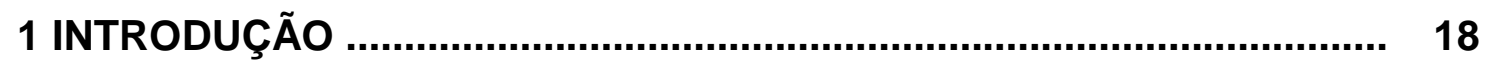

1.1 Considerações Gerais ............................................................. 18

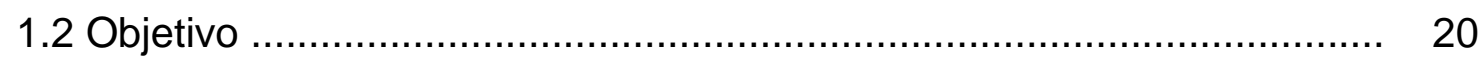

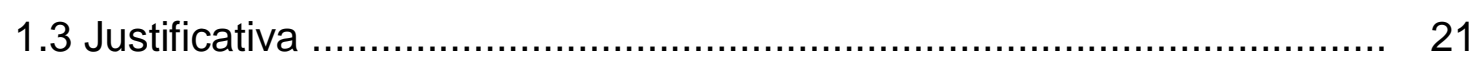

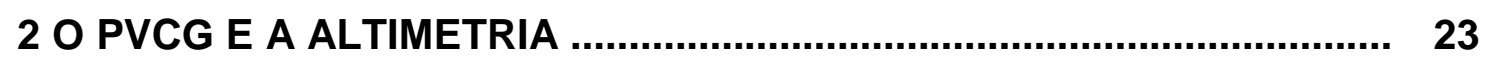

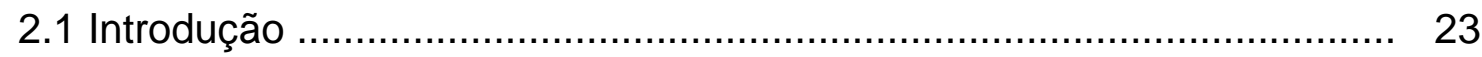

2.2 A Teoria do Potencial ............................................................ 24

2.3 O Problema de Valor de Contorno da Geodésia ................................. 26

2.4 A Formulação Clássica do PVCG ................................................... 28

2.5 A Formulação Moderna do PVCG ................................................... 30

2.6 Considerações sobre o PVCG .......................................................... 34

2.6.1 O PVCG "Livre" ............................................................... 35

2.6.2 O PVCG "Escalar Livre" ........................................................... 35

2.6.3 O PVCG "Fixo" .................................................................. 37

2.6.4 O PVCG “Gravimétrico Fixo” ..................................................... 38

2.7 Síntese do PVCG ..................................................................... 39

2.8 Sistemas de Altitudes ................................................................... 40

2.8.1 Número Geopotencial ........................................................... 41

2.8.2 Altitudes Físicas .................................................................. 42

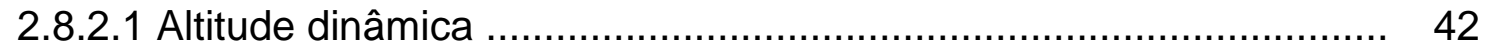

2.8.2.2 Altitude ortométrica ............................................................... 43

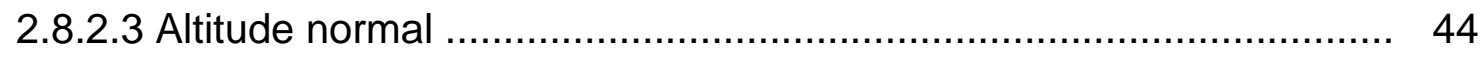

2.8.3 Altitudes Geométricas .............................................................. 45

2.8.3.1 Altitude nivelada ................................................................... 46

2.8.3.2 Altitude geodésica ................................................................. 47

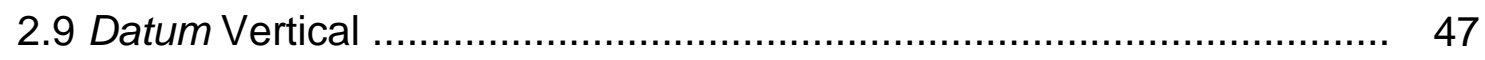

2.10 Topografia da Superfície Oceânica ................................................. 51

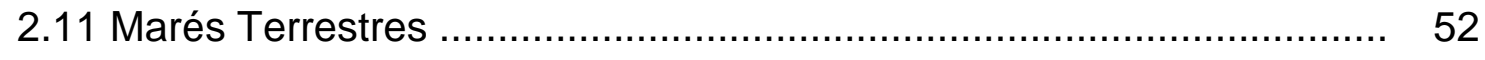

2.12 Gravimetria ….................................................................... 53 
3 MODELOS DO GEOPOTENCIAL

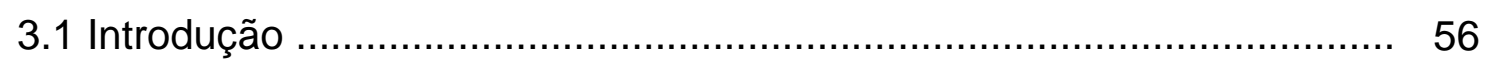

3.2 A Evolução dos Modelos do Geopotencial ........................................ 57

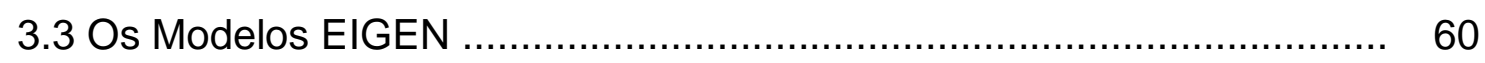

3.3.1 O Modelo EIGEN-GL04C ...................................................... 60

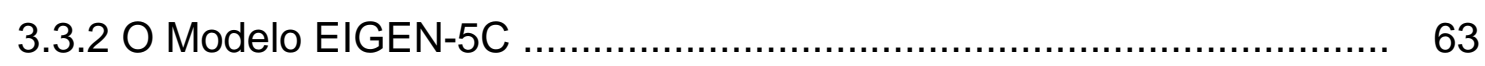

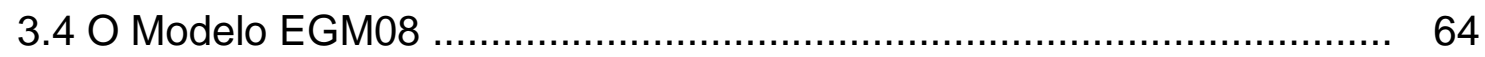

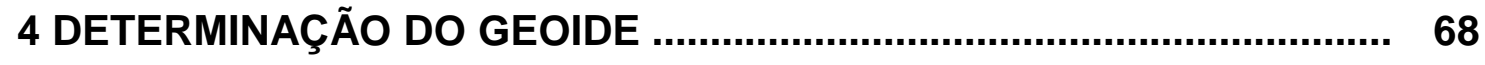

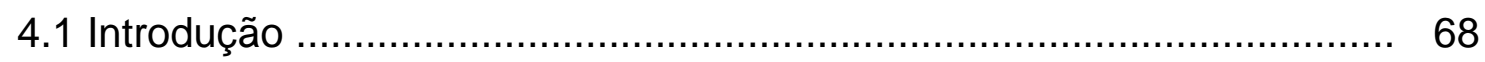

4.2 Integral de Stokes .................................................................. 69

4.2.1 Integral Modificada de Stokes ...................................................... 70

4.3 Transformada de Fourier ........................................................... 72

4.4 Anomalias de Gravidade ......................................................... $\quad 74$

4.4.1 Condensação de Helmert ......................................................... 76

5 CONSISTÊNCIA ENTRE A ALTIMETRIA E O MODELO GEOIDAL .... 78

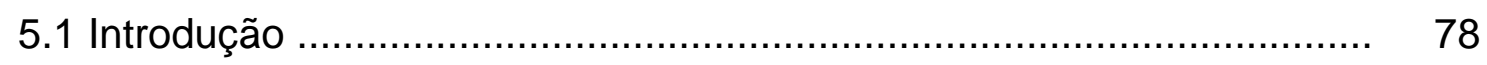

5.2 Comportamento da Crosta Terrestre no Litoral Paulista .................... $\quad 78$

5.2.1 Posicionamento Preciso por Ponto ……………........................... $\quad 79$

5.2.1.1 Serviços disponíveis do PPP ............................................... 80

5.2.2 Resultados das Estações NEIA e UBAT ......................................... 83

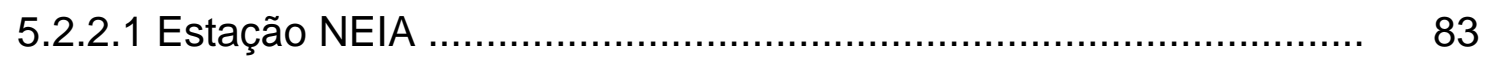

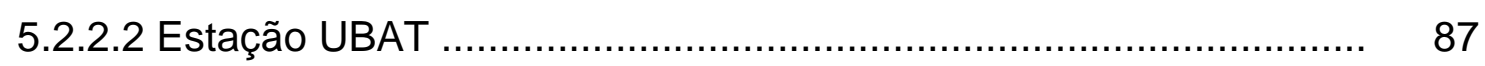

5.3 Comparação do Nivelamento com o Nível Médio do Mar .................... 91

5.4 Comparação entre GPS/RN e GGMs .............................................. 93

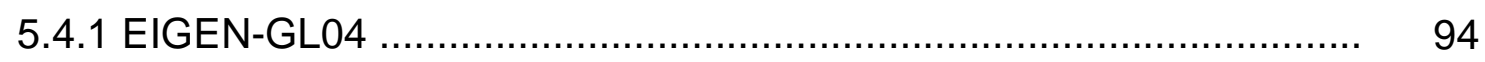

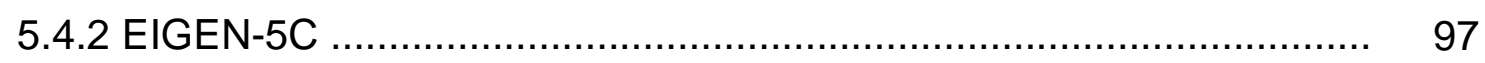

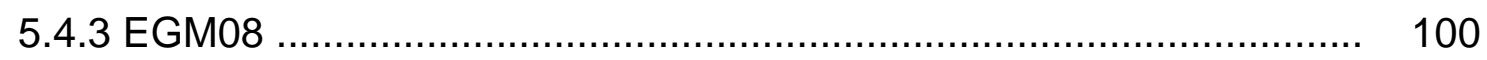

5.5 Modelo Geoidal do Estado de São Paulo ........................................ 102

5.5.1 Validação do Modelo Geoidal ................................................... 105

5.5.1.1 Comparação GPS/RN e GEOIDSP2010 absoluta ....................... 106

5.5.1.2 Comparação GPS/RN e GEOIDSP2010 relativa ......................... 108 
6 CONCLUSÕES E CONSIDERAÇÕES

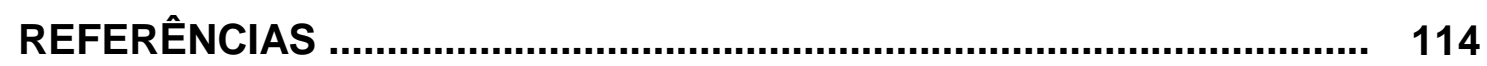




\section{INTRODUÇÃO}

\subsection{Considerações Gerais}

No passado, a Geodésia era dividida em Geométrica, Espacial e Física. Entretanto, essa divisão já não tem sentido, pois, atualmente há uma interação entres essas três partes. É plausível, então, dizer que a Geodésia se preocupa com 3 objetos: o estudo da forma e das dimensões da Terra, os parâmetros de orientação da Terra no espaço e o campo de gravidade. A determinação da forma da Terra é realizada por meio do conhecimento do campo de gravidade envolvendo a distribuição de massa e o efeito rotacional do planeta. Para se determinar a função potencial do referido campo é necessário envolver o que se denomina de "Problema de Valor de Contorno da Geodésia".

O lançamento do satélite Sputnik iniciou a era espacial. A partir dessa época, a comunidade científica vislumbrou a grande contribuição que os satélites artificiais poderiam oferecer aos problemas vinculados à Geodésia. De início utilizou-se a técnica de posicionamento que se valia do efeito Doppler-fizeau, resultando numa tecnologia de posicionamento denominada de Transit, passando por sistemas que vêm utilizando laser, tais como, o Satellite Laser Range (SLR) e o Lunar Laser Range (LLR) e, posteriormente, no emprego dos sistemas que compõem o GNSS (Global Navigation Satellite System), como o norte americano GPS (Global Positioning System), o russo GLONASS (Global'naya Navigatisionnaya Sputnikovaya Sistema) e futuramente o europeu Galileo e o chinês Compass. Projetado e desenvolvido em 1973 com o objetivo de ser o principal sistema de navegação das forças armadas americanas, o GPS passou a ser utilizado para posicionamento pelos mais diversos segmentos da comunidade civil (navegação, agricultura, trabalhos de prospecção e recursos naturais, etc.). Tal fato é devido à acurácia e ao grande desenvolvimento da tecnologia empregada, associada com a modernização do mesmo. A era espacial contribuiu também para o aperfeiçoamento do conjunto dos coeficientes do desenvolvimento em série de funções harmônicas esféricas do potencial gravitacional; os primeiros modelos datam da década de 60 . A 
evolução dos satélites artificiais permitiu o aperfeiçoamento dos modelos, sendo que o EGM08 (Earth Gravity Model 2008) é o mais recente deles.

A informação altimétrica que no passado era determinada por meio de nivelamento geométrico, atualmente pode ser estabelecida com o auxílio das observações de satélites. O advento do GPS propiciou a determinação de altitudes geodésicas com facilidade e alta precisão. A partir dessa altitude pode-se obter a altitude ortométrica ou normal, por meio do conhecimento da ondulação geoidal ou quase-geoidal. Além disso, a altimetria está intimamente vinculada ao estabelecimento de um referencial altimétrico.

No Brasil, a rede altimétrica do Sistema Geodésico Brasileiro (SGB) encetou-se com uma atividade de nivelamento de alta precisão a partir de uma seção de nivelamento em 1945, sendo denominada de Rede Altimétrica de Alta Precisão (RAAP). Até então, não havia no país um referencial altimétrico, o que ocasionava divergências, pois não possuía uma superfície de referência, a partir da qual as altitudes pudessem ser calculadas. Tal tarefa foi executada no município de Urussanga, Santa Catarina, onde está localizada a Referência de Nível (RN) 1-A. Sendo assim, tornou-se possível realizar o cálculo das altitudes das referências de nível por meio de uma conexão com a estação maregráfica de Torres, no Rio Grande do Sul, em 1946. No ano de 1958, quando a rede altimétrica já possuía mais de 30.000 km de linhas de nivelamento, ocorreu a substituição da referência de origem vertical de Torres para Imbituba, pois a segunda possuía uma série de observações de 9 anos, bem superior à primeira. Após anos de trabalho, as linhas de nivelamento expandiram-se por todo o país chegando aos estados mais distantes, como o Acre e Roraima (ALENCAR, 1990).

A maioria dos marcos da RAAP está referida ao nível médio do mar no Porto de Imbituba. Outra porção da RAAP, no Amapá, está conectada com o nível médio no Porto Santana, uma vez que não é possível cruzar o rio Amazonas com nivelamento geométrico. O longo período decorrido desde a definição torna ambas as referências inadequadas às necessidades da Geodésia atual. Além disso, a localização no extremo sul, da referência de origem vertical acarreta diferenças de até $25 \mathrm{~cm}$ em relação aos níveis médios locais na costa norte. Outro aspecto a ser ressaltado é que nas regiões mais distantes a propagação de erros do nivelamento geométrico pode atingir valores de até $13 \mathrm{~cm}$ (costa norte) (LUZ; GUIMARÃES, 2001). Com 
isso, o Departamento de Geodésia do IBGE (Fundação Instituto Brasileiro de Geografia e Estatística), concebeu em 1997 a Rede Maregráfica Permanente para Geodésia (RMPG), cujo objetivo é monitorar de forma precisa as diferenças entre as referências de origem vertical do SGB, além dos respectivos níveis médios regionais (IBGE, 2009a). A adoção de um referencial altimétrico não é algo trivial. O estabelecimento de uma origem altimétrica está intimamente relacionado com 0 nível médio dos mares. Para tanto, devem ser executadas medições ao longo da costa dos oceanos, onde o geoide e o quase-geoide são acessíveis.

A superfície geoidal tem despertado interesses específicos. Ao contrário da superfície física, do teluroide e do quase-geoide, ela é uma superfície de nível do campo de gravidade possuindo características físicas. A determinação de um modelo geoidal pode ser realizada a partir de várias técnicas: a integração numérica da fórmula de Stokes diretamente ou com o uso da FFT (Fast Fourier Transform), a colocação por mínimos quadrados, o desenvolvimento em série das funções harmônicas esféricas, a obtenção direta da ondulação geoidal pela diferença entre a altitude geodésica (GNSS) e a ortométrica (nivelamento geométrico), a altimetria por radar a bordo de satélites (oceanos) e as possíveis combinações entre elas. No cálculo de um modelo geoidal, os modelos do geopotencial contribuem por meio dos médios e longos comprimentos de onda, enquanto que os dados gravimétricos proporcionam os curtos comprimentos de onda.

\subsection{Objetivo}

Realizar um estudo sobre a altimetria e o modelo geoidal no estado de São Paulo. Verificar a existência da consistência, convergência e compatibilidade a partir de estudos que envolvam alguns conceitos da altimetria, tais como, a análise do movimento da crosta terrestre, o estudo do Nível Médio do Mar no litoral paulista, as comparações entre GPS sobre nivelamento e os modelos do geopotencial e a determinação e validação de um modelo geoidal. 


\subsection{Justificativa}

O estado de São Paulo é a unidade federativa brasileira mais importante economicamente. Possui o maior PIB (Produto Interno Bruto) dentre todos os estados. Além disso, é o estado mais populoso da nação e a terceira unidade administrativa mais populosa da América do Sul, atrás apenas do próprio Brasil e da Colômbia.

Algumas das mais conceituadas universidades públicas do país situam-se em São Paulo: Universidade de São Paulo (USP), Universidade Estadual Paulista (UNESP), Universidade de Campinas (UNICAMP), Universidade Federal de São Carlos (UFSCAR), entre outras. Inseridos a algumas dessas instituições, está um curso de graduação em Engenharia Cartográfica (UNESP - Campus Presidente Prudente) e três cursos de pós-graduação (stricto sensu) direcionados para a área de Geodésia: Ciências Cartográficas (UNESP - Campus Presidente Prudente) e Engenharia de Transporte (EESC - Escola de Engenharia de São Carlos e EPUSP - Escola Politécnica da Universidade de São Paulo, ambas pertencentes à USP).

Atualmente, no estado de São Paulo, encontram-se grandes obras de engenharia: duplicações de rodovias, projetos viários de grande porte como o RODOANEL, expansão do metrô no município de São Paulo, estudo para a construção de um trem de alta velocidade interligando os municípios de Campinas e Rio de Janeiro, o mapeamento do estado na escala de 1:10.000 para as regiões metropolitanas de São Paulo, Campinas e Baixada Santista e 1:25.000 para as outras regiões, etc. Alguns projetos, no âmbito geodésico, foram e estão sendo executados por meio de esforços de algumas das instituições citadas acima e também envolvendo outros órgãos. No passado, a implantação da rede GPS passiva de São Paulo em conjunto com o IBGE, proporcionou uma maior viabilidade para os levantamentos geodésicos. A rede é composta de 24 marcos, distribuídos em várias cidades. Atualmente, o projeto intitulado de Temático (processo: 06/04008-2 da Fundação de Amparo à Pesquisa do Estado de São Paulo - FAPESP), pretende contribuir na infraestrutura GNSS para o posicionamento geodésico e a integração à ciência e tecnologia. Divididos em 4 grupos de trabalho, o Laboratório de Topografia e Geodésia da USP (LTG) está incumbido de realizar investigações relacionadas à 
avaliação do modelo geoidal, sistemas de altitude e monitoramento vertical da crosta para a estimativa desta componente no Nível Médio dos Mares (NMM).

A importância do estado de São Paulo no contexto nacional aliado aos expressivos projetos geodésicos acadêmicos e também às grandes obras de engenharia que estão sendo e que serão desenvolvidas, torna o estudo da altimetria e do modelo geoidal fundamental. 


\section{O PVCG E A ALTIMETRIA}

\subsection{Introdução}

A componente altimétrica sempre foi uma das preocupações da Geodésia. $O$ advento da era espacial tornou possível obter as coordenadas cartesianas $(X, Y, Z)$ que podem ser transformadas em coordenadas geodésicas $(\varphi, \lambda, h)$ de maneira simples. Anteriormente, as componentes planimétricas eram estabelecidas a partir da triangulação e poligonação e a componente altimétrica por meio de nivelamento geométrico, o que ocasionava uma dicotomia entre as redes planimétrica e altimétrica. Hoje, a altitude geodésica também pode ser determinada a partir de observações de satélites e está referenciada a um modelo geométrico utilizado para os cálculos geodésicos (elipsoide) e que não possui um significado físico. Isso faz com que essa componente não atenda todas as exigências das atividades de Engenharia e também em trabalhos específicos. Logo, percebe-se a necessidade de uma altitude adequada às exigências usuais.

O estabelecimento de um referencial altimétrico está associado à definição e à realização do mesmo. A escolha de uma superfície de referência adequada juntamente com um tipo ou um sistema de altitude constitui a definição de um referencial altimétrico. A realização pode ser conduzida através da determinação do nível médio dos mares durante um determinado período a partir de observações maregráficas. Além disso, deve-se efetuar correções referentes à carga oceânica e atmosférica e às marés oceânicas. Na Geodésia, as altitudes se classificam segundo a sua determinação, a aplicação e o modelo matemático ou físico considerado na sua definição. Desse modo, elas se distinguem em altitudes com característica geométrica (niveladas e geodésicas) e altitudes com característica física (dinâmicas, normais e ortométricas). Além do auxílio das técnicas espaciais, a altitude de um ponto também é obtida a partir de um procedimento conhecido como nivelamento. Esse pode ser barométrico, trigonométrico ou geométrico. 
Gauss $^{1}$ caracterizou a forma da Terra como sendo um geoide. A superfície geoidal é equipotencial do campo de gravidade coincidente com o nível médio não perturbado dos mares em um dado instante. Uma das preocupações da Geodésia é o estudo do geoide e sua determinação realizada por meio do campo de gravidade que envolve a distribuição de massa e o efeito rotacional da Terra e que permite deduzir a sua forma. Para se determinar a função potencial do referido campo é necessário envolver o que se denomina de "Problema de Valor de Contorno da Geodésia (PVCG)" (FREITAS; BLITZKOW, 1999).

Existe uma relação direta entre o conceito de altitude e o PVCG, a qual deve ser analisada tanto do ponto de vista geométrico quanto físico. Contudo, deve-se levar em conta a superfície eleita como origem para as medições altimétricas, além do seu significado como superfície de referência do campo de gravidade. Ademais, é necessário considerar os efeitos seculares e periódicos sobre as observações maregráficas na materialização da superfície de referência (BLITZKOW; CAMPOS; FREITAS, 2007).

\subsection{A Teoria do Potencial}

A atração física que um determinado corpo exerce sobre objetos próximos a ele é o resultado da força gravitacional. Isaac Newton ${ }^{2}$ formulou a Lei Universal da Gravitação em sua obra Philosophiae Naturalis Principia Mathematica, publicada em 1687, que descreve também as Leis de Newton - leis do movimento dos corpos celestes, base da mecânica clássica.

Duas partículas se atraem mutuamente com uma força proporcional ao produto de suas massas e inversamente proporcional ao quadrado da distância que as separa (2.1):

$$
F=G \frac{m_{1} m_{2}}{l^{2}}
$$

\footnotetext{
${ }^{1}$ Carl Friedrich Gauss (1777-1855)

${ }^{2}$ Isaac Newton (1642-1717).
} 
onde $G$ é a constante universal da gravitação, cujo valor no Sistema Internacional (SI) é:

$$
G=6,6742 * 10^{-11} \mathrm{~m}^{3} \mathrm{~kg}^{-1} \mathrm{~s}^{-2}
$$

É conveniente, para evitar possível ambiguidade, considerar uma das partículas como "atrativa" e outra como "atraída", atribuindo massa unitária à última. Desta forma:

$$
F=G \frac{m}{l^{2}}
$$

O potencial de atração gravitacional ou newtoniano é uma função escalar definida por:

$$
V=G \frac{m}{l}
$$

No caso de um sistema discreto de partículas:

$$
V=G \sum_{i=1}^{n} \frac{m_{i}}{l_{i}}
$$

Introduzindo um sistema de coordenadas cartesianas, considerando o potencial de atração $V$, as correspondentes derivadas parciais de primeira ordem (2.5) (GEMAEL, 1999):

$$
\begin{aligned}
& \frac{\partial V}{\partial x}=-G \sum_{i=1}^{n} \frac{m_{i}\left(x-x_{i}^{\prime}\right)}{l_{i}^{3}}, \\
& \frac{\partial V}{\partial y}=-G \sum_{i=1}^{n} \frac{m_{i}\left(y-y_{i}^{\prime}\right)}{l_{i}^{3}}, \\
& \frac{\partial V}{\partial z}=-G \sum_{i=1}^{n} \frac{m_{i}\left(z-z_{i}^{\prime}\right)}{l_{i}^{3}}
\end{aligned}
$$


e as de segunda ordem:

$$
\begin{aligned}
& \frac{\partial^{2} V}{\partial x^{2}}=G \sum_{i=1}^{n} \frac{m_{i}}{l_{i}^{3}}-3 G \sum_{i=1}^{n} \frac{m_{i}\left(x-x_{i}^{\prime}\right)^{2}}{l_{i}^{5}} \\
& \frac{\partial^{2} V}{\partial y^{2}}=G \sum_{i=1}^{n} \frac{m_{i}}{l_{i}^{3}}-3 G \sum_{i=1}^{n} \frac{m_{i}\left(y-y_{i}^{\prime}\right)^{2}}{l_{i}^{5}} \\
& \frac{\partial^{2} V}{\partial z^{2}}=G \sum_{i=1}^{n} \frac{m_{i}}{l_{i}^{3}}-3 G \sum_{i=1}^{n} \frac{m_{i}\left(z-z_{i}^{\prime}\right)^{2}}{l_{i}^{5}}
\end{aligned}
$$

somando membro a membro a (2.6) tem-se:

$$
\frac{\partial^{2} V}{\partial x^{2}}+\frac{\partial^{2} V}{\partial y^{2}}+\frac{\partial^{2} V}{\partial z^{2}}=3 \sum_{i=1}^{n} \frac{m_{i}}{l_{i}^{3}}-3 \sum_{i=1}^{n} \frac{m_{i}}{l_{i}^{3}}=0
$$

ou, simplesmente:

$$
\nabla^{2} V=0
$$

A (2.8) é conhecida como equação de Laplace $^{3}$. Ela traduz o fato de que o laplaciano do potencial gravitacional é nulo fora das massas atrativas. Por essa razão ela é denominada função harmônica, pois satisfaz a equação de Laplace em todos os pontos no exterior do corpo.

\subsection{O Problema de Valor de Contorno da Geodésia}

O conhecimento de valores de uma determinada variável sobre uma superfície limitante e a partir daí, a determinação de uma função que se relacione àquela variável, conduz ao que é chamado de "problema de valor de contorno" (BLITZKOW, 1996). Em suma, no PVC o que se busca determinar é a função potencial que se relacione com um dado corpo.

\footnotetext{
${ }^{3}$ Pierre Simon Laplace (1749-1827).
} 
O problema de valor de contorno é determinar o campo de gravidade externo às massas sendo que a superfície limitante é desconhecida. Stokes ${ }^{4}$ propôs uma formulação para obter o potencial perturbador em função da anomalia de gravidade sobre a superfície geoidal. Entretanto, essa proposição implica em algumas dificuldades, pois se trata de um problema interno às massas. Uma nova formulação do problema fundamental da Geodésia foi proposta por Molodenskii ${ }^{5}$. Trata-se de um problema externo às massas que utiliza a superfície física como limite. Com isso não é necessário o conhecimento, mesmo que aproximado, de um modelo de distribuição de densidade no interior da crosta entre a superfície física e o geoide. Entretanto, essa superfície não tem o mesmo significado físico que a superfície geoidal, pois não é uma superfície equipotencial.

A teoria do potencial apresenta 3 problemas de valor de contorno:

- Primeiro problema (Dirichlet $\left.{ }^{6}\right)$ : a partir do conhecimento dos valores de uma função $V$ sobre uma superfície $S$, determina-se essa função $V$ de tal maneira que ela seja harmônica no interior ou no exterior de $S$ quando são conhecidos os valores que a função assume sobre a superfície;

- Segundo problema (Newmann ${ }^{7}$ ): a partir do conhecimento dos valores da derivada normal da função $V$ sobre a superfície $S, \partial V / \partial n$, determina-se a função $V$ de modo que ela seja harmônica interna ou externamente a $S$;

- Terceiro problema $\left(\right.$ Hilbert $\left.^{8}\right)$ : a partir dos valores da combinação linear da função $V$ com sua derivada normal sobre a superfície $S$, determinase a função $V$ nas condições anteriores.

\footnotetext{
${ }^{4}$ George Gabriel Stokes (1819-1903).

${ }^{5}$ Mikhail Sergeevich Molodenskii (1909-1991).

${ }^{6}$ Peter Gustav Lejeune Dirichlet (1805-1859).

${ }^{7}$ Carl Gottfried Newmann (1832-1925).

${ }^{8}$ David Hilbert (1862-1943).
} 
Tais problemas não apresentam solução única, pois infinitas distribuições de massa podem gerar o mesmo potencial. O terceiro problema tem relevância para a Geodésia, uma vez que a determinação do potencial perturbador de certa forma se relaciona a ele. A anomalia de gravidade é representada como uma combinação linear do potencial perturbador e sua derivada normal e é expressa por uma equação diferencial conhecida como "equação fundamental da Geodésia".

$$
\Delta g=-\frac{\partial T}{\partial h}+\frac{1}{\gamma} \frac{\partial \gamma}{\partial h} T
$$

\subsection{A Formulação Clássica do PVCG}

A concepção clássica do PVCG é devida a Stokes. A fórmula ou integral de Stokes publicada em 1849 é considerada a de maior importância para a Geodésia. O problema clássico pode ser resolvido em termos do potencial perturbador por meio da referida integral, que numa aproximação esférica assim se expressa (HOFMANNWELLENHOF; MORITZ, 2005):

$$
T=\frac{R}{4 \pi} \iint_{\sigma} \Delta g S(\psi) d \sigma
$$

onde o vetor anomalia de gravidade (Figura 2.1) é definido por:

$$
\Delta g=\vec{g}(P)-\vec{\gamma}(Q)
$$

$\vec{g}(P)=$ vetor gravidade num ponto $P$ da Terra real.

$\vec{\gamma}(Q)=$ vetor gravidade num ponto $Q$ da Terra normal. 


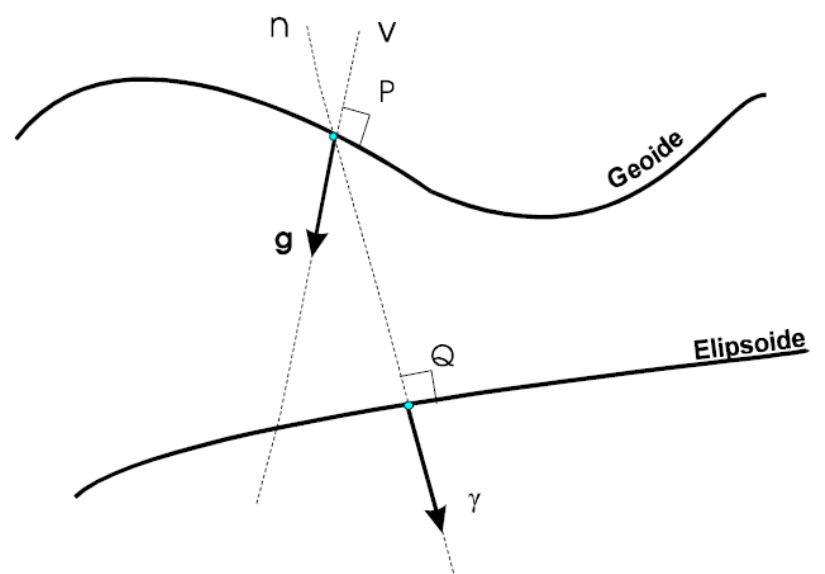

Figuras 2.1 - Vetores $g$ e $\gamma$ (Blitzkow, 1996)

e a função de Stokes $S(\psi)$ é dada por:

$$
S(\psi)=\frac{1}{\operatorname{sen}\left(\frac{\psi}{2}\right)}-6 \operatorname{sen} \frac{\psi}{2}+1-5 \cos \psi-3 \cos \psi \ln \left(\operatorname{sen} \frac{\psi}{2}+\operatorname{sen}^{2} \frac{\psi}{2}\right)
$$

Considerando o teorema de Bruns:

$$
N=\frac{T}{\gamma}
$$

chega-se a:

$$
N=\frac{R}{4 \pi \gamma} \iint_{\sigma} \Delta g S(\psi) d \sigma
$$

onde $N$ é a ondulação geoidal.

A fórmula de Stokes na sua forma original (2.10) e (2.14) somente se aplica a um elipsoide de referência que (1) tenha o potencial de gravidade $U_{0}$ sobre o elipsoide igual ao potencial $W_{0}$ sobre o geoide; (2) cuja massa seja numericamente igual à massa da Terra; e (3) com mesma velocidade angular $(\omega)$ do que a Terra real (HOFMANN-WELLENHOF; MORITZ, 2005). 


\subsection{A Formulação Moderna do PVCG}

O desconhecimento de um modelo de distribuição de densidade no interior das massas topográficas levou Molodenskii, em 1945, a propor a superfície física como superfície limitante. Neste caso, substitui-se o conceito de geoide pelo quasegeoide. A anomalia de gravidade e as deflexões da vertical referem-se à superfície física e não mais à superfície geoidal. Além disso, as anomalias de altura tomam lugar antes ocupado pelas ondulações geoidais e a superfície limitante agora não possui um sentido físico, não sendo equipotencial. A fórmula de Gauss (2.15), bem como as identidades de Green $^{9}$ estão entre as equações básicas da teoria do potencial e integram a fundamentação matemática para a formulação moderna do PVCG.

$$
\iiint_{v} \operatorname{div} F d v=\iint_{S} F_{n} d S
$$

onde $v$ é o volume delimitado pela superfície $S, F_{n}$ é a projeção do vetor $F$ na superfície externa normal $n$ e $\operatorname{div} F$ é a chamada divergência do vetor $F$.

A partir das seguintes relações (maiores detalhes em HEISKANEN; MORITZ, 1967):

$$
F_{n}=\frac{\partial V}{\partial n} \text { e } F=\nabla V
$$

chega-se a integral de Gauss para o potencial:

$$
\iiint_{v} \nabla V d v=\iint_{S} \frac{\partial V}{\partial n} d S
$$

\footnotetext{
${ }^{9}$ George Green (1793-1841).
} 
As identidades de Green são derivadas a partir da (2.15). A terceira identidade aplicada ao potencial de gravidade $W$ para um ponto sobre a superfície da Terra $S$ $(p=2 \pi)$, a menos de algumas transformações (HEISKANEN; MORITZ, 1967) escreve-se:

$$
-2 \pi W+\iint_{S}\left[W \frac{\partial}{\partial n}\left(\frac{1}{l}\right)-\frac{1}{l} \frac{\partial W}{\partial n}\right] d S+2 \pi \omega^{2}\left(x^{2}+y^{2}\right)+2 \omega^{2} \iiint_{v} \frac{d v}{l^{\prime}}=0
$$

onde $S$ é a superfície física da Terra; $l$ é a distância entre o ponto fixo $P$ e o elemento da superfície $d S$; $n$ a normal à superfície, orientada para fora de $S$; $\omega$ é a velocidade angular; $l$ 'é a distância entre o ponto $P$ e o elemento do volume $d v ; \partial W / \partial n$ a componente do vetor $\vec{g}$ normal a $S$.

Esse conceito retrata a determinação da forma da Terra $S$ a partir de medidas de $g$ e $W$. A combinação do nivelamento com medidas de gravidade em um ponto $P$ resulta no potencial de gravidade $W$, a menos da constante $W_{0}$.

$$
W=W_{0}-\int_{0}^{P} g d n
$$

As incógnitas a serem determinadas são $S$ e $W$, já que a componente normal $\partial W / \partial n$ do vetor gravidade $\vec{g}$ é determinada por medidas de gravimetria e sua direção estabelecida por coordenadas astronômicas. A (2.18) caracteriza-se por uma forma integral não-linear e impõe sua linearização para uma solução. Detalhes acerca da linearização podem ser encontrados em (HEISKANEN; MORITZ, 1967) e (BLITZKOW, 1996). Após o processo de linearização tem-se a seguinte equação (HEISKANEN; MORITZ, 1967):

$$
T-\frac{1}{2 \pi} \iint_{\Sigma}\left[\frac{\partial}{\partial n}\left(\frac{1}{l}\right)-\frac{1}{\gamma} \frac{\partial \gamma}{\partial h} \frac{\cos \beta}{l}\right] T d \Sigma=\frac{1}{2 \pi} \iint_{\Sigma}^{1} \frac{1}{l}\left[\Delta g-\gamma\left(\xi \tan \beta_{1}+\eta \tan \beta_{2}\right)\right] \cos \beta d \Sigma
$$


A (2.20) retrata o PVCG segundo a concepção de Molodenskii. Para tanto, alguns elementos devem ser enfatizados para a compreensão do problema. A Figura 2.2 ilustra as quantidades envolvidas no problema de Molodenskii.

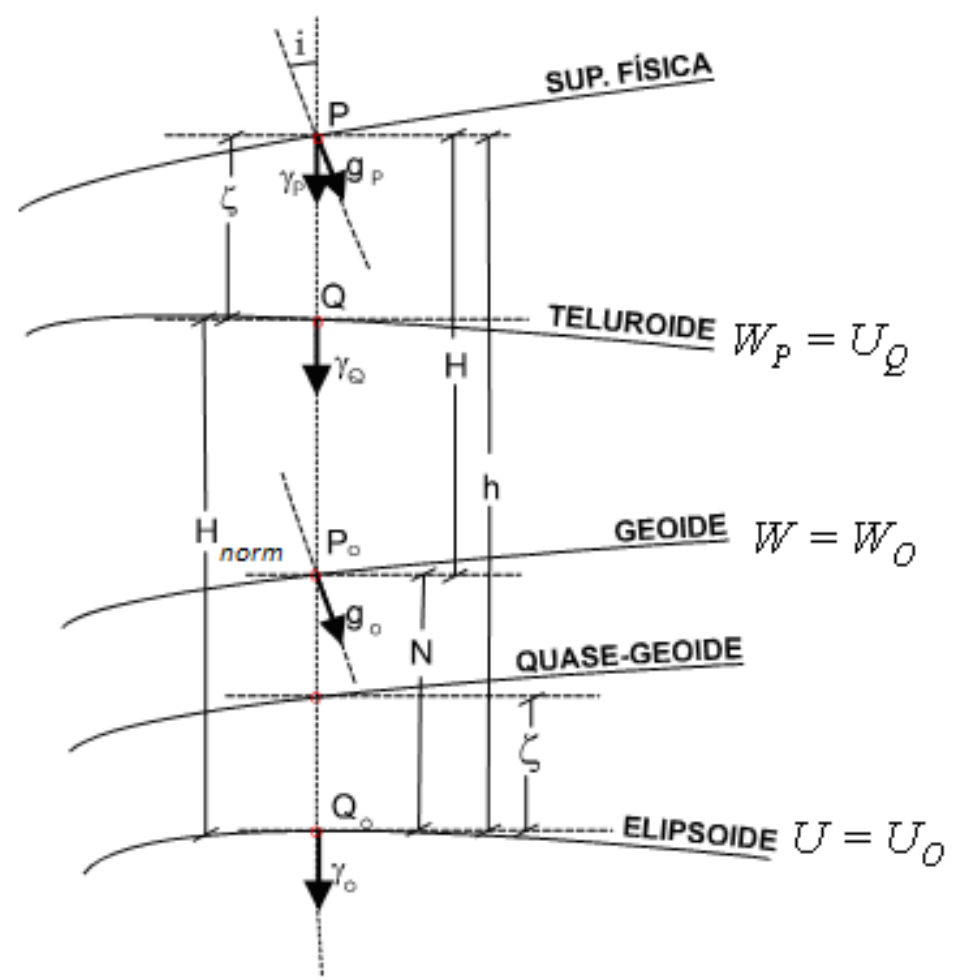

Figura 2.2 - Quantidades envolvidas no problema de Molodenskii (Blitzkow, 1996)

A anomalia de altura $\zeta$ considerada a partir da superfície física é a distância entre a superfície referida e a superfície do teluroide. Ela é obtida por meio da seguinte equação:

$$
\zeta=\frac{T}{\gamma}
$$

A altitude normal $H_{\text {norm }}$ substitui a altitude ortométrica $H$ e a anomalia de altura $\zeta$ a ondulação geoidal $N$.

$$
h=H_{n o r m}+\zeta
$$


A superfície de referência utilizada passa a ser o teluroide (HIRVONEN, 1960, 1961). Trata-se de uma superfície cujo potencial normal $U$ em um ponto $Q$ é igual ao potencial de gravidade $W$ em um ponto $P$ da superfície física, $W_{P}=U_{Q}$. A altitude normal $H_{\text {norm }}$ é obtida a partir do número geopotencial $C$ :

$$
H_{\text {norm }}=\frac{C}{\gamma Q_{0}}\left[1+\left(1+f+m-2 f \operatorname{sen}^{2} \varphi\right) \frac{C}{a \gamma Q_{0}}+\left(\frac{C}{a \gamma Q_{0}}\right)^{2}\right]
$$

onde o potencial perturbador $T$ é obtido pela solução da (2.20) e a anomalia de gravidade pela (2.11). No caso da $\zeta$ ser representada a partir do elipsoide, resultará em uma superfície denominada por Molodenskii de quase-geoide. A partir da Figura 2.2 obtêm-se as seguintes relações:

$h=H+N$
$N-\zeta=H_{\text {norm }}-H$

A formulação acima pode ser aplicada ao geoide desde que um adequado processo de regularização cuide da remoção das massas externas ao mesmo. Nessas condições, ao invés do teluroide adota-se, como superfície aproximada, a do elipsoide. Por outro lado, $\beta_{1}=\beta_{2}=\beta=0$ e $\partial / \partial n=\partial / \partial h$. Assim a (2.20) reduz-se a:

$$
T-\frac{1}{2 \pi} \iint_{\Sigma}\left[\frac{\partial}{\partial h}\left(\frac{1}{l}\right)-\frac{1}{\gamma} \frac{\partial \gamma}{\partial h} \frac{1}{l}\right] T d E=\frac{1}{2 \pi} \iint_{\Sigma} \frac{\Delta g}{l} d E
$$

O fato de não conter as componentes da deflexão $\xi$ e $\eta$, faz com que a (2.24) se torne mais simples que a (2.20). No caso de uma aproximação esférica, a solução da (2.24) é dada simplesmente pela integral de Stokes. Tal fato é verdadeiro, uma vez que a fórmula de Stokes expressa $T$ em termos de $\Delta g$. 


\subsection{Considerações sobre o PVCG}

É sabido que a determinação do campo de gravidade da Terra a partir de vários tipos de dados está relacionada com a formulação do problema de valor de contorno. Várias versões do PVCG podem ser formuladas. Isso depende do tipo de dados, além do tipo e da quantidade de funções desconhecidas. Ademais, os dados ditos "clássicos", tal como as coordenadas combinados com dados de satélites e com o potencial de gravidade, contribuem para novas versões do PVCG, como: misto e super determinado (HECK, 1997). Nos próximos parágrafos será apresentada uma revisão conceitual dos 3 problemas clássicos: livre ou vetorial livre, escalar livre e fixo, além do PVCG gravimétrico fixo.

O modelo físico-matemático do PVCG pode ser formulado da seguinte forma (HECK, 1988), (BLITZKOW, 1996), (HECK, 1997):

(1) A Terra é assumida como um corpo rígido, não deformável, com velocidade uniforme ao redor de um eixo no espaço. Toda a massa de atração está localizada no interior da superfície de contorno, no caso, a superfície física. 0 potencial gravitacional newtoniano é gerado a partir da atração dos elementos de massa atuando sobre uma partícula teste, sendo esse regular no infinito e satisfazendo a equação de Laplace no exterior às massas e a equação de Poisson no interior.

(2) A fim de descrever as posições no espaço, além de quantidades como o vetor gravidade, introduz-se à Terra um referencial fixo, com origem $O$ no seu centro de massa. O eixo $x$ contido no plano do Meridiano Internacional de Referência, 0 eixo $z$ na direção do eixo de rotação orientado para o norte e por fim o eixo y contido no plano do equador completando o sistema dextrógiro. O vetor de gravidade $\vec{g}$ é representado pela equação:

$$
\frac{\partial W}{\partial x}=-\vec{g}
$$

(3) A superfície de contorno $S$ é suficientemente suave. Além disso, assumese que tanto $W$ quanto $g$ sejam conhecidos sobre o contorno de forma contínua. 
(4) Como incógnitas têm-se o potencial de gravidade $W$ no exterior das massas e a geometria da superfície de contorno $S$.

\subsubsection{O PVCG “Livre”}

Antes do advento das técnicas espaciais era impossível determinar a geometria da superfície terrestre com alta precisão. O estabelecimento de redes globais tridimensionais a partir de medidas de distâncias, ângulos horizontais, azimutes e distâncias zenitais não era possível devido à dificuldade da refração vertical. Perante essa situação originou-se a formulação do PVCG Livre, também conhecido como problema de Molodenskii.

Trata-se de um problema de valor de contorno não linear "livre" ou "vetorial livre", onde a qualificação "livre" está ligada ao fato do vetor posição ser uma incógnita. As observações disponíveis são: $W, g, \Phi$ e $\Lambda$. A aplicação do PVCG livre possui a restrição de que o vetor posição está definido somente pelas coordenadas astronômicas e que indicam somente a direção do vetor. Além disso, não possuem uma distribuição requerida e não atendem à precisão exigida (o erro é da ordem de $\sim 0,3 " \cong 10 \mathrm{~m}$ ). A componente vertical do mesmo vetor é derivada de maneira muito aproximada no PVCG sendo muito depende da qualidade dos dados gravimétricos. Logo, a obtenção do terno geodésico para todo $P \in S$ se torna uma dificuldade.

\subsubsection{O PVCG “Escalar Livre”}

No passado, a dificuldade na determinação das componentes horizontais do vetor posição levou ao desenvolvimento de um PVCG escalar livre. De fato, a informação proveniente da posição horizontal na superfície não pode ser extraída a partir de soluções do chamado PVCG clássico. Nos levantamentos geodésicos, as

coordenadas geográficas $(\varphi, \lambda)$ eram derivadas dos métodos de poligonação e triangulação, a partir de medidas de ângulos e distâncias. A coordenada altimétrica (altitude geodésica), geralmente não era conhecida pelo fato de não se realizar regularmente o nivelamento geométrico nas triangulações e poligonações. Além 
disso, para se obter a altitude geodésica era necessário conhecer a ondulação geoidal, sendo que esta não figura no problema de Molodenskii. Com isso a opção foi de se utilizar o PVCG escalar livre, uma vez que se conhecem as coordenadas geográficas em todos os pontos $P \in S$.

Ressaltando a diferença deste com o problema livre: neste, as coordenadas planimétricas da posição $P$ são conhecidas sobre a normal em $Q$, sendo somente necessário conhecer $(h(\varphi, \lambda))$ para fixar a superfície desconhecida. Além disso, para suprir a falta de informação, duas quantidades do campo de gravidade são medidas: $(W, g)$. Ao passo que no outro, não se conhece nada (terno geodésico) sobre a posição $P$ e para suprir a informação necessária 4 grandezas são medidas: $(W, g, \Phi, \Lambda)$.

As condições para a solução do PVCG escalar livre são assim enunciadas (HECK, 1989a):

"Combinando as forças, gravitacional e centrífuga, o potencial de gravidade $W$ é determinado no exterior de $S$

$$
\nabla^{2} W=2 \omega^{2}
$$

e, além disso, deve-se admitir que $W$ (a menos de uma constante $W_{o}$ ) e o módulo do vetor gravidade $\|\vec{g}\|$ sejam fornecidos na forma de uma função contínua, suficientemente suave sobre a superfície $S$. Admite-se também que as coordenadas geográficas estejam vinculadas a um elipsoide de referência."

Seja um elipsoide de revolução, com mesma velocidade angular e mesma massa da terra real, na qual, o potencial $U_{o}$, constante sobre a superfície, seja igual ao potencial $W_{o}$ sobre a superfície geoidal e com seu centro no centro de massa da terra. Essa figura de referência é denominada de terra normal. A esta vincula-se o potencial de gravidade normal $U$ e o vetor gravidade normal $\vec{\gamma}$.

Logo, esse PVC pode ser reformulado em termos de "pequenas" quantidades elegendo o potencial normal $U$ e uma superfície limite conveniente $\Sigma$ com $Q \in \Sigma$. Os pontos $P \in S$ e $Q \in \Sigma$ devem satisfazer uma correspondência biunívoca. Uma 
definição do teluroide consistente com a informação que é inserida no PVCG escalar livre é dada fixando $P$ e $Q$ ao longo da mesma normal passando por $P$ (HECK, 1989a).

Consequentemente, o vetor da posição é expresso pela diferença de altitudes geodésicas, chamada de "anomalia de altura".

$$
\zeta=h-H_{n o r m}
$$

Analogamente, pode-se transformar a observação sobre a superfície física em "anomalia de potencial" $\Delta C$ e "anomalia de gravidade" $\Delta \gamma$. Para tanto, é necessário linearizar. A série de Taylor conduz à forma linearizada (HECK, 1989a). Outros detalhes acerca desse problema podem ser encontrados em (SACERDOTE; SANSÒ, 1986).

\subsubsection{O PVCG “Fixo”}

Esta alternativa do PVCG possui uma estreita relação com a era espacial. O advento da mesma propiciou a determinação de coordenadas em um referencial tridimensional geocêntrico. O desenvolvimento tecnológico colaborou para que se alcançasse alta precisão no posicionamento. São algumas destas técnicas: LLR, SLR e GNSS. O completo conhecimento da geometria da superfície limite $(\varphi, \lambda, h)$ faz com que somente uma incógnita permaneça indeterminada, o potencial de gravidade externo às massas atrativas. Para tanto, assume-se que o módulo do vetor gravidade $\|\vec{g}\|$ seja conhecido de forma contínua e suficientemente suave sobre toda a superfície $S$. O problema continua não linear sendo que a escolha de um potencial de referência $U$ permite linearizar em função do potencial perturbador (HECK, 1991).

Um aspecto relevante tanto na escolha do PVCG escalar livre quanto no fixo é que, em ambos, a altitude empregada $H_{\text {norm }}$ não possui significado físico e sim matemático. Isso implicará na determinação do quase-geoide e não do geoide. Em termos físicos, a diferença entre geoide e quase-geoide é que o primeiro é uma 
superfície equipotencial do campo de gravidade, enquanto o segundo não. Tal escolha pode afetar trabalhos relacionados ao fluxo de água, como a transposição de rios, construção de hidrelétricas, etc.

\subsubsection{O PVCG “Gravimétrico Fixo”}

O lançamento de satélites com o objetivo de explorar o comportamento dos oceanos, sobretudo aqueles com tecnologia por radar, contribuiu de forma significativa para uma nova alternativa do PVCG, o chamado problema gravimétrico fixo.

A altimetria por radar tem auxiliado nas pesquisas sobre circulação oceânica e suas variações temporais, sendo que vários satélites têm colaborado para isso. Os mais recentes, JASON-1, JASON-2 e ENVISAT (Environmental Satellite), possuem uma precisão na medição de 2, 1 e $3 \mathrm{~cm}$, respectivamente (CHELTON et al., 2001). O princípio da medição está associado em determinar uma distância $R$ entre o satélite e a superfície do oceano. Para tanto, um pulso curto de radiação de microondas é transmitido do satélite até a superfície por um aparelho denominado altímetro, sendo que parte desta radiação é refletida retornando ao sensor. A distância é calculada a partir do tempo de percurso do pulso (2.28) (CHELTON et al., 2001).

$$
R=\hat{R}-\sum_{j} \Delta R_{j}
$$

onde $\hat{R}=c t / 2$ é a distância calculada baseada na velocidade da luz no vácuo $c$ e $t$ é o tempo de propagação (ida e volta); $\Delta R_{j}$, (com $\left.j=1, \ldots\right)$ são as correções para as várias componentes da refração atmosférica.

Desta forma, a altitude elipsoidal (Figura 2.3) é determinada pela seguinte expressão:

$$
h=H_{\text {sat }}-R
$$


onde $H_{\text {sat }}$ é a altitude da posição do satélite em relação a um elipsoide de referência específico do satélite altimétrico. É evidente que várias correções precisam ser realizadas até obter o valor de uma medida final. Mais detalhes podem ser encontrados em (CHELTON et al., 2001).

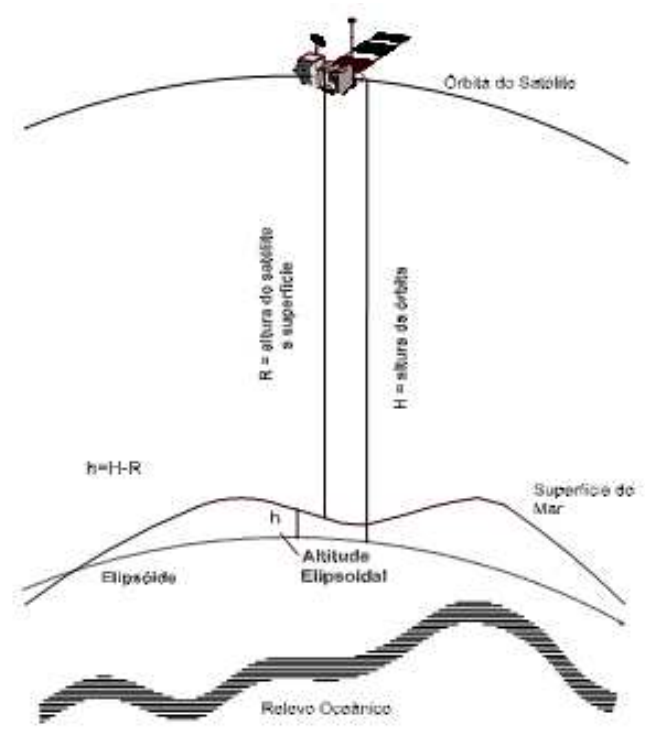

Figura 2.3 - Determinação da altitude elipsoidal e correções aplicadas (Chelton et al., 2001)

Estabelecida a altitude elipsoidal por meio de radar, a determinação da ondulação geoidal é simples, uma vez que a superfície de referência é a superfície geoidal coincidente de certa forma com o nível médio dos mares. Logo, a diferença deste para o PVCG fixo é a superfície de contorno. Além disso, a única incógnita é o potencial de gravidade externo às massas atrativas, que pode ser determinado por meio de medidas gravimétricas a partir do auxílio de navios ou aeronaves adaptados para esse tipo de levantamento. De fato, esse também é um problema não-linear. Após a linearização, o resultado é um PVCG gravimétrico fixo de derivada oblíqua, sendo a direção da derivada na superfície de contorno idêntica com a direção normal do vetor de gravidade normal $\gamma=\operatorname{grad} U$ (HECK,1989b).

\subsection{Síntese do PVCG}

Apresentadas as duas formulações do PVCG e os aspectos relevantes do mesmo, a indagação que surge é saber qual a formulação a ser utilizada, ou melhor, qual a 
superfície em que se trabalhará. A resposta está vinculada à possibilidade de dispor dos dados sobre a superfície conveniente. Será a partir dos mesmos que se poderá estabelecer subsídios para uma melhor determinação do geoide ou do quasegeoide. A Tabela 2.1 apresenta um comparativo entre os PVCG.

Tabela 2.1 - Grandezas do PVCG

\begin{tabular}{cccc}
\hline PVCG & Conhecido & Desconhecido & Sup. de contorno \\
\hline Livre & $\Phi, \Lambda, W, g$ & $\varphi, \lambda, h$ & superfície física \\
Escalar livre & $\varphi, \lambda, W, g$ & $h$ & superfície física \\
Fixo & $\varphi, \lambda, h, W, g$ & - & superfície física \\
Gravimétrico fixo & $\varphi, \lambda, H, W, g$ & - & superfície geoidal
\end{tabular}

\subsection{Sistemas de Altitudes}

A distância que separa duas superfícies equipotenciais ou não segundo uma determinada direção pode ser definida como altitude. O PVCG possui uma estreita ligação com o estabelecimento de um sistema de altitudes e também com a obtenção da mesma (FREITAS; BLITZKOW, 1999). Existem vários tipos de altitudes, a maioria está relacionada com o campo de gravidade da Terra. Por outro lado, a definição e o uso do termo "altitude" necessita de esclarecimento.

Essencialmente, existem duas classes de altitudes: a primeira que ignora o campo de gravidade da Terra e por isso não envolve quantidade física, somente matemática (altitudes geométricas); e a segunda, vinculada à superfície equipotencial do campo de gravidade da Terra possuindo um sentido físico, além da possibilidade de uma interpretação geométrica associada (altitudes físicas). Vale ressaltar que na maioria das aplicações de levantamentos, a altitude de um ponto deve estar referida ao NMM ou mais precisamente a uma referência de origem vertical (JEKELI, 2000).

Nos trabalhos de Engenharia envolvendo água, o conhecimento de tal assunto é fundamental. Em geral, nesses projetos, trabalha-se com as diferenças de altitudes (niveladas). Entretanto, quem governa o sentindo da água é a força de gravidade e não o sistema de altitude. Por consequência, selecionar um sistema que negligencia 
a gravidade ou então que não a considere com certo rigor, pode possibilitar que o fluxo da água não obedeça ao caminho planejado ou, então, que a quantidade de água não seja aquela programada.

\subsubsection{Número Geopotencial}

Todo sistema de altitude, geométrico ou físico, deve se basear no número geopotencial $C$ (FEATHERSTONE; KUHN, 2006). Tal grandeza é a diferença entre o potencial de gravidade da Terra no ponto de interesse $W_{A}$ e na superfície de referência do geopotencial $W_{0}$. A expressão algébrica é vista na (2.30) (HOFMANNWELLENHOF; MORITZ, 2005):

$$
\int_{0}^{A} g d n=W_{A}-W_{0}=C
$$

O número geopotencial é medido em unidades de geopotencial (GPU), onde 1 GPU $=1 \mathrm{kgal} \mathrm{m}=1000 \mathrm{gal} \mathrm{m}=10 \mathrm{~m}^{2} \mathrm{~s}^{-2}$. Utilizando $\mathrm{g}=0,98 \mathrm{kgal}$ na (2.30), obtém-se:

$$
C \cong g H \cong 0,98 H
$$

Logo, o valor de $C$ é praticamente igual à altitude de um ponto sobre o nível do mar. Além disso, $C$ é positivo acima da superfície geoidal, zero sobre a mesma e negativo abaixo (VANÍČEK; KRAKIWSKY, 1986). O número geopotencial não pode ser observado diretamente, uma vez que não existem instrumentos que possam medir o potencial de gravidade. Além disso, ele não é expresso em unidades de comprimento, implicando que seu uso direto não seja conveniente; sendo assim, os valores podem ser traduzidos em unidades de distância, dividindo o número geopotencial por um valor de gravidade adequado (2.32) (DREWES et al., 2002b).

$$
H=\frac{C}{g}
$$




\subsubsection{Altitudes Físicas}

As altitudes físicas ou científicas estão vinculadas a uma grandeza física. São obtidas pela combinação de valores da aceleração de gravidade e da diferença de altitude dos pontos nivelados.

A altitude física possui as seguintes vantagens (GEMAEL, 1999):

- é uma função unívoca;

- tem a dimensão de um comprimento;

- pouco difere da soma dos desníveis brutos $\sum \Delta h$;

- $\quad$ pode ser facilmente convertida em número geopotencial (e vice-versa).

Pela (2.32) se $g$ for um valor constante de gravidade normal, para uma dada latitude, a altitude é chamada de dinâmica. Caso $g$ corresponda à gravidade real média entre o ponto observado e a superfície geoidal, a altitude será a ortométrica. Finalmente, se a opção para $g$ for um valor médio de gravidade normal nas mesmas condições acima, a altitude determinada é dita normal (DREWES et al., 2002b).

\subsubsection{Altitude dinâmica}

O não paralelismo das superfícies equipotenciais impede que a altitude geométrica se mantenha constante sobre elas, exceto na superfície geoidal. Essa deve ter sido a razão para a concepção da altitude dinâmica (GEMAEL, 1999). Proposta por Helmert $^{10}$ em 1884, esta altitude, dada pela (2.33), é obtida dividindo o número geopotencial por um valor padrão que pode ser a gravidade normal para a latitude de $45^{\circ}$ ou um valor constante de gravidade (gravidade média da região considerada).

$$
H_{d i n}=\frac{C}{\gamma_{0}}
$$

\footnotetext{
${ }^{10}$ Friedrich Robert Helmert (1843-1917).
} 
A vantagem dessa altitude é que uma mesma superfície equipotencial tem valor constante para a mesma. A desvantagem é que devido à convergência das superfícies equipotenciais, a distância geométrica entre as altitudes dinâmicas varia consideravelmente (DREWES et al., 2002a). A Figura 2.4 ilustra a altitude dinâmica.

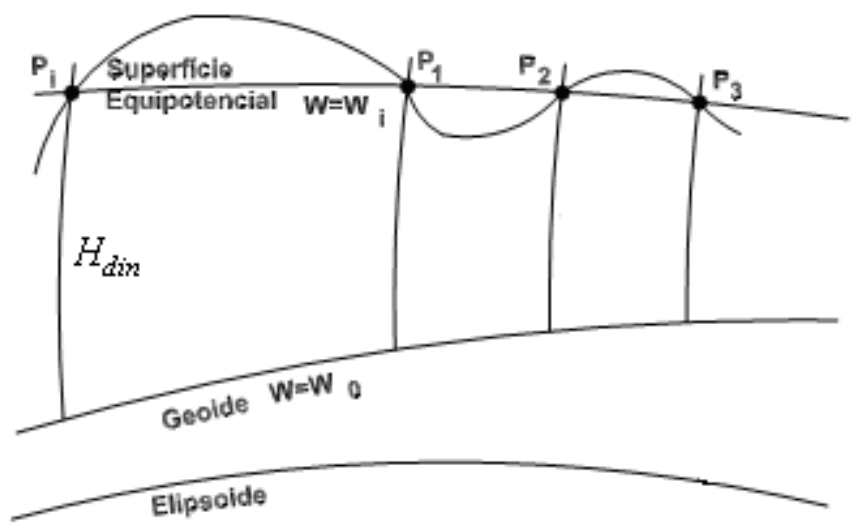

Figura 2.4 - Altitude dinâmica (adaptado de Vaníček; Krakiwsky, 1986).

\subsubsection{Altitude ortométrica}

A distância entre a superfície geoidal até o ponto de interesse na superfície física da Terra, medida ao longo da vertical, é denominada de altitude ortométrica (Figura 2.5).

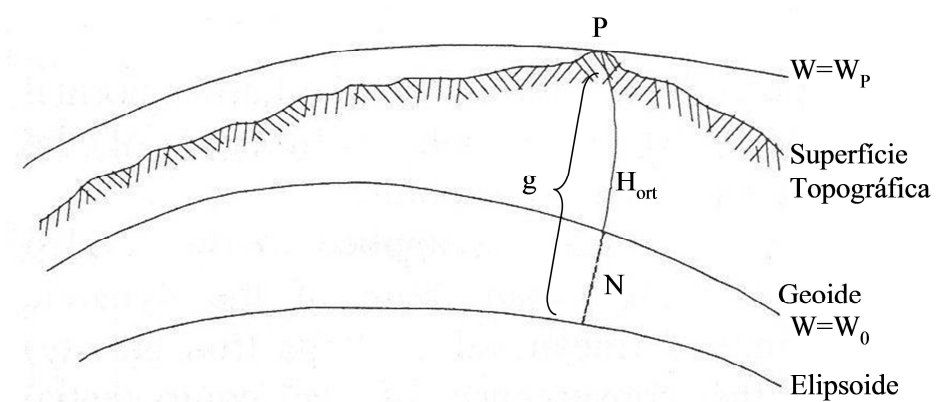

Figura 2.5 - Altitude ortométrica (Adaptado de Drewes et al., 2002a)

A altitude ortométrica (2.34) é obtida dividindo o número geopotencial pelo valor médio de gravidade entre o ponto de interesse e a superfície de referência correspondente (geoidal). Mais detalhes sobre a formulação matemática em 
(VANÍČEK; KRAKIWSKY, 1986), (JEKELI, 2000) e (HOFMANN-WELLENHOF; MORITZ, 2005).

$$
H_{o r t}=\frac{C}{\bar{g}}
$$

sendo $\bar{g}$ dado por:

$$
\bar{g}=\frac{1}{H_{\text {ort }}} \int_{0}^{H_{o r t}} g d H
$$

Para determinar $\bar{g}$ é necessário, teoricamente, conhecer o valor da aceleração de gravidade em pontos ao longo da linha de prumo. Isso implica em conhecer as variações de gravidade ou a distribuição de densidade das massas no interior da crosta. Como essas informações são desconhecidas, o cálculo exato da altitude ortométrica não é possível, possuindo um caráter puramente teórico.

A altitude ortométrica também pode ser calculada, de modo aproximado, pela diferença entre a altitude geodésica e a ondulação geoidal $(H \cong h-N)$. Vale salientar que para a determinação do $N$ também é necessário a hipótese do conhecimento de um modelo de densidades das massas no interior da crosta.

\subsubsection{Altitude normal}

A impossibilidade de se obter na prática a altitude ortométrica, levou Molodenskii a sugerir em 1954, que a mesma fosse substituída pela altitude normal. Esta é obtida a partir da divisão do número geopotencial pela gravidade normal (2.36).

$$
H_{\text {norm }}=\frac{C}{\gamma^{\prime}}
$$

sendo: 


$$
\gamma^{\prime}=\frac{1}{H_{n o r m}} \int_{0}^{H_{\text {norm }}} \gamma d H
$$

Essa altitude é definida geometricamente como sendo a distância desde um ponto na superfície elipsoidal até a superfície do teluroide ou a separação entre a superfície física e a superfície do quase-geoide, contada ao longo da normal, ilustrada pela Figura 2.6.

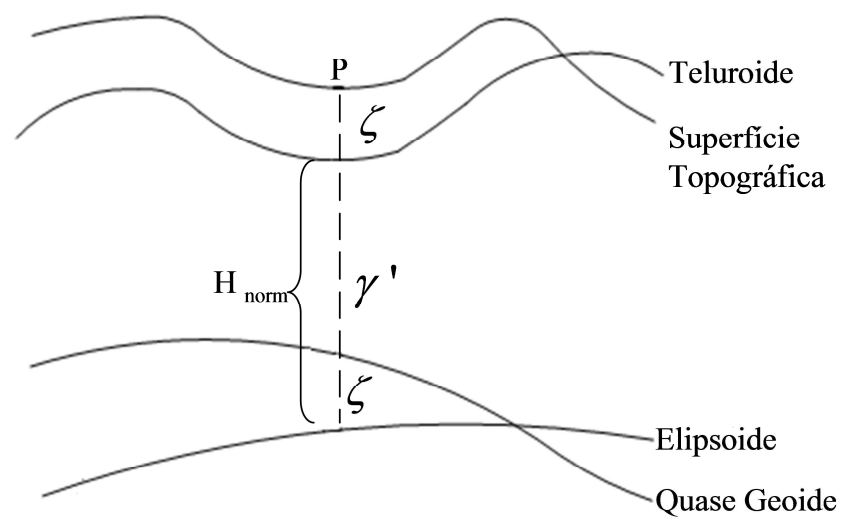

Figura 2.6 - Altitude normal (adaptado de Vaníček; Krakiwsky, 1986)

A distância entre a superfície do teluroide e a superfície física ou a separação entre o quase-geoide e o elipsoide de referência é denominada de anomalia de altura $(\zeta)$ (2.27).

Existem outros tipos de altitudes científicas que não serão abordadas neste trabalho: Helmert, Vignal, Baranov, ortométrica Free-Air ou Ar-Livre (BLITZKOW, 1996) ortométrica Neithammer, ortométrica Mader (JEKELI, 2000).

\subsubsection{Altitudes Geométricas}

As altitudes geométricas são aquelas que não envolvem uma grandeza física em sua determinação e são definidas independentemente do campo de gravidade da Terra. Fazem parte desse grupo as altitudes niveladas e geodésicas. A primeira é determinada pelo processo de nivelamento geométrico, enquanto que a segunda 
pode ser obtida a partir das coordenadas cartesianas, provenientes de observações GNSS, transformadas no terno geodésico, referido a um elipsoide de referência.

\subsubsection{Altitude nivelada}

O procedimento para a determinação da altitude com nivelamento geométrico, nesta pesquisa denominada altitude nivelada, consiste na leitura de duas miras graduadas, ré e vante, efetuando a diferença de valores lidos nas mesmas e considerando que essa diferença represente a diferença de altitude entre os pontos de apoio das miras. O princípio da determinação da altitude nivelada está na diferença de altitude $(\Delta h)$ entre dois pontos na superfície terrestre (Figura 2.7).

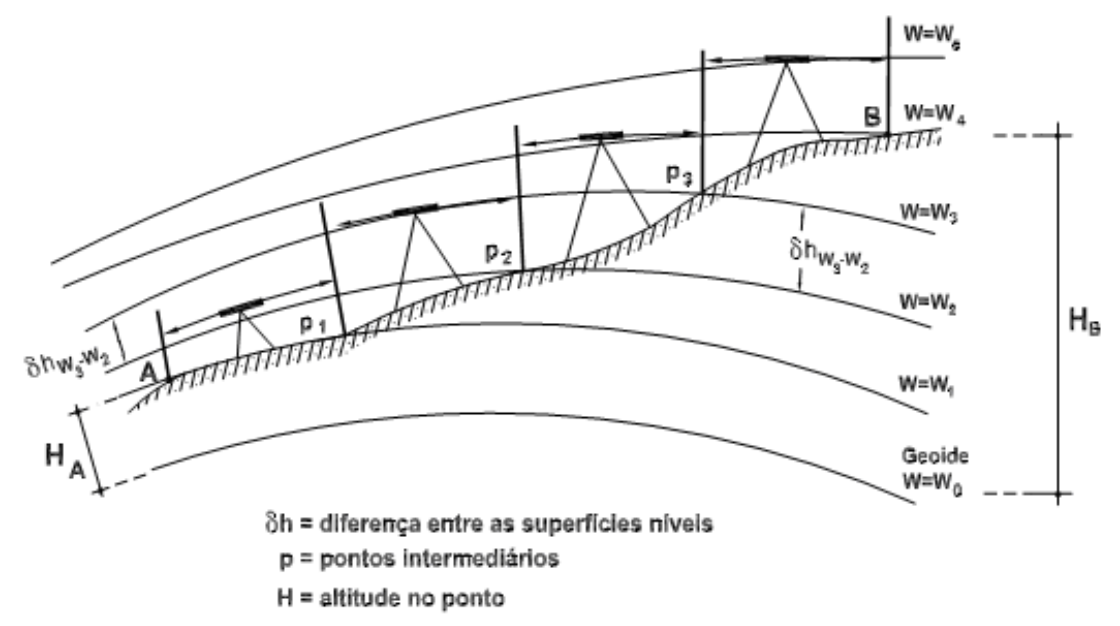

Figura 2.7 - Altitudes niveladas (Campos, 2004)

Mais exatamente as quantidades observadas são distâncias entre as superfícies equipotenciais do campo de gravidade da Terra. Entretanto, essas superfícies não são paralelas devido à forma elipsoidal e outras irregularidades menores na distribuição de massa. A similaridade entre duas superfícies equipotenciais é a diferença de potencial e não a distância entre elas. Isso faz com que o desnível entre duas referências de nível obtidas através do somatório dos desníveis observados em cada lance do nivelamento, seja distinto quando distintos trajetos forem percorridos (FREITAS; BLITZKOW, 1999). 


\subsubsection{Altitude geodésica}

A altitude geodésica ou elipsoidal é a distância entre a superfície física e a superfície elipsoidal contada ao longo da normal (Figura 2.8). Por se tratar de uma quantidade matemática ela é facilmente determinada com o auxílio de modernas técnicas, tal como o posicionamento por satélites. A não vinculação com o campo de gravidade da Terra leva esse tipo de altitude a não ter relação com o fluxo da água. Valores iguais para pontos situados em diferentes níveis, ou vice-versa, podem ocorrer. Assim sendo, esse tipo de altitude deve ser empregado com restrições em trabalhos de Engenharia.

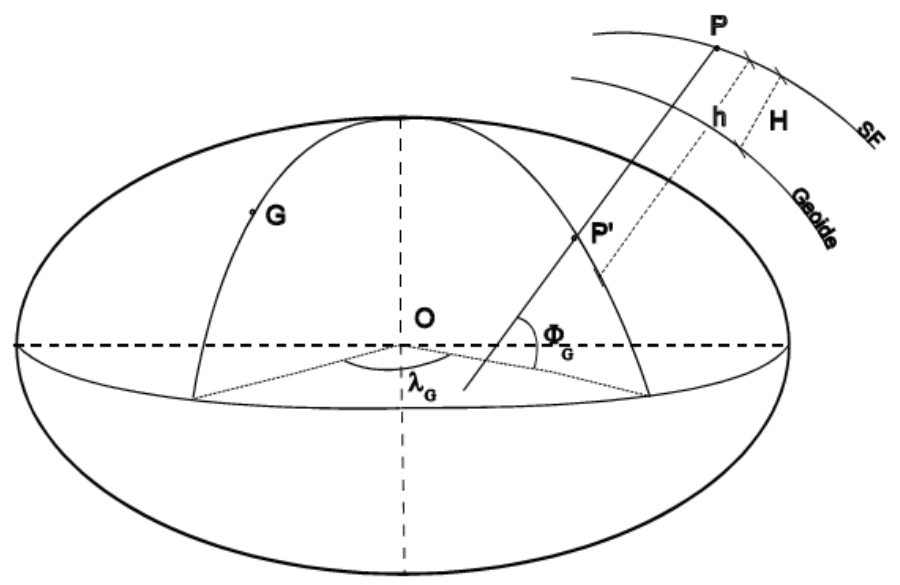

Figura 2.8 - Elementos da altitude geodésica (Freitas; Blitzkow, 1999)

\subsection{Datum Vertical}

A origem da altitude é estabelecida através de uma superfície de referência associado a um valor do potencial de gravidade sobre a mesma. Isso caracteriza o datum vertical. Além disso, ainda é imprescindível escolher um sistema de altitude, ou seja, uma maneira de associar um número com uma unidade à separação entre superfícies.

No Brasil, a "altitude zero" também denominada de "ponto origem" está referida ao nível médio do mar no Porto de Imbituba - SC com observações coletadas entre 1949 e 1957, perfazendo um período de 9 anos. Em 1959 o IBGE definiu e adotou 
oficialmente o maregráfo de Imbituba como referência de origem vertical do SGB. Anteriormente, as altitudes eram referidas ao maregráfo de Torres, definido por um período de um ano de coleta (1919 a 1920) (ALENCAR, 1990).

A RAAP (Figura 2.9) iniciou-se em 1945 e é a estrutura de referência vertical do SGB contando com mais de 65.000 referências de nível implantadas em todo território nacional (LUZ et al., 2002). O último ajustamento da RAAP ocorreu no início da década de 90. Em 2005 o IBGE iniciou esforços para a realização de um novo ajustamento. Ao final do projeto estima-se disponibilizar cerca de 60.000 estações com altitudes ajustadas e os respectivos desvios-padrões (PINHEIRO et al., 2007).

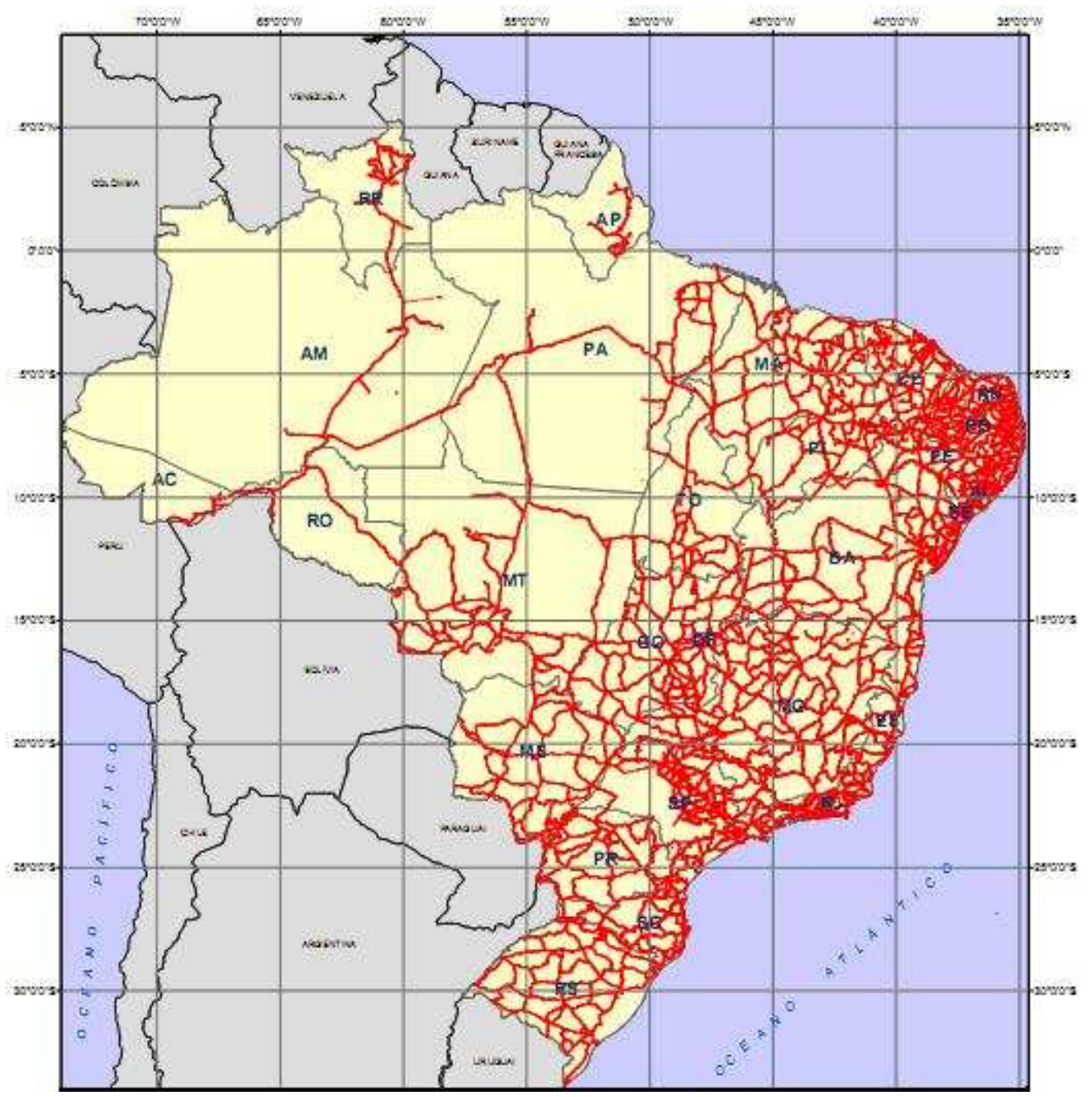

Figura 2.9 - Rede Altimétrica de Alta Precisão do Sistema Geodésico Brasileiro (IBGE, 2009b)

Em 1940, iniciou-se no estado de São Paulo o nivelamento de precisão. A realização dessa tarefa coube ao então Instituto Geográfico e Geológico (IGG), atual IGC (Instituto Geográfico e Cartográfico). A linha de nivelamento partiu da referência do 
nível médio do mar no marégrafo da Mortona, no porto de Santos. O primeiro marco foi implantado no prédio da alfândega daquele porto, pela Companhia Docas de Santos, cuja altitude ortométrica determinada foi de 3,065 m (IGG, 1943 apud Sá et al., 2006). Após alguns anos de trabalho, as equipes chegaram até o município de Itapeva onde tiveram o primeiro contato com uma RN do então Conselho Nacional de Geografia do IBGE, referida ao marégrafo de Torres. A diferença de altitude encontrada naquela RN foi de $3 \mathrm{~cm}$ (Boletim IGG no 36, 1962), sendo considerada pequena. Decidiu-se então adotar como referência do nivelamento do IGG o nível médio do mar fornecido pelo marégrafo de Torres. O nivelamento realizado pelo IGG consistiu em circuitos, obedecendo a uma precisão de $4 \mathrm{~mm} \sqrt{k}$. As linhas de nivelamento acompanharam as principais ou melhores rodovias do estado (Figura 2.10) e a materialização das RNs foi realizada a cada $5 \mathrm{~km}$. Após 20 anos de trabalho o estado já contava com mais de 10.000 km de linhas niveladas.

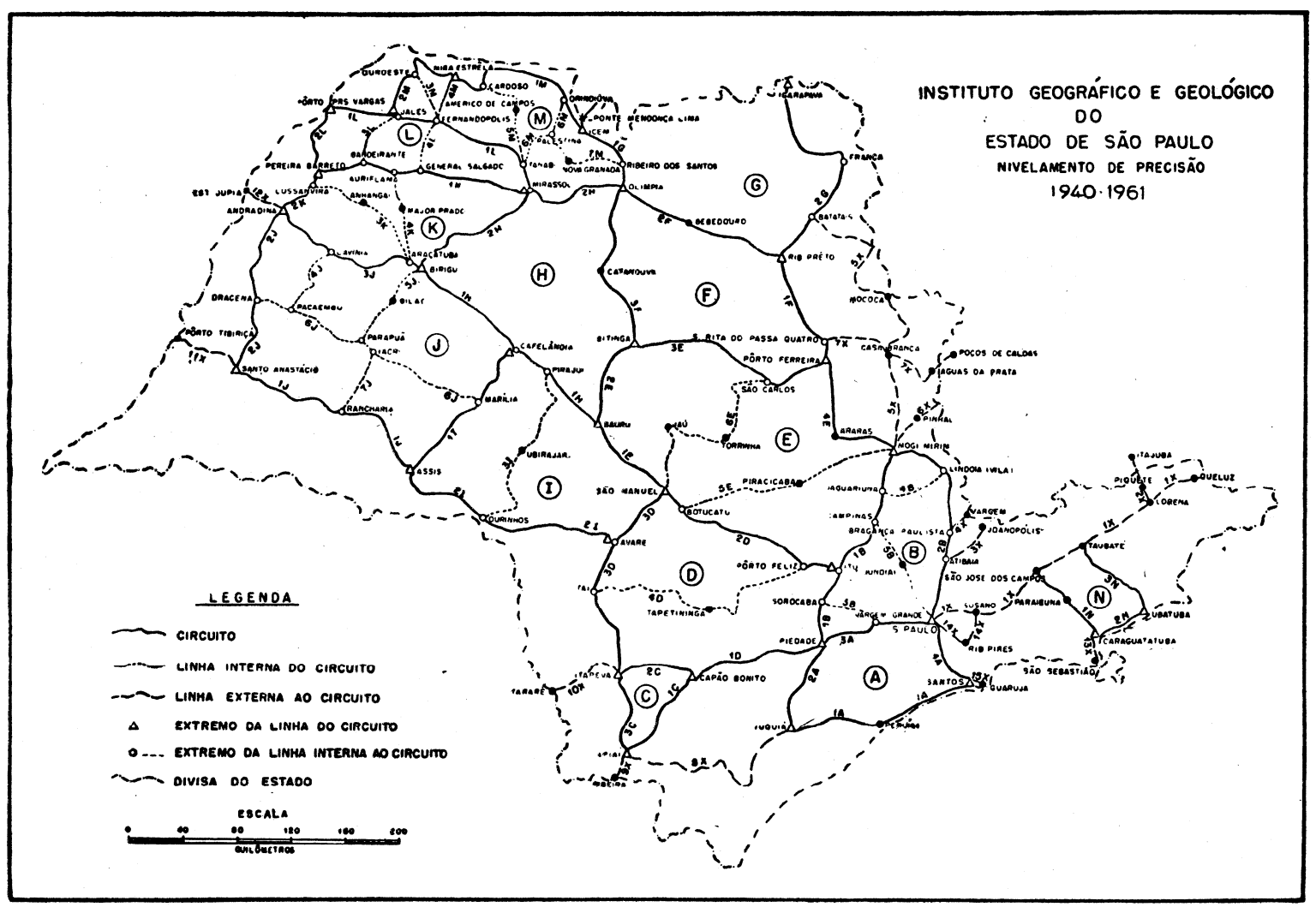

Figura 2.10 - Nivelamento de Precisão do estado de São Paulo (Boletim IGG no 36, 1962).

A rede de nivelamento do IGG serviu de origem e apoio para muitas outras redes: Emplasa (Empresa Metropolitana de Planejamento da Grande São Paulo S.A.), Metrô (Companhia do Metropolitano de São Paulo), Sabesp (Companhia de 
Saneamento Básico do Estado de São Paulo) e Prefeitura de São Paulo. Entretanto, algumas divergências altimétricas foram detectadas, o que resultou em diversas referências altimétricas em obras de Engenharia e trabalhos cartográficos. Barbosa (1996) propôs uma unificação do sistema altimétrico da região metropolitana de São Paulo, cujo objetivo foi estabelecer uma única rede, com cobertura e distribuição adequada para a Grande São Paulo.

A RMPG (Figura 2.11) conta atualmente com 5 estações maregráficas, cuja finalidade é acompanhar a evolução dos data altimétricos do SGB. A rede também permite que o nível médio em toda a costa brasileira seja determinado e correlacionado com observações pretéritas. Além disso, ela beneficia na realização de trabalhos e pesquisas nas regiões costeiras e nas operações portuárias (LUZ; GUIMARÃES, 2003).

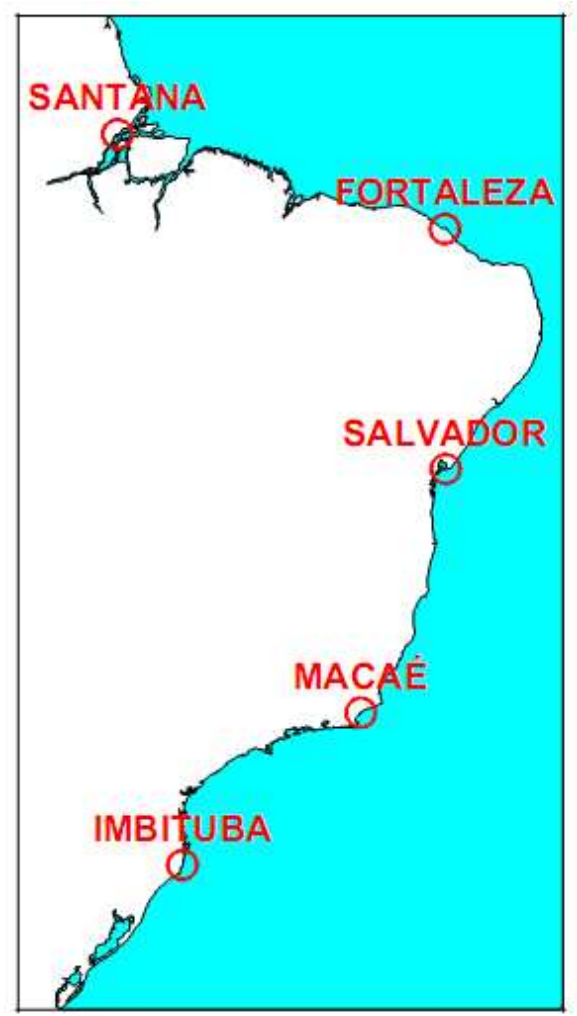

Figura 2.11 - Rede Maregráfica Permanente para Geodésia (Luz; Guimarães, 2003) 


\subsection{Topografia da Superfície Oceânica}

Numa abordagem clássica pressupõe-se que o geoide coincida com $\circ$ NMM. Entretanto, as pesquisas realizadas ao longo dos anos aliada ao avanço da tecnologia (altimetria por radar) sobre a dinâmica dos oceanos, levou a uma revisão dessa hipótese. A Topografia da Superfície Oceânica (TSO) (do inglês - Sea Surface Topography) é expressa como a separação entre o geoide e o NMM resultante de diversos agentes metereológicos e oceanográficos. Vários fatores contribuem para 0 surgimento da TSO (pressão atmosférica, ventos, derretimento das calotas polares, correntes oceânicas, diferenças de densidade d'água, de salinidade, de temperatura, etc.) (PUGH, 1987). A ação desses agentes físicos pode ocorrer de forma diferenciada em diferentes locais da costa, sendo possível associar um valor de TSO para cada estação maregráfica existente (LUZ, 2008). Isso explicaria as grandes diferenças mostradas na Figura 2.12.

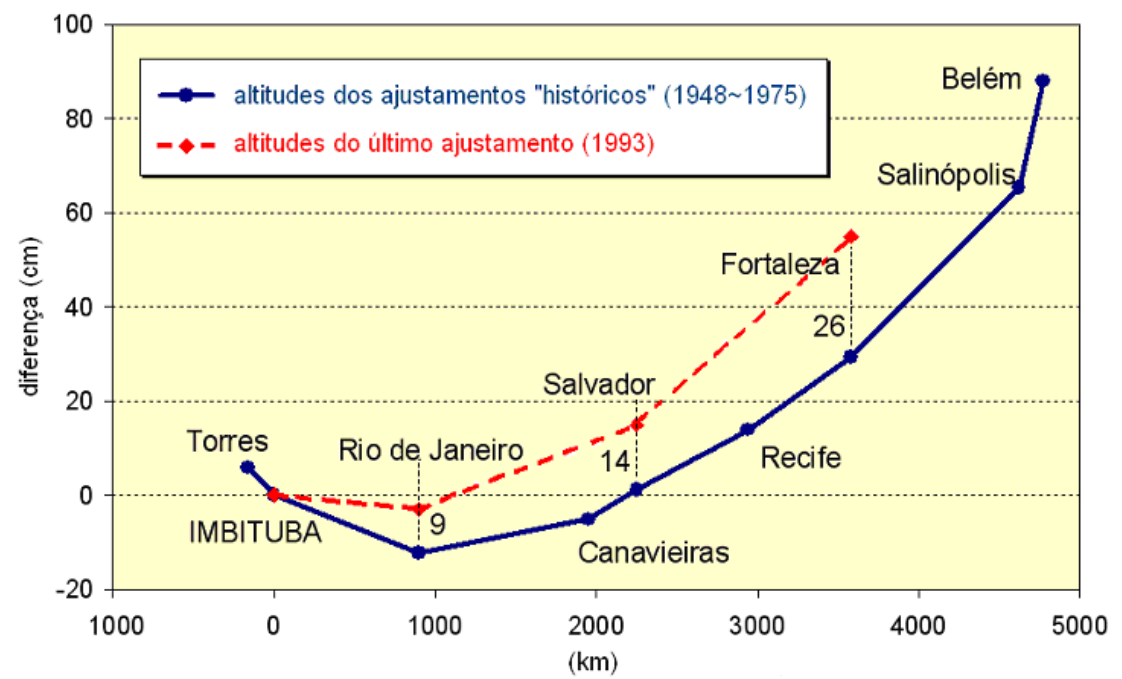

Figura 2.12 - Discrepância entre o datum de Imbituba e o NMM local em algumas estações maregráficas (Luz; Guimarães, 2003)

Com isso, Luz (2008) propôs a definição de um datum altimétrico baseado em múltiplas estações maregráficas. A integração de dados de marégrafos e de altimetria por radar é uma opção, apesar de apresentarem algumas dificuldades. 


\subsection{Marés Terrestres}

A definição de um datum vertical e alguns parâmetros geodésicos é afetada pelas variações da força de maré. Gemael (1999) define força de maré em um ponto $P$ como sendo a diferença entre a força de atração exercida pelo Sol e pela Lua sobre a unidade de massa colocada nesse ponto e no centro do modelo. O potencial gravitacional nas imediações da Terra é uma combinação do potencial gravitacional de marés de corpos externos e do próprio potencial da Terra. O potencial de maré possui uma parte permanente e outra periódica.

Existem 3 maneiras de lidar com os efeitos permanentes de maré (RAPP et al., 1991) e (BURŠA, 1995): 1) maré média (mean-tide) os efeitos permanentes e elásticos não são removidos; 2) livre de maré (tide-free ou non-tidal) são eliminados, tanto o efeito permanente, quanto o periódico (elástico); 3) maré-zero (zero-tide) somente o efeito permanente é eliminado, preservando a componente relacionada à deformação elástica da Terra. A expressão "maré-zero" é utilizada para se referir a uma maré de referência.

A escolha de um desses 3 modos para a definição de um sistema de altitude e a redução de observações gravimétricas tem sido objeto de conjectura. O modelo de maré-média é o que melhor se aproxima da forma do nível dos mares. O modelo de maré livre é concordante com a fórmula de Stokes, pois as massas externas são eliminadas. Entretanto, exige diferentes números de Love ${ }^{11}$ na atribuição das deformações permanentes e periódicas, o que não é possível, uma vez que esses números não são bem conhecidos para uma Terra real. O modelo de maré zero também é consistente com a fórmula de Stokes. A vantagem apresentada sobre o modelo livre de maré é que este não necessita de uma hipótese sobre a remoção do efeito periódico.

A resolução 16 da International Association of Geodesy (IAG) de 1983 (IAG, 1984) reconhece a necessidade de uniformidade no tratamento das correções de marés nas diferentes quantidades geodésicas. Os modelos de maré são determinados a partir do uso de gravímetros de alta sensibilidade ou sistemas de satélites.

\footnotetext{
${ }^{11}$ Augustus Edward Hough Love (1863-1940).
} 


\subsection{Gravimetria}

A técnica utilizada para medir as variações da aceleração de gravidade de forma absoluta ou relativa em toda a superfície terrestre é denominada de gravimetria. $\mathrm{Na}$ determinação absoluta o valor de $g$ é obtido diretamente em uma estação, enquanto, na relativa, determina-se a diferença de $g$ entre duas estações.

Galilei $^{12}$ introduziu dois métodos de medidas absolutas: pendular e "queda-livre" (free-fall). O primeiro foi utilizado para realizar a primeira medição da aceleração de gravidade no observatório de Potsdam, Alemanha, em 1906. A expressão do movimento do pêndulo é a seguinte:

$$
T=2 \pi \sqrt{\frac{l}{g}}
$$

onde $T$ é o período, $l$ o comprimento e $g$ a aceleração de gravidade. A partir do comprimento e de uma série de observações do período do movimento durante certo intervalo de tempo, obtém-se o valor de $g$ por meio de um método de ajustamento de observações (e.g, TORGE, 2001; GEMAEL, 1999).

O valor da aceleração de gravidade pode variar desde 978 mGal no equador até 983 mGal nos polos (VANÍČEK; KRAKIWSKY, 1986). Em Geodésia, a unidade empregada para representar $g$ é o Gal, em homenagem a Galilei, e os submúltiplos são apresentados conforme a Tabela 2.2.

Tabela 2.2 - Unidades de medidas de $g$

\begin{tabular}{ccc}
\hline Nome & Símbolo & Equivalência \\
\hline gal & Gal & $\mathrm{cm} / \mathrm{s}^{2}$ \\
miligal & $\mathrm{mGal}$ & $0,001 \mathrm{Gal}$ \\
Microgal & $\mu \mathrm{Gal}$ & $0,000001 \mathrm{Gal}$ \\
\hline
\end{tabular}

\footnotetext{
${ }^{12}$ Galileo Galilei (1564-1642).
} 
Antes do advento dos gravímetros, as determinações relativas eram executadas utilizando-se de pêndulos. Os gravímetros de mola (Figura 2.13) surgiram na primeira metade do século passado. Um sistema elástico mantém suspensa uma massa que é atraída com mais ou menos intensidade dependendo da força de gravidade do local. Um parafuso de compensação restabelece uma certa posição de equilíbrio que é definida por construção. Essa posição é traduzida por uma leitura que posteriormente é transformada em unidades de aceleração (BLITZKOW, 1996).

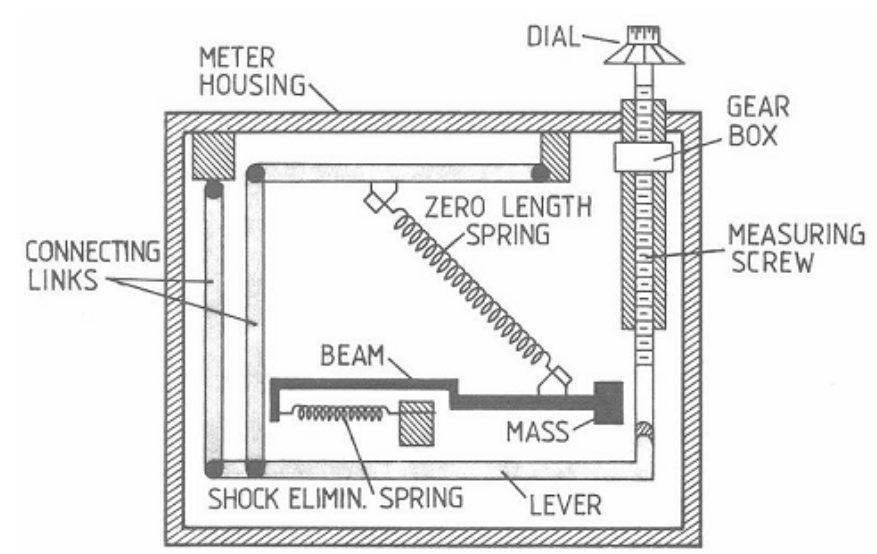

Figura 2.13 - Gravímetro de mola (Torge, 2001)

O avança tecnológico permitiu o desenvolvimento de aparelhos altamente sensíveis, entretanto, não se conseguiu aliar uma grande estabilidade. Com o decorrer do tempo os gravímetros sofrem variações em suas condições elásticas, o que se chama deriva e que necessita ser corrigida. Além disso, outros fatores devem ser examinados com certa frequência: sensibilidade, calagem dos níveis e calibração (e.g, GEMAEL, 1999; BLITZKOW, 2003; CASTRO JUNIOR, 2005). O desenvolvimento de gravímetros eletrônicos foi outra contribuição tecnológica. Nestes, o operador fica restrito somente a nivelar o equipamento, sendo que as outras etapas são conduzidas de forma eletrônica. Uma desvantagem é que, como qualquer outro equipamento eletrônico, esse está sujeito a falhas em seu sistema, podendo ocasionar perda das informações já armazenadas. As Figuras 2.14a, 2.14b e 2.14c ilustram alguns modelos de gravímetros. 


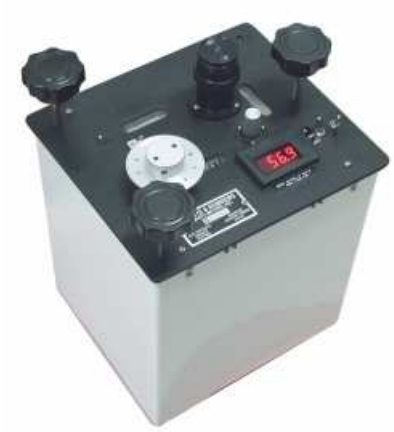

Figura 2.14a - Gravímetro LaCoste \& Romberg

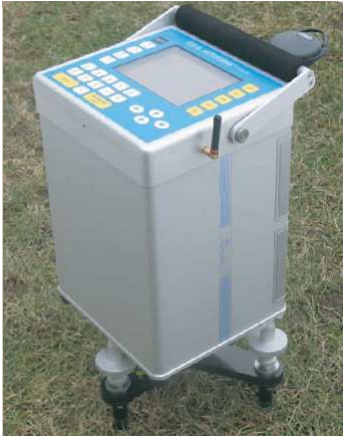

Figura 2.14b - Gravímetro SCINTREX

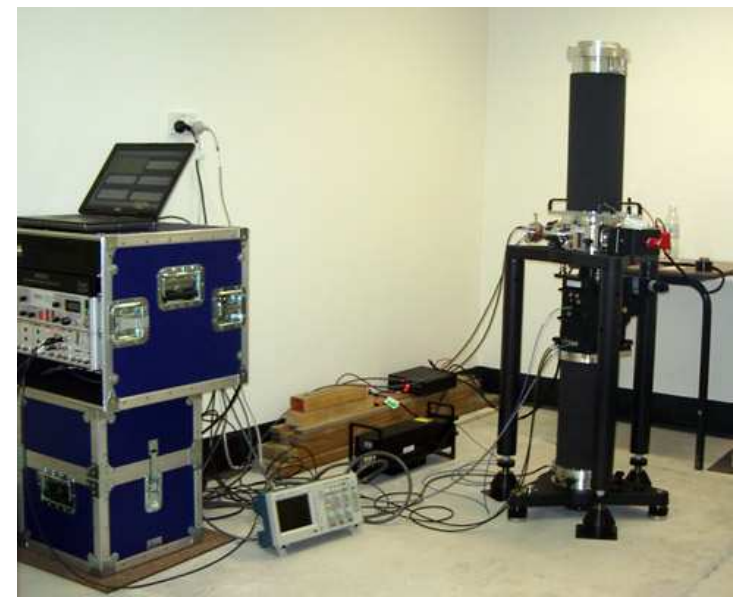

Figura 2.14c - Gravímetro absoluto FG5, Foto: ANU

A gravimetria no Brasil iniciou-se por volta de 1967, com determinações pendulares na Paraíba (GEMAEL, 1999). Desde então, alguns órgãos contribuíram e contribuem na organização, planejamento, execução e controle dos levantamentos gravimétricos. Destacam-se nesse trabalho o Observatório Nacional (ON), a Universidade Federal do Paraná (UFPR), a Universidade de Brasília (UNB), a Petróleo do Brasil S.A (PETROBRAS), a Agência Nacional de Petróleo (ANP), o IBGE e a USP.

Nos trabalhos gravimétricos atuais, a utilização do GNSS é essencial, permitindo obter as coordenadas geodésicas $(\varphi, \lambda, h)$ com precisão centimétrica. Nesse caso, a aplicação do PVCG fixo é possível, uma vez que é conhecido o valor de $g$ proveniente das medidas gravimétricas com sua posição no espaço. 


\section{MODELOS DO GEOPOTENCIAL}

\subsection{Introdução}

O modelo do geopotencial é um conjunto de coeficientes da função potencial gravitacional da Terra desenvolvida em série de funções harmônicas esféricas. A era espacial, inicializada com o lançamento do Sputnik, que em russo significa "amigo" ou "companheiro", em 04 de outubro de 1957, foi considerada um marco para o desenvolvimento dos modelos do geopotencial global (Global Geopotential Models GGMs), além de contribuir no desenvolvimento do PVCG. Os primeiros modelos datam da década de 60 (GUIER; NEWTON, 1965), (KAULA, 1966), (ANDERLE, 1966), (LUNDQUIST; VEIS, 1966), (ANDERLE; SMITH, 1967) e (KÖHNLEIN, 1967). Os avanços tecnológicos por meio de satélites artificiais mais eficazes, do incremento computacional e do refinamento da base teórica, permitiram 0 aprimoramento de GGMs com grau e ordem cada vez mais elevados.

A partir da década de 90 iniciou-se a chamada década da gravidade. As missões gravitacionais modernas como também ficaram conhecidas, possuíam objetivos específicos. Os satélites foram desenvolvidos para trafegarem em órbita baixa, além de serem projetados com os mais sofisticados equipamentos: GPS, DORIS (Doppler Orbit determination and Radiopositioning Integrated on Satellite) e laser. Dessas missões resultaram 3 satélites: CHAMP (CHAlleging Minisatellite Payload), GRACE (Gravity Recovery And Climate Experiment) e GOCE (Gravity field and steady-state Ocean Circulation Explorer). Vários modelos do geopotencial derivados tanto do CHAMP quanto do GRACE têm sido publicados; com relação aos resultados do GOCE, foi publicado o primeiro modelo geoidal em 29/06/2010 ${ }^{1}$ fruto de dois meses de dados. Dentre os diversos modelos, utilizar-se-á nesta dissertação o EIGENGL04C, EIGEN-GL04S, EIGEN-5C (European Improved Gravity Model of the Earth by New Techniques) e o EGM08.

\footnotetext{
${ }^{1}$ http://www.esa.int/esaLP/SEMYOFOZVAG_LPgoce_0.html
} 
A partir das variações no movimento dos satélites artificiais, torna-se possível obter as perturbações devido ao campo gravitacional e assim modelar as heterogeneidades. Dessa forma, os longos comprimentos de onda (baixo grau) são melhor definidos por meio dos satélites, enquanto que os coeficientes de alto grau são determinados a partir de dados terrestres.

\subsection{A Evolução dos Modelos do Geopotencial}

Rapp (1998) estabelece uma abordagem detalhada do passado e do futuro acerca do desenvolvimento dos modelos do geopotencial. Diversos pesquisadores ${ }^{2}$ apresentaram estudos teóricos mostrando que as variações da gravidade na superfície limitante de um esferoide rotante, poderiam ser expressas pela seguinte expressão:

$$
\gamma=\gamma_{E}\left(1+\beta_{1} \operatorname{sen}^{2} \phi+\beta_{2} \operatorname{sen}^{2} 2 \phi+\ldots\right)
$$

onde $\gamma$ é o valor da gravidade normal, $\gamma_{E}$ é a gravidade equatorial, $\beta_{1}, \beta_{2}, \ldots$ são as constantes a serem determinadas ou calculadas a partir de pressupostos sobre a figura na qual as variações da gravidade estão descritas e $\phi$ a latitude geodésica. Os parâmetros da expressão (3.1) podem ser determinados a partir da estimativa da massa da Terra, do raio equatorial, do achatamento e dos parâmetros de gravidade.

Outra contribuição importante na evolução dos modelos do geopotencial foi concebida por Helmert em 1901, que reduziu pelo método de condensação desenvolvido por ele, 1603 estações para a determinação do achatamento terrestre, obtendo o valor de $1 / 298,3$.

As variações da gravidade, descritas em (3.1) dependem somente da latitude. Para o caso da Terra tomar a forma de um elipsoide triaxial, acrescenta-se um termo relacionado à longitude:

\footnotetext{
${ }^{2}$ Clairaut, deSitter, Helmert, Pizzetti, Somigliana, Lambert.
} 


$$
\gamma=\gamma_{E}\left(1+\beta_{1} \operatorname{sen}^{2} \phi+\beta_{2} \operatorname{sen}^{2} 2 \phi+\beta_{3} \cos ^{2} \phi \cos 2\left(\lambda-\lambda_{0}\right)\right)
$$

Em 1937, Dubovskii representou as anomalias de gravidade até grau e ordem 6 com o seguinte modelo (RAPP, 1998):

$$
\Delta g=(\theta, \lambda)=\sum_{n=0}^{m} \sum_{m=0}^{n}\left(a_{n m} \cos m \lambda+b_{n m} \operatorname{senm} \lambda\right) P_{n m}(\cos \theta)
$$

onde $\theta$ é a co-latitude, $a_{n m}$ e $b_{n m}$ coeficientes da expansão harmônica, $\lambda$ é a longitude, $P_{n m}$ são as funções de Legendre associadas.

Outro passo importante deve-se ao finlandês Heiskanen ${ }^{3}$. Sob sua orientação diversas medidas da aceleração de gravidade foram coletadas e reduzidas. Um de seus alunos, L. Tanni apresentou em 1948 um mapa mundial estabelecido pela fórmula de Stokes. Para tal, 13.000 medidas de pêndulos e milhares de medidas gravimétricas foram utilizadas. São vários os pesquisadores que contribuíram para o desenvolvimento dos GGMs e esses esforços resultaram em modelos globais mais efetivos e precisos. Para uma análise global do campo de gravidade, o potencial gravitacional da Terra é representado pelas chamadas funções harmônicas esféricas (HOFMANN-WELLENHOF; MORITZ, 2005):

$$
V(r, \theta, \lambda)=\sum_{n=0}^{\infty}\left(\frac{a}{r}\right)^{n+1} \sum_{m=0}^{n}\left(A_{n m} Y_{n m}^{c}+B_{n m} Y_{n m}^{s}\right)
$$

sendo:

$$
Y_{n m}^{c}=P_{n m}(\cos \theta) \cos (m \lambda)
$$

e

$$
Y_{n m}^{s}=P_{n m}(\cos \theta) \operatorname{sen}(m \lambda)
$$

\footnotetext{
${ }^{3}$ Weikko Aleksanteri Heiskanen (1895-1971).
} 
onde $P_{n m}(\cos \theta)$ representa as funções principais da equação de Legendre, $a$ é o raio equatorial da Terra e $n, m$ os autovalores. $Y_{n m}^{c}$ e $Y_{n m}^{s}$ podem ser vistas como funções principais da equação de Laplace sobre a superfície de uma esfera; são as chamadas funções harmônicas esféricas (de superfície) (VANÍČEK; KRAKIWSKY, 1986). Considerando (HOFMANN-WELLENHOF; MORITZ, 2005):

$$
\left.\begin{array}{l}
\bar{A}_{n m}=\frac{G M}{r} C_{n m} \\
\bar{B}_{n m}=\frac{G M}{r} S_{n m}
\end{array}\right\}(n \neq 0)
$$

e utilizando coeficientes adimensionais e plenamente normalizados a (3.4) toma a seguinte forma (BIANCALE, 2002 apud ALMEIDA FILHO, 2009):

$$
V(r, \theta, \lambda)=\frac{G M}{r} \sum_{n=1}^{\infty}\left(\frac{a}{r}\right)^{n+1} \sum_{m=0}^{n} P_{n m}(\operatorname{sen} \phi)\left(C_{n m} \cos m \lambda+S_{n m} \operatorname{sen} \lambda\right)
$$

onde os coeficientes de Stokes são definidos como:

$$
\left\{\begin{array}{c}
C_{n, m} \\
S_{n, m}
\end{array}\right\}=\frac{1}{M a^{n}} \iiint_{Q}\left(2-\delta_{m, 0}\right) \frac{(n-m) !}{(n+m) !} r^{\prime n} P_{n, m}\left(\operatorname{sen} \phi^{\prime}\right)\left\{\begin{array}{c}
\cos m \lambda^{\prime} \\
\operatorname{sen} m \lambda^{\prime}
\end{array}\right\} d m
$$

Os termos $C_{n, 0}\left(=-J_{n}\right),\left[C_{n, m}, S_{n, m}\right]$ e $\left[C_{n, n}, S_{n, n}\right]$ são os coeficientes de Stokes correspondentes aos harmônicos esféricos zonais, tesserais e sectoriais, respectivamente. Os valores obtidos para os coeficientes $C_{n m}, S_{n m}$ na expressão (3.8) até um grau e ordem $L$ representam o que se denomina "modelo do geopotencial".

O avanço tecnológico aliado às missões gravimétricas terrestres ou a aerogravimetria está contribuindo para o desenvolvimento dos GGMs. Tal fato proporciona uma divisão dos modelos do geopotencial em três classes primárias (RAPP, 1998), (FEATHERSTONE, 2002) e (RUMMEL et al., 2002): 
- GGMs derivado somente com dados de satélite (satellite-only GGMs). São modelos obtidos a partir da análise do movimento orbital de satélites artificiais;

- GGMs combinado (combined GGMs). Derivados a partir da combinação de dados de satélite, observações de gravidade terrestre e oceânica, dados de altimetria por radar e aerogravimetria. Essas informações adicionais permitem um aumento no grau dos coeficientes das funções harmônicas esféricas do GGM;

- GGMs adaptado (tailored GGMs). São aqueles gerados apenas com dados já existentes de satélites ou combinado com GGM ajustado a partir de novos dados, não necessariamente utilizados antes.

\subsection{Os Modelos EIGEN}

Os modelos do geopotencial da série EIGEN tiveram início no ano de $2001 \mathrm{com}$ apenas 88 dias não consecutivos de dados de rastreio GPS da missão CHAMP. Desde então, vários modelos foram publicados, como, por exemplo, os modelos EIGEN-GL04C e EIGEN-5C.

\subsubsection{O Modelo EIGEN-GL04C}

No modelo EIGEN-GL04C (FÖRSTE et al., 2006), GL refere-se às iniciais dos satélites GRACE e LAGEOS (Laser Geodynamics Satellite) (Figura 3.1a e 3.1b, respectivamente), 04 o ano de publicação e $C$ indica um modelo combinado. 


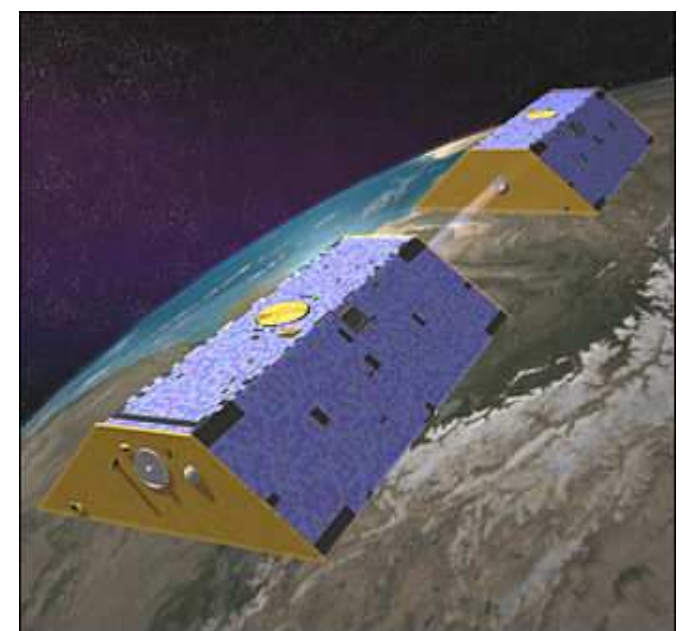

Figura 3.1a - Satélite GRACE Fonte: Earth Observatory - NASA

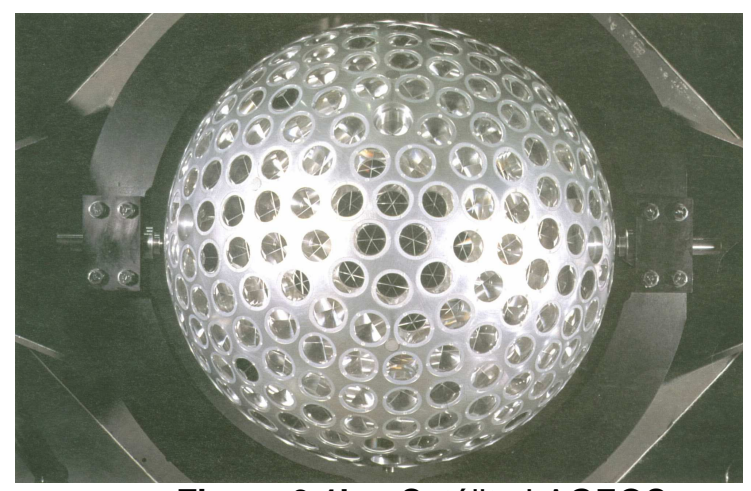

Figura 3.1b - Satélite LAGEOS

Fonte: Mission and SpaceCraft Library - NASA

Os dados foram processados e analisados por dois órgãos: GFZ (GeoForschungsZentrum Potsdam) - GRACE de fevereiro de 2003 a julho de 2005 (exceto o mês de janeiro de 2004) e CNES (Centre National D'Étudies Spatiales) GRACE e LAGEOS de fevereiro de 2003 a fevereiro de 2005. Os dados de superfície utilizados são os seguintes (FÖRSTE et al., 2006):

1) Anomalia de gravidade do Arctic Gravity Project (ArcGP) para regiões com latitudes maiores que 64은 (FORSBERG; KENYON, 2004);

2) Anomalias de gravidade fornecidas pelo NRCan (Natural Resources Canada) para a cobertura da América do Norte;

3) Anomalias de gravidade para pequenas áreas da Antártica;

4) Anomalias de gravidade altimétrica sobre os oceanos incluindo os desvios padrões cedidas pelo NIMA (National Imagery and Mapping Agency) atual NGA (National Geo-spatial Intelligence Agency);

5) Ondulações geoidais sobre os oceanos derivadas da média das alturas da superfície do mar subtraído de um modelo de simulação da topografia da superfície do mar;

6) Anomalias de gravidade e desvios padrões para quase toda a cobertura mundial, exceto Antártica, alguns vazios (cor branca) e itens 1) e 3) cedidas pelo NGA;

7) Anomalias de gravidade sobre a água para profundidades menores que $2.000 \mathrm{~m}$ fornecidas pelo NGA. 
Todos os dados cedidos estão disponíveis para um bloco de valor médio de 30' $x$ 30', exceto os dados dos itens 5) e 7) que foram fornecidos com uma resolução de $1^{\circ} \times 1 \stackrel{0}{ }$. A Figura 3.2 ilustra a distribuição dos dados.

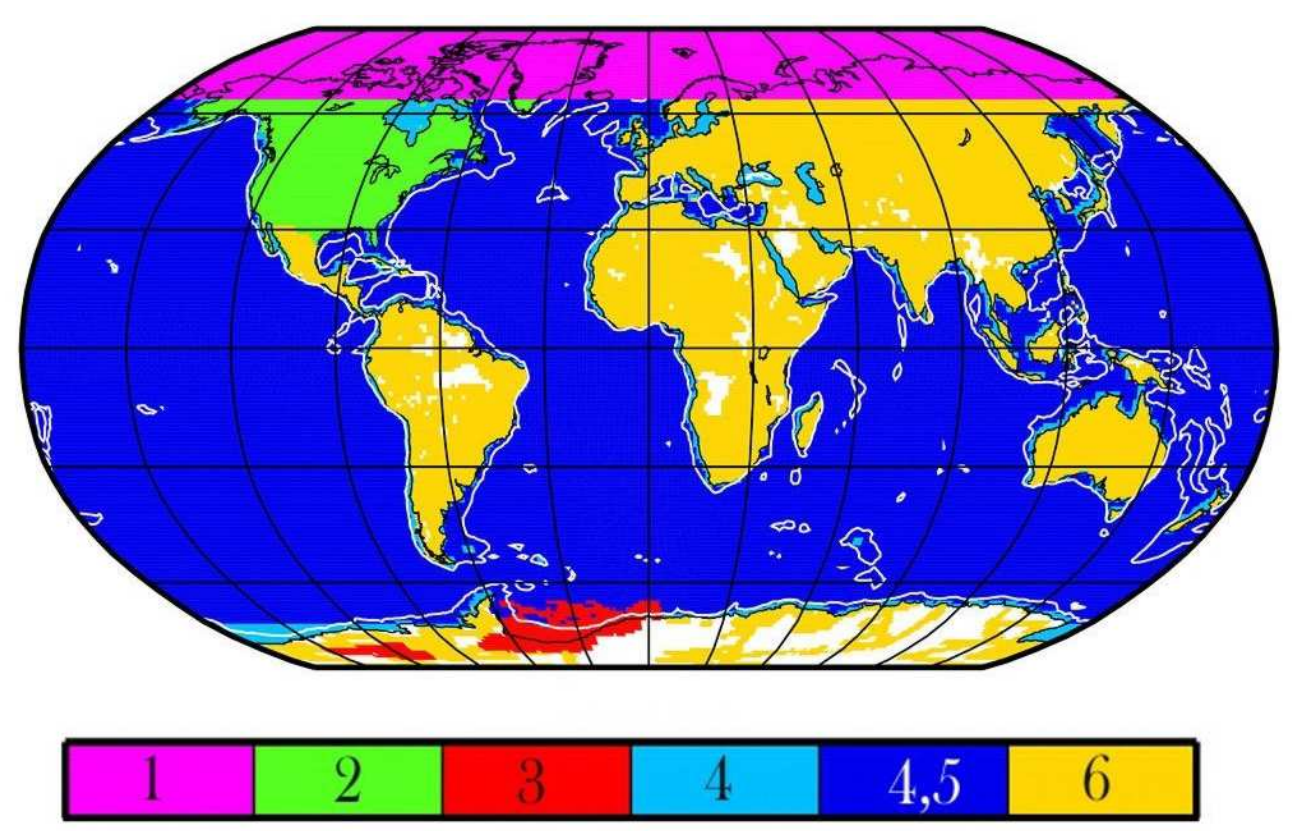

Figura 3.2 - Distribuição dos dados de superfície (Förste et al., 2006)

A validação da qualidade de um GGM é uma das etapas realizadas durante o processo de desenvolvimento. Em geral, um GGM é comparado com outros a fim de verificar os resultados obtidos. A comparação das ondulações geoidais a partir das técnicas de GPS e nivelamento sobre RN, nesta dissertação denominado de GPS/RN, envolvendo alguns dos GGMs é vista na Tabela 3.1.

Tabela 3.1 - RMS da média dos dados GPS/RN menos o modelo do campo de gravidade derivada das ondulações geoidais - EIGEN-GL04C

\begin{tabular}{ccccc}
\hline \multirow{2}{*}{ GGM } & \multicolumn{4}{c}{ RMS (cm) } \\
\cline { 2 - 5 } & $\begin{array}{c}\text { EUA } \\
\text { (6169 pontos) }\end{array}$ & $\begin{array}{c}\text { Canadá } \\
(1930 \text { pontos })\end{array}$ & $\begin{array}{c}\text { Europa } \\
\text { (186 pontos })\end{array}$ & $\begin{array}{c}\text { Alemanha } \\
(675 \text { pontos })\end{array}$ \\
\hline EIGEN-GL04C & 33,9 & 25,3 & 33,5 & 17,8 \\
EIGEN-CG03C & 34,6 & 30,6 & 39,2 & 19,8 \\
EIGEN-CG01C & 35,1 & 27,1 & 40,8 & 21,7 \\
EGM96 & 37,8 & 35,7 & 48,4 & 28,6
\end{tabular}

Fonte: http://op.gfz-potsdam.de/grace/results/grav/g005_eigen-gl04c.html - Acessado em 20/08/2009 


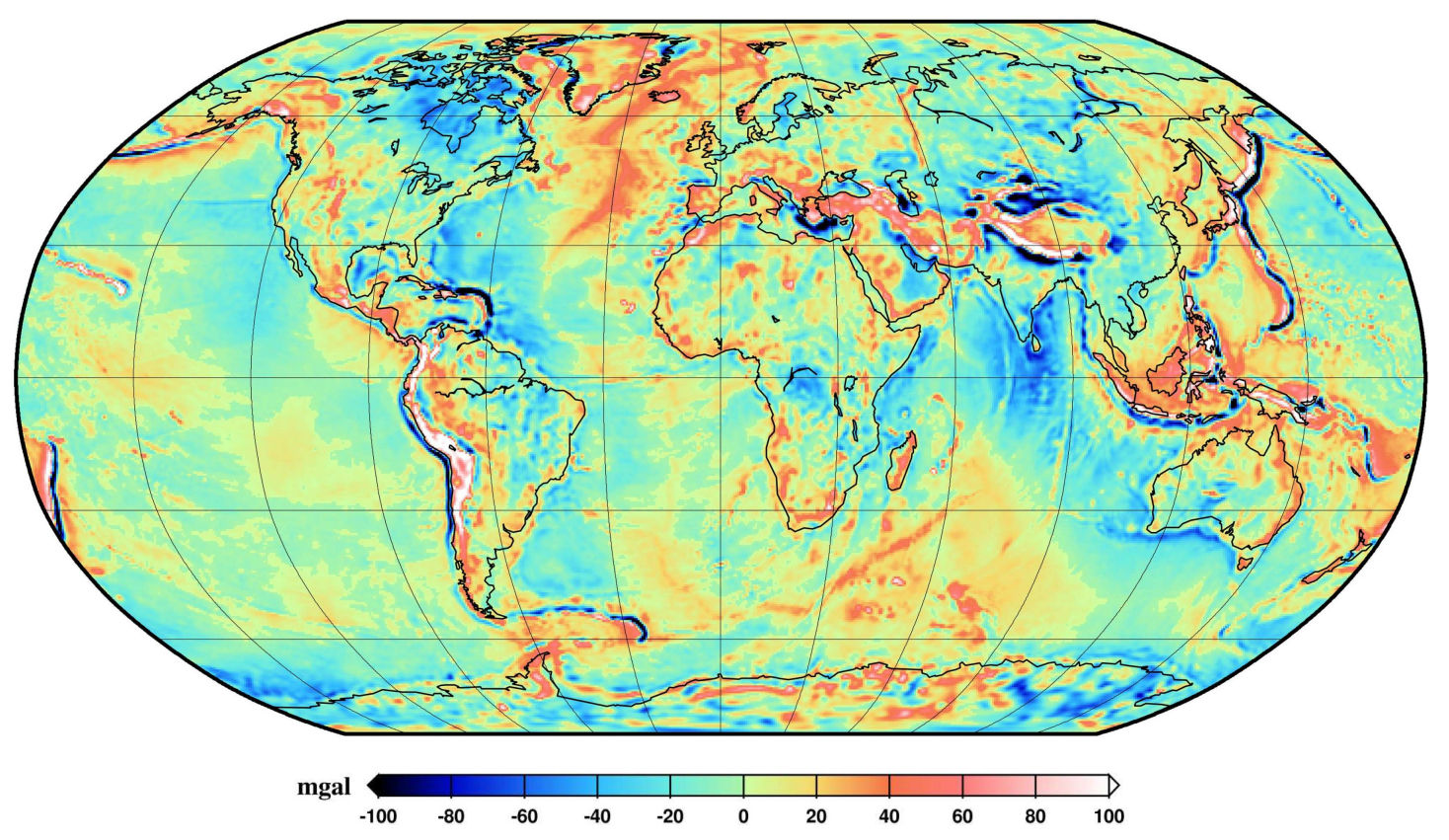

Figura 3.3 - Anomalia de gravidade para um modelo digital de 30' x 30' (Förste et al., 2006)

\subsubsection{O Modelo EIGEN-5C}

O modelo EIGEN-5C é um aprimoramento do EIGEN-GL04C. Uma das diferenças é a quantidade de dados utilizados nos processamento. No modelo EIGEN-GL04C foram processados 30 meses de dados do satélite GRACE, enquanto que para o EIGEN-5C foram 54 meses (Agosto de 2002 a janeiro de 2007). Com relação ao satélite LAGEOS foram 24 meses (EIGEN-GL04C) e 14 anos (EIGEN-5C - 1993 a 2006). Outra diferença é o grau máximo utilizado na matriz normal: 179 EIGENGL04C e 280 EIGEN-5C. Além disso, foram incorporados dados gravimétricos terrestres da Europa e da Austrália.

Para esse modelo a comparação das ondulações geoidais a partir de GPS/RN foi repetida (Tabela 3.2). 
Tabela 3.2 - RMS da média dos dados GPS/RN menos o modelo do campo de gravidade derivada das ondulações geoidais - EIGEN-5C

\begin{tabular}{|c|c|c|c|c|}
\hline \multirow{2}{*}{$\begin{array}{l}\text { Modelo do } \\
\text { geopotencial }\end{array}$} & \multicolumn{4}{|c|}{ RMS (cm) } \\
\hline & $\begin{array}{c}\text { EUA } \\
\text { (6169 pontos) }\end{array}$ & $\begin{array}{c}\text { Canadá } \\
\text { (1930 pontos) }\end{array}$ & $\begin{array}{c}\text { Europa } \\
\text { (1234 pontos) }\end{array}$ & $\begin{array}{c}\text { Alemanha } \\
\text { (675 pontos) }\end{array}$ \\
\hline EIGEN-5C & 34,1 & 25,1 & 30,1 & 15,2 \\
\hline EIGEN-GL04C & 33,9 & 25,3 & 33,6 & 17,8 \\
\hline EIGEN-CG03C & 34,6 & 30,6 & 35,5 & 19,8 \\
\hline EIGEN-CG01C & 35,1 & 27,1 & 37,0 & 21,7 \\
\hline
\end{tabular}

Fonte: http://op.gfz-potsdam.de/grace/results/grav/g007_eigen-05c.html - Acessado em 20/08/2009

\subsection{O Modelo EGM08}

O primeiro modelo da série Earth Gravity Model (EGM) foi desenvolvido a partir do esforço do NGA em parceria com a GSFC (Goddard Space Flight Center) na metade da década de 90. O EGM96 (LEMOINE et al., 1998a) e (LEMOINE et al., 1998b) possui grau e ordem 360, resolução de 30' x 30' e precisão da ordem de 0,5 - 1,0 m em todo o globo. Essa precisão foi confirmada por um grupo de avaliação pertencente à IAG.

A continuidade dos modelos da série EGM foi proposta com o objetivo de atingir a mais alta resolução espacial. Novamente, sob a coordenação do NGA/GSFC foi desenvolvido o EGM08 (PAVLIS et al., 2008). Esse é o mais recente modelo do geopotencial atingindo o grau 2190 e ordem 2159 em relação aos coeficientes das funções harmônicas esféricas. Aspirou atingir a resolução de 5' x 5' e a precisão objetivada foi de $15 \mathrm{~cm}$. Uma comparação entre o EGM96 e o EGM08 é vista na Tabela 3.3. 
Tabela 3.3 - Comparativo entre o EGM96 e o EGM08

\begin{tabular}{ccc}
\hline $\begin{array}{c}\text { Número máximo grau } \\
\text { e ordem }\end{array}$ & EGM96 & EGM08 \\
$\begin{array}{c}\text { Número de } \\
\text { Coeficientes do } \\
\text { Potencial }\end{array}$ & 360 & 2160 \\
Resolução & $130.317,00$ & $4.669 .917,00$ \\
Precisão & $30^{\prime} \times 30^{\prime}$ & $5^{\prime} \times 5^{\prime}$ \\
\hline
\end{tabular}

O EGM08 possui uma solução combinada, baseada em dados de 57 semanas do satélite GRACE e dados de anomalia de gravidade para um modelo digital de 5' x 5' sobre todo o globo. Foi necessária a criação de um banco de dados composto de dados gravimétricos de superfície, determinados a partir de medidas terrestres, aéreas e marítimas, além de anomalias de gravidade nas áreas oceânicas derivadas de altimetria por radar. Uma cooperação envolvendo alguns países e órgãos de pesquisas contribuíram na disponibilidade dos dados. A Figura 3.4 ilustra as fontes de dados utilizadas no EGM08.

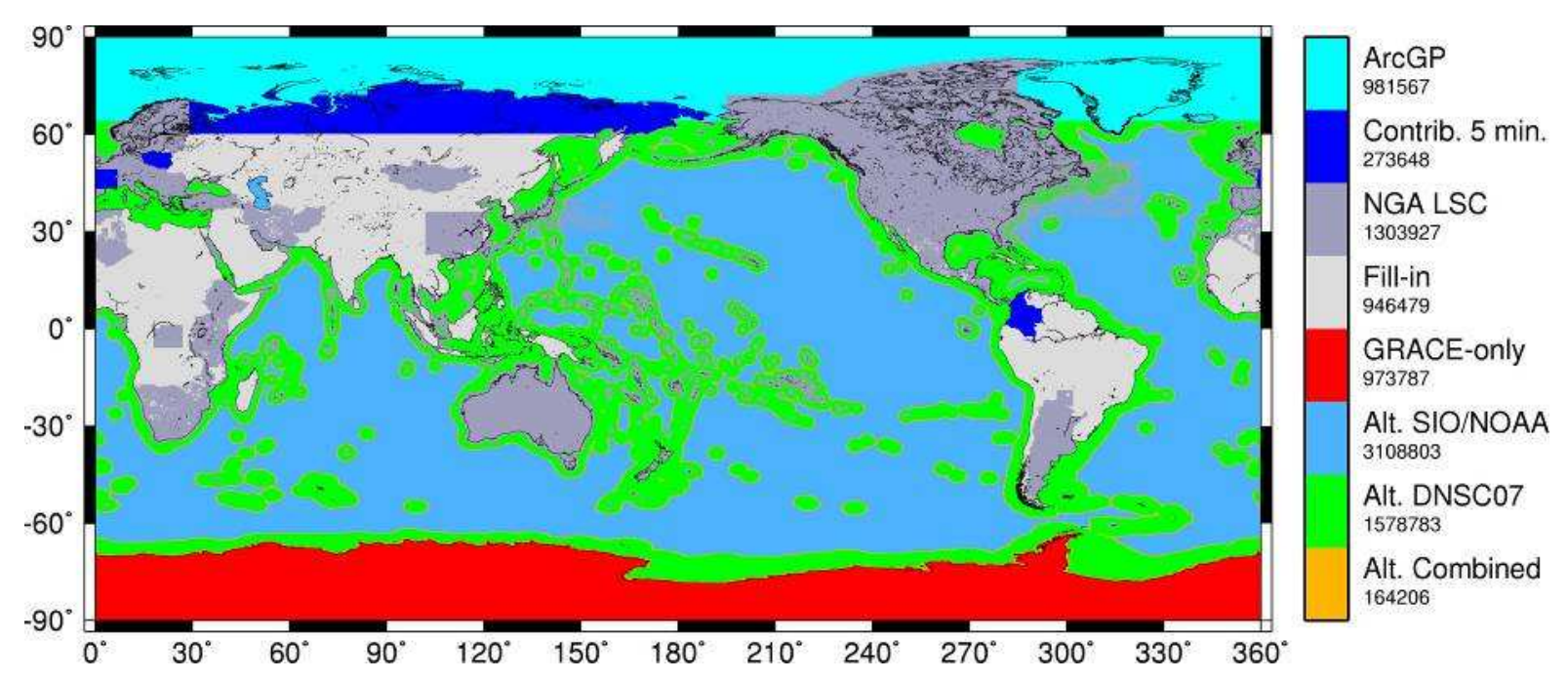

Figura 3.4 - Fonte de dados de $\Delta$ g para um modelo digital de 5' x 5' (Holmes; Pavlis, 2008)

Ao contrário das anomalias de gravidade derivadas da altimetria que formam um conjunto bastante homogêneo, os dados terrestres ainda contêm lacunas (Antártica, algumas regiões da África, América do Sul e Sudeste Asiático) (Figura 3.5), bem como áreas com dados de qualidade duvidosa. 


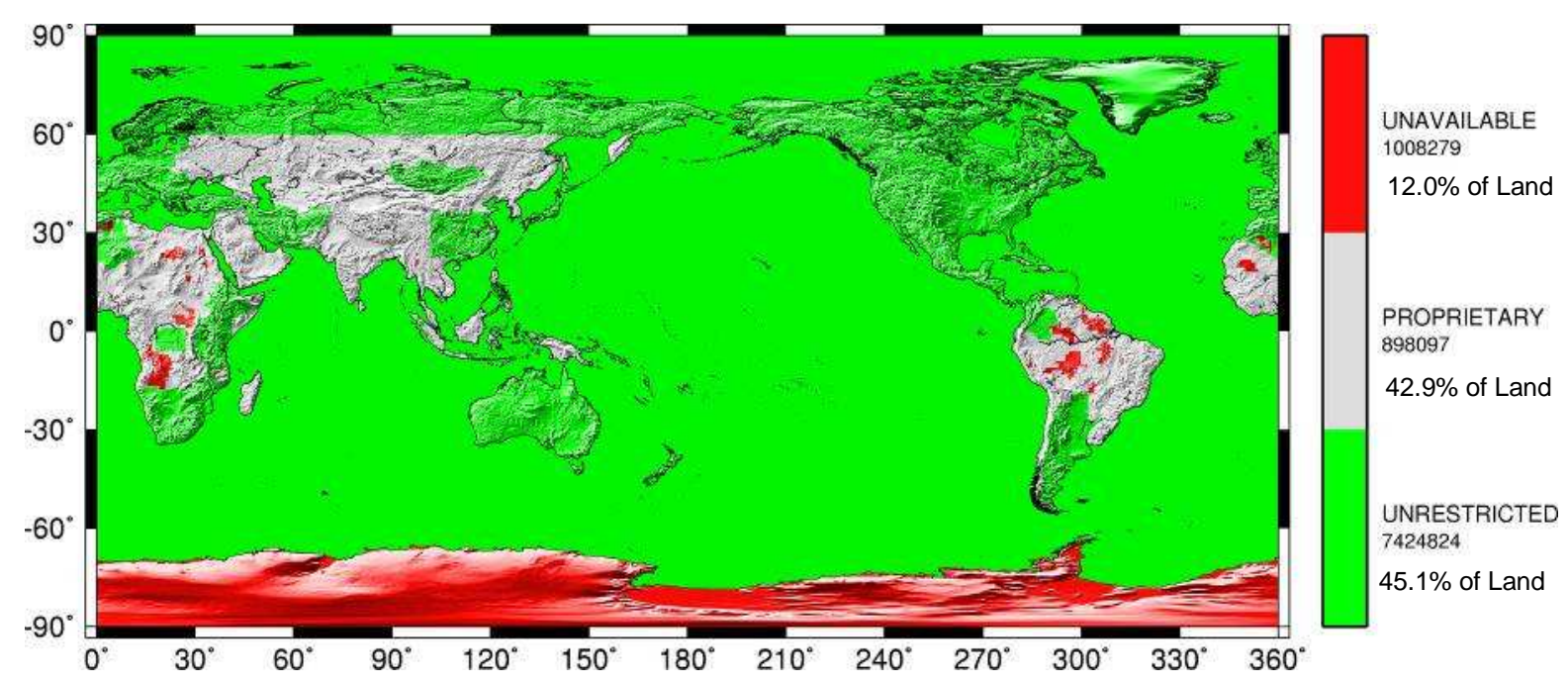

Figura 3.5 - Disponibilidade dos dados de $\Delta$ g para um modelo digital de 5' x 5' (Holmes; Pavlis, 2008)

Os dados representados pela cor vermelha caracterizam a não existência de medidas gravimétricas, cerca de $12,0 \%$ da superfície terrestre. Os dados na cor cinza estão disponíveis, porém com alguma restrição, nas quais as anomalias de gravidade utilizadas foram para um modelo digital de 15' x 15', resultando em coeficientes dos harmônicos esféricos até grau e ordem 720. Por fim, os dados na cor verde representam $45,1 \%$ da superfície terrestre e foram utilizados sem nenhuma restrição para um modelo digital de 5' x 5'.

O EGM08 está referenciado ao WGS84 (World Geodetic System 1984) e adota a opção livre de maré (Tide Free) no cálculo dos coeficientes. Os dados do SRTM (Shuttle Radar Topographic Mission) foram utilizados juntamente com outras fontes de dados para desenvolver um modelo digital global altimétrico de 30" x 30" de um modelo digital de terreno. Esse banco de dados foi o maior avanço em relação ao EGM96, sendo que 29 diferentes fontes de dados de altimetria foram empregadas. Com relação ao nível médio dos mares, o Danish National Space Center (DNSC) produziu um modelo do NMM a partir de dados da altimetria por radar. Os avanços na modelagem e correções das órbitas dos satélites altimétricos, resultaram em uma melhora nos dados altimétricos em relação ao EGM96.

Em termos de avaliação, realizaram-se estudos envolvendo GPS/RN (Tabela 3.4), deflexões da vertical, dados de altimetria do satélite TOPEX e dados GRACE KBRR. 
Vale ressaltar que no desenvolvimento do EGM08 não foi incorporado nenhum dado de GPS/RN nem deflexão da vertical.

Tabela 3.4 - Desvio padrão da ondulação geoidal dos dados de GPS/RN

Total de pontos $=12387$ edição aplicada $\pm 2 \mathrm{~m}$

\begin{tabular}{ccccc}
\cline { 2 - 5 } Modelo do geopotencial & \multicolumn{2}{c}{ Média removida } & \multicolumn{2}{c}{ Tendência removida } \\
\cline { 2 - 5 } (N máximo) & $\begin{array}{c}\text { Números } \\
\text { editados } \\
\text { aprovados }\end{array}$ & $\begin{array}{c}\text { Desvio } \\
\text { Padrão } \\
\text { (cm) }\end{array}$ & $\begin{array}{c}\text { Números } \\
\text { editados } \\
\text { aprovados }\end{array}$ & $\begin{array}{c}\text { Desvio } \\
\text { Padrão } \\
\text { (cm) }\end{array}$ \\
\hline EGM96 (360) & 12220 & 30,3 & 12173 & 27,0 \\
GGM02C_EGM96 (360) & 12305 & 25,6 & 12258 & 23,2 \\
EIGEN-GL04C (360) & 12299 & 26,2 & 12252 & 23,5 \\
EGM08 (360) & 12329 & 23,0 & 12283 & 20.9 \\
EGM08 (2190) & 12352 & 13,0 & 12305 & 10,3 \\
\hline
\end{tabular}

Fonte: (Pavlis et al., 2008) 


\section{DETERMINAÇÃO DO GEOIDE}

\subsection{Introdução}

Muitas são as ferramentas e tecnologias disponíveis hoje para a determinação das ondulações geoidais. Entre elas, a integração numérica da fórmula de Stokes diretamente ou com o uso da FFT, a colocação por mínimos quadrados, o desenvolvimento em série das funções harmônicas esféricas, a obtenção direta da ondulação geoidal pela diferença entre a altitude geodésica derivada de observações GNSS, e a ortométrica, obtida pelo nivelamento geométrico, a altimetria por radar a bordo de satélites (oceanos) e as combinações entre elas. Os detalhes de cada uma dessas técnicas podem ser encontrados em (LOBIANCO, 2005). Nesta dissertação utilizou-se a propriedade da convolução para o cálculo das ondulações geoidais (quase-geoidais) através da primeira técnica mencionada acima.

A partir do conhecimento das anomalias de gravidade reduzidas ao geoide é possível utilizar a integral de Stokes para calcular as ondulações geoidais. Devido à dificuldade de obtenção de medidas gravimétricas sobre toda a superfície terrestre, foram propostas modificações na função da integral de Stokes. Além disso, os longos comprimentos de onda contribuem no procedimento de integração sobre uma calota esférica de dimensão limitada.

A representação da ondulação geoidal na forma abreviada é expressa da seguinte maneira (BLITZKOW, 1996):

$$
N(\theta, \lambda)=N_{L}(\theta, \lambda)+\delta N_{L}(\theta, \lambda)
$$

onde o termo $N_{L}$ traduz a componente de longo comprimento de onda da ondulação geoidal e o termo $\delta N_{L}$ a componente de comprimento de onda mais curto. 
O primeiro termo do segundo membro da (4.1) representa geometricamente a separação entre o elipsoide e o esferoide de referência representado pelo modelo do geopotencial; o segundo termo é a separação entre o esferoide e o geoide, obtido a partir dos dados gravimétricos (Figura 4.1).

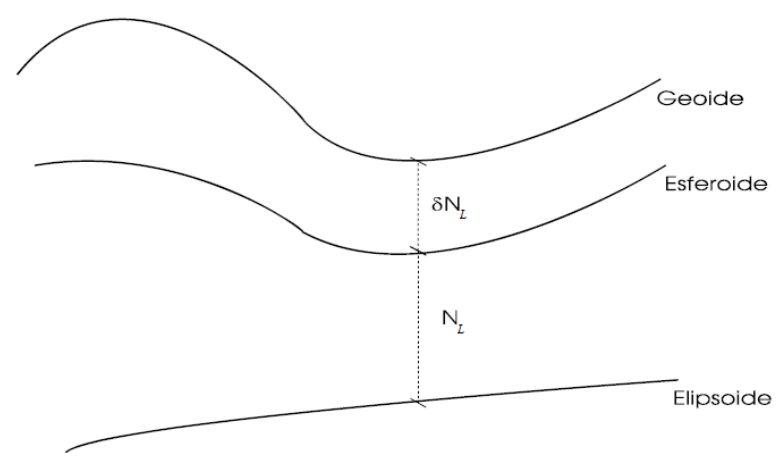

Figura 4.1 - Componentes da ondulação geoidal (Blitzkow, 1996)

Os longos comprimentos de onda são calculados a partir de um modelo do geopotencial, o que significa estender a série até um dado grau e ordem $L$. Os curtos comprimentos de onda podem ser calculados através de uma modificação na integral de Stokes, permitindo restringi-la a uma calota de raio $\psi_{0}$.

\subsection{Integral de Stokes}

A fórmula de Stokes (2.19), quando foi apresentada, teve um caráter puramente teórico. A razão era a ausência de medidas gravimétricas sobre toda a superfície terrestre e, principalmente, nos oceanos. As determinações gravimétricas oceânicas inicializadas com as expedições de Meinesz ${ }^{1}$ por meio de um dispositivo tri-pendular instalado a bordo de um submarino propiciaram uma perspectiva para a utilização dessa integral. Junte-se a isso a contribuição dos gravímetros relativos que permitiram a disseminação de medidas gravimétricas nos continentes; hoje ainda existem vazios em algumas regiões do planeta, ao passo que, nos oceanos, a altimetria por radar equacionou o problema de determinação da gravidade.

\footnotetext{
${ }^{1}$ Felix Andries Vening Meinesz (1887-1966).
} 
$\mathrm{Na}$ dedução da fórmula, Stokes admitiu a inexistência de massas externas à superfície equipotencial considerada. Nesse caso, deve-se reduzir as medidas de gravidade realizadas sobre a superfície terrestre para a superfície geoidal e compensar as massas externas ao geoide. Tal redução acarreta numa redistribuição das massas o que significa a criação de uma Terra fictícia com a consequente alteração no potencial de gravidade. A ondulação geoidal obtida pela integral de Stokes é representada pela separação entre o elipsoide de referência e um "geoide fictício", denominado de co-geoide. A separação entre o geoide e o co-geoide é resultado do chamado efeito indireto. O objetivo é sempre adotar modelos de redução que minimizam o referido efeito.

\subsubsection{Integral modificada de Stokes}

A utilização de um modelo do geopotencial no cálculo da componente de longo comprimento de onda leva a restringir a integral de Stokes a uma região próxima ao ponto, não necessitando estendê-la a toda a Terra. Nesse sentido utiliza-se o valor $\psi_{0}$ como distância limite para estender a integral. Mesmo assim haverá o erro de truncamento; porém, esse erro é minimizado ou quase anulado por meio dos longos comprimentos de onda do GGM. A nova filosofia de procedimento torna necessário alterar a integral original (2.14), o que consiste em modificar a função de Stokes $S(\psi)$ e subtrair os longos comprimentos de onda da anomalia. Diversas propostas de modificação têm sido apresentadas (WONG; GORE, 1969), (MEISSL, 1971), (VANIČEK et al., 1987), (BLITZKOW et al., 1991) e (VANIČEK; FEATHERSTONE, 1998). A integral de Stokes na sua forma modificada pode ser assim escrita (BLITZKOW, 1996):

$$
\delta N_{L}(\theta, \lambda)=\frac{R}{4 \pi \gamma} \int_{\psi=0}^{\pi} \int_{\alpha=0}^{2 \pi} \Delta g_{L}(\alpha, \psi) \delta S_{L}^{m}(\psi) \operatorname{sen} \psi d \psi d \alpha
$$

sendo $\delta S_{L}^{m}$ a função modificada de Stokes, $\gamma$ a gravidade normal da superfície do elipsoide de referência geocêntrico como exigido pela fórmula de Bruns, $\psi$ o ângulo geocêntrico ou distância esférica, entre o ponto de interesse e o ponto utilizado na 
integração e $\Delta g_{L}$ a anomalia de gravidade subtraída dos longos comprimentos de onda.

O núcleo (esférico) de Stokes pode ser representado por uma expansão em série:

$$
S(\cos \psi)=\sum_{n=2}^{\infty} \frac{(2 n+1)}{(n-1)} P_{n}(\cos \psi) \quad \text { para } 0 \leq \psi \leq \pi
$$

onde $P_{n}(\cos \psi)$ é a ordem do polinômio de Legendre.

A redução da magnitude ou o aumento da taxa de convergência dos coeficientes de truncamento $\left(Q_{n}\right)$ é a base para a diminuição do erro de truncamento (LOBIANCO, 2005). A modificação do núcleo da integral de Stokes permite reduzir o erro de truncamento no cálculo do geoide sobre uma calota esférica através dos métodos definidos como determinísticos, estatísticos e estocásticos. Em geral, um maior enfoque é dado às modificações determinísticas, uma vez que as estatísticas, embora ofereçam uma ótima combinação dos dados gravimétricos terrestres e dos GGMs, juntamente com a minimização do erro de truncamento (no sentido dos mínimos quadrados), possuem uso prático limitado, pois exigem estimativas acuradas dos erros dos dados, o que dificilmente está disponível (LOBIANCO, 2005). As modificações determinísticas são divididas, segundo Featherstone (1999), naquelas que melhoram a taxa de convergência da expansão em série do erro de truncamento e naquelas que reduzem o limite superior do erro de truncamento de acordo com alguma norma prescrita.

De acordo com Molodenskii, Eremeev e Yurkina (1962) apud Lobianco (2005), a base da modificação do núcleo de Stokes onde (4.3) é redefinida na região $\psi_{0}<\psi \leq \pi$, assim se expressa:

$$
\bar{S}(\cos \psi)=\sum_{n=2}^{\infty} \frac{2 n+1}{2} Q_{n}\left(\psi_{0}\right) P_{n}(\cos \psi)
$$

Os coeficientes de truncamento de Molodenskii são expressos por: 


$$
Q_{n}\left(\psi_{0}\right)=\int_{\psi_{0}}^{\pi} S(\psi) P_{n}(\cos \psi) \operatorname{sen} \psi d \psi
$$

e podem ser calculados por meio dos algoritmos recursivos de Paul (1973).

O erro de truncamento é uma função dos coeficientes de truncamento que, por sua vez, é função do núcleo de integração (FEATHERSTONE; EVANS; OLLIVER, 1998). Desse modo, a modificação no núcleo de Stokes fornece a base para a redução do impacto do erro de truncamento nas determinações gravimétricas do geoide. Além disso, a função modificada de Stokes tende a zero mais rapidamente que a função normal (BLITZKOW et al., 1991) e isso justifica o limite da integral a uma vizinhança $\psi_{0}$. Tal afirmação possui uma justificativa de caráter físico: trata-se do fato de que a influência dos longos comprimentos de onda da região afastada é levada em consideração pelo GGM na componente $N_{L}$ (BLITZKOW, 1996). Maiores detalhes sobre a modificação do núcleo da integral de Stokes são encontrados em (LOBIANCO, 2005).

\subsection{Transformada de Fourier}

O avanço tecnológico, as missões espaciais, a busca por GGMs cada vez mais precisos, têm ocasionado um aumento na quantidade de dados e de informações. Com isso, exige-se um maior esforço computacional e maior capacidade no processamento. As quantidades utilizadas em Geodésia (medidas gravimétricas, dados derivados da altimetria por radar, modelos digitais do terreno) são apresentadas na forma discreta e o processamento pode envolver intervalos longos de tempo (BLITZKOW, 1996). Uma maneira de solucionar tal fato é realizar as integrais de convolução no espaço das frequências, como por exemplo, as integrais de Stokes e de Vening Meinesz. A propriedade fundamental dessas integrais é que elas se transformam em um simples produto de funções caso o processo de avaliação das mesmas seja realizado no espaço da frequência (BLITZKOW, 1973). 
A transformada de Fourier $^{2}$ realiza a transformação de uma função definida no domínio do espaço para o domínio da frequência. O par de transformada de Fourier é definido por:

$$
\begin{aligned}
& X(f)=\int_{-\infty}^{\infty} x(t) e^{-i 2 \pi f t} d t \\
& x(t)=\int_{-\infty}^{\infty} X(f) e^{i 2 \pi t} d f
\end{aligned}
$$

A (4.6) e a (4.7) permitem a transformação analítica de um sinal no domínio do espaço para o da frequência e vice-versa. A (4.6) é conhecida como transformada de Fourier de $x(t)$ e a (4.7) transformada inversa de $X(f)$.

Existem algoritmos específicos conhecidos como Transformada Rápida de Fourier (Fast Fourier Transform - FFT) que processam o sinal espectral (no domínio da frequência) de forma rápida, permitindo solucionar a integral de Stokes em uma malha regular. Caso os dados não estejam distribuídos em uma malha com espaçamento constante é necessário aplicar uma técnica de interpolação. Nesse caso, a função pode ser representada em uma série de funções senoidais com frequências discretas.

A transformada de Fourier bidimensional (FFT-2D) é definida como:

$$
H\left(k_{x}, k_{y}\right)=\int_{-\infty-\infty}^{\infty} \int_{-\infty}^{\infty} h(x, y) e^{-i\left(k_{x} x+k_{y} y\right)} d x d y=F[h(x, y)]
$$

onde $F$ é o operador Fourier 2D, $H$ é o espectro da função $h(x, y), k_{x}, k_{y}$ são os números de onda correspondentes às coordenadas $x$ e $y$, respectivamente, e $i$ é a parte imaginária $i=\sqrt{-1}$.

Da mesma forma a transformada inversa é definida como:

\footnotetext{
${ }^{2}$ Jean-Baptiste Joseph Fourier (1768-1830).
} 


$$
h\left(k_{x}, k_{y}\right)=\frac{1}{4 \pi^{2}} \int_{-\infty-\infty}^{\infty} \int_{-\infty}^{\infty} H\left(k_{x}, k_{y}\right) e^{i\left(k_{x} x+k_{y} y\right)} d k_{x} d k_{y}=F^{-1}\left[H\left(k_{x}, k_{y}\right)\right]
$$

sendo $F^{-1}$ o operador inverso da função Fourier 2D.

O par de transformadas de Fourier das funções $h(x, y)$ e $H\left(k_{x}, k_{y}\right)$ é representado por:

$$
h(x, y) \leftrightarrow H\left(k_{x}, k_{y}\right) \quad \text { ou } \quad h(x, y) \leftrightarrow H(u, v)
$$

onde $u$ e $v$ são as frequências espaciais nas direções $x$ e $y$, respectivamente, relacionadas a $k_{x}$ e $k_{y}$ pelas equações:

$$
k_{x}=2 \pi u \text { e } \quad k_{y}=2 \pi v
$$

Dessa forma as integrais (4.8) e (4.9) podem ser escritas da seguinte maneira

$$
\begin{aligned}
& H(u, v)=\int_{-\infty-\infty}^{\infty} \int^{\infty} h(x, y) e^{-2 \pi i(u x+v y)} d x d y \\
& h(x, y)=\int_{-\infty}^{\infty} \int_{-\infty}^{\infty} H(u, v) e^{2 \pi i(u x+v y)} d u d v
\end{aligned}
$$

As propriedades da transformada de Fourier são encontradas com detalhes em (BLITZKOW, 1973), (SCHWARZ et al., 1990) ou (LOBIANCO, 2005).

\subsection{Anomalias de Gravidade}

A integral de Stokes pressupõe a inexistência de massas externas ao geoide. Isso implica em dizer que o potencial perturbador é uma função harmônica no exterior do geoide, podendo-se tratar a questão como um "problema de valor de contorno" no que diz respeito à teoria do potencial. Sendo assim, deve-se adotar um 
procedimento de remoção das massas externas. Isso é realizado por meio das "correções" ou "reduções" gravimétricas. Qualquer que seja a escolha do método de correção, a implicação será uma mudança no potencial e, consequentemente, no geoide. O resultado será um efeito indireto que ocasionará uma superfície ora mais ora menos discrepante em relação ao geoide, o co-geoide.

A anomalia de gravidade $\Delta g$ é a diferença entre a gravidade observada $g_{o b s}$ com a correção gravimétrica $C_{g}$ para reduzí-la ao geoide e a gravidade teórica ou normal $\gamma$ e é obtida pela expressão:

$$
\Delta_{g}=g_{o b s}+C_{g}-\gamma
$$

As exigências para que as reduções sejam de valia para a Geodésia, em ordem de importância, são (SIDERIS, 1993):

- as anomalias de gravidade reduzidas devem ser pequenas e suaves, 0 que torna sua representação fácil e suave;

- os efeitos indiretos devem ser pequenos;

- as anomalias de gravidade devem ter sentido geofísico, devem ser úteis para as interpretações geofísicas.

As anomalias de gravidade mais comumente utilizadas são: anomalia ar livre (freeair) que despreza as massas topográficas externas à superfície geoidal considerando o aumento da aceleração de gravidade sobre o geoide relativamente à superfície física em função da altitude; em outras palavras, corrige apenas a elevação do ponto de observação. A anomalia de Bouguer considera os efeitos das massas entre a superfície de referência e o ponto de observação. Essa correção remove o chamado platô de Bouguer causando uma grande mudança no potencial e, por consequência, um considerável efeito indireto (BLITZKOW, 1996). A anomalia isostática trata do efeito de relevo e das variações de densidade segundo as teorias da isostasia. Maiores detalhes sobre cada uma das correções podem ser encontrados em (GEMAEL, 1999), (HOFMANN-WELLENHOF; MORITZ, 2005) e (LOBIANCO, 2005). Em Geodésia, o procedimento que tem sido mais promissor é a chamada "condensação de Helmert". A Figura 4.2 ilustra quatro tipos de reduções gravimétricas. 


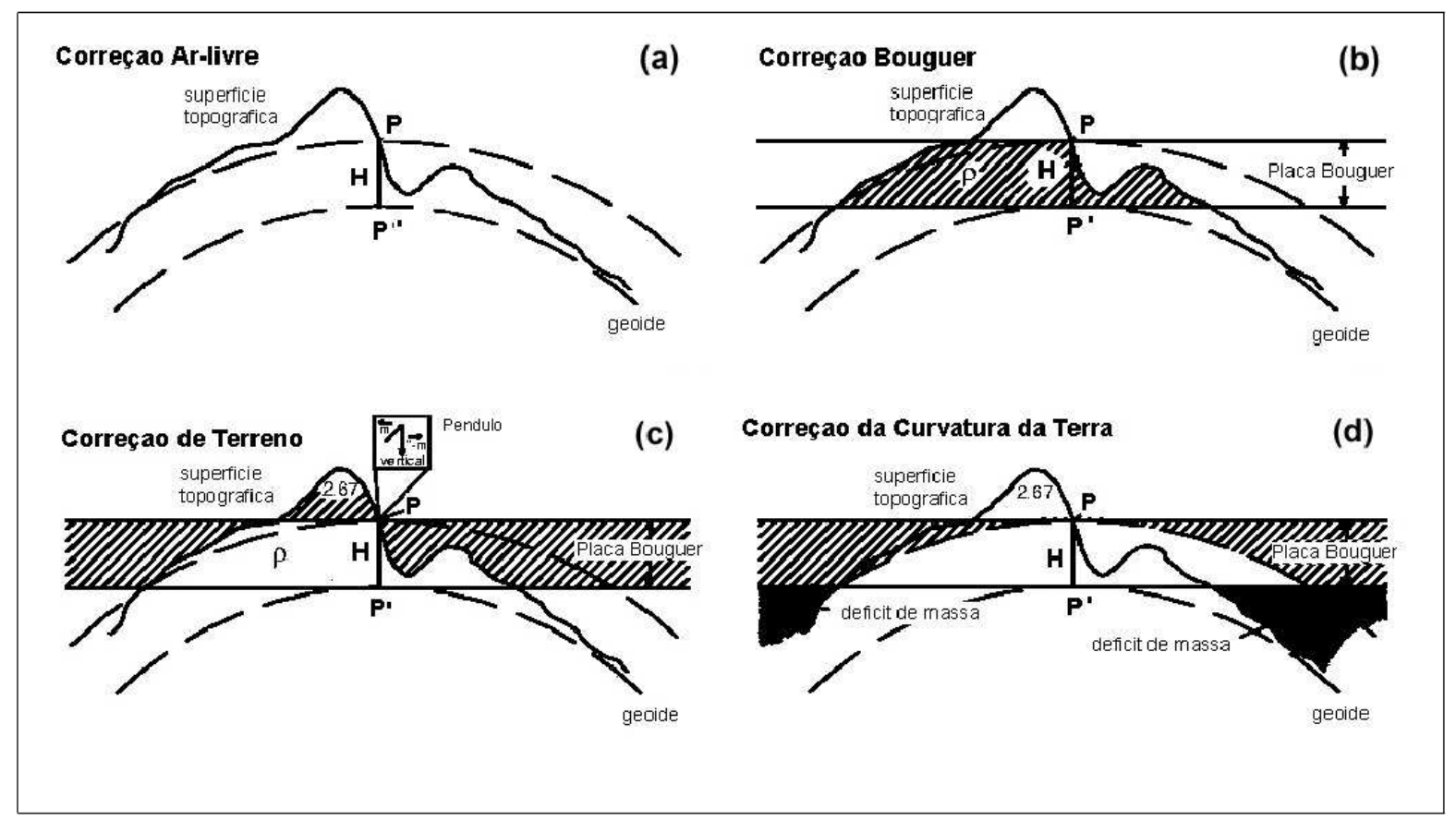

Figura 4.2 - Reduções gravimétricas (Dirren, 2001 modificado por Lobianco, 2005)

\subsubsection{Condensação de Helmert}

O método da condensação de Helmert também chamado de "segundo método da condensação de Helmert" não elimina as massas topográficas acima do geoide, como na correção de Bouguer, e sim as condensa sobre o geoide de modo a formar uma camada superficial. A massa da Terra não sofre alteração e um determinado elemento na área do geoide terá densidade proporcional à altitude das massas condensadas.

Esse método pode ser resumido em duas etapas (Blitzkow, 1996):

a) substituir o efeito das massas topográficas sobre a aceleração da gravidade observada pelo efeito da camada superficial sobre o geoide.

b) reduzir o valor da aceleração da gravidade observada na superfície ao geoide mediante continuação para baixo (correção ar livre).

Após essas etapas pode-se aplicar a integral de Stokes resultando no cálculo de alturas do co-geoide. Dependendo da precisão esperada para o valor da ondulação geoidal, o efeito indireto pode ser desprezado (BLITZKOW, 1996). A anomalia de Helmert pode ser expressa da seguinte forma: 


$$
\Delta_{g H}=g_{o b s}+C_{A L}+C_{T}-\gamma
$$

onde $g_{o b s}$ é a gravidade observada, $C_{A L}$ é a correção ar-livre, $C_{T}$ a correção do terreno e $\gamma$ é a gravidade teórica ou normal. 


\section{CONSISTÊNCIA ENTRE A ALTIMETRIA E O MODELO GEOIDAL}

\subsection{Introdução}

Este capítulo aborda quatro estudos que objetivam contribuir para a análise sobre a altimetria e o modelo geoidal no estado de São Paulo. Uma análise do comportamento da crosta terrestre no litoral paulista foi realizada a partir do processamento de dados GPS de duas estações de monitoramento contínuo, localizadas nas bases do Instituto Oceanográfico Dr. João Paiva de Carvalho em Cananeia e Clarimundo de Jesus em Ubatuba. Uma comparação preliminar envolvendo o NMM nesses municípios com o nivelamento proveniente de Imbituba foi outra análise realizada. Outro estudo refere-se à comparação entre a ondulação geoidal de pontos GPS/RN e a anomalia de altura derivada a partir de três GGMs. Por fim, a determinação do modelo geoidal, bem como sua validação é o quarto estudo.

\subsection{Comportamento da Crosta Terrestre no Litoral Paulista}

O litoral paulista possui $622 \mathrm{~km}$ de extensão sendo composto por 16 municípios litorâneos. O relevo do estado é dividido em 5 unidades geomorfológicas: planalto ocidental, cuestas basálticas, depressão periférica, planalto atlântico e província costeira, sendo a última localizada na região do litoral.

O Brasil possui uma rede GNSS $^{1}$ de monitoramento contínuo administrada pelo IBGE. Atualmente, 80 estações compõem a rede e mais 3 estão em fase de teste. A contribuição fornecida por essas estações resulta na vantagem ao usuário de utilizar os dados do receptor das mesmas, o que the permite dispor de seus próprios receptores como itinerantes no método diferencial em levantamentos geodésicos.

\footnotetext{
${ }^{1} \mathrm{ftp} / / /$ geoftp.ibge.gov.br/RBMC/relatorio/RBMC_2010.pdf
} 
Além disso, recentemente, o IBGE disponibilizou um serviço para posicionamento em tempo real a partir da RBMC (Rede Brasileira de Monitoramento Contínuo), para usuários que utilizam a técnica RTK (Real Time Kinematic) ou DGPS (Differential GPS). Na RBMC², os dados são disponibilizados em arquivos diários, cada sessão iniciando às $00 \mathrm{~h} 01 \mathrm{~min}$ e encerrando às $24 \mathrm{~h} 00 \mathrm{~min}$ (tempo universal) com intervalo de rastreio de $15 \mathrm{seg}$. As estações NEIA (Cananeia) e UBAT (Ubatuba) (Figura 5.1) situadas no litoral paulista apresentam potencial para a análise do movimento da crosta nos referidos pontos. As duas estações foram processadas através do processamento preciso por ponto (PPP) no período de 01/2006 a 08/2009.

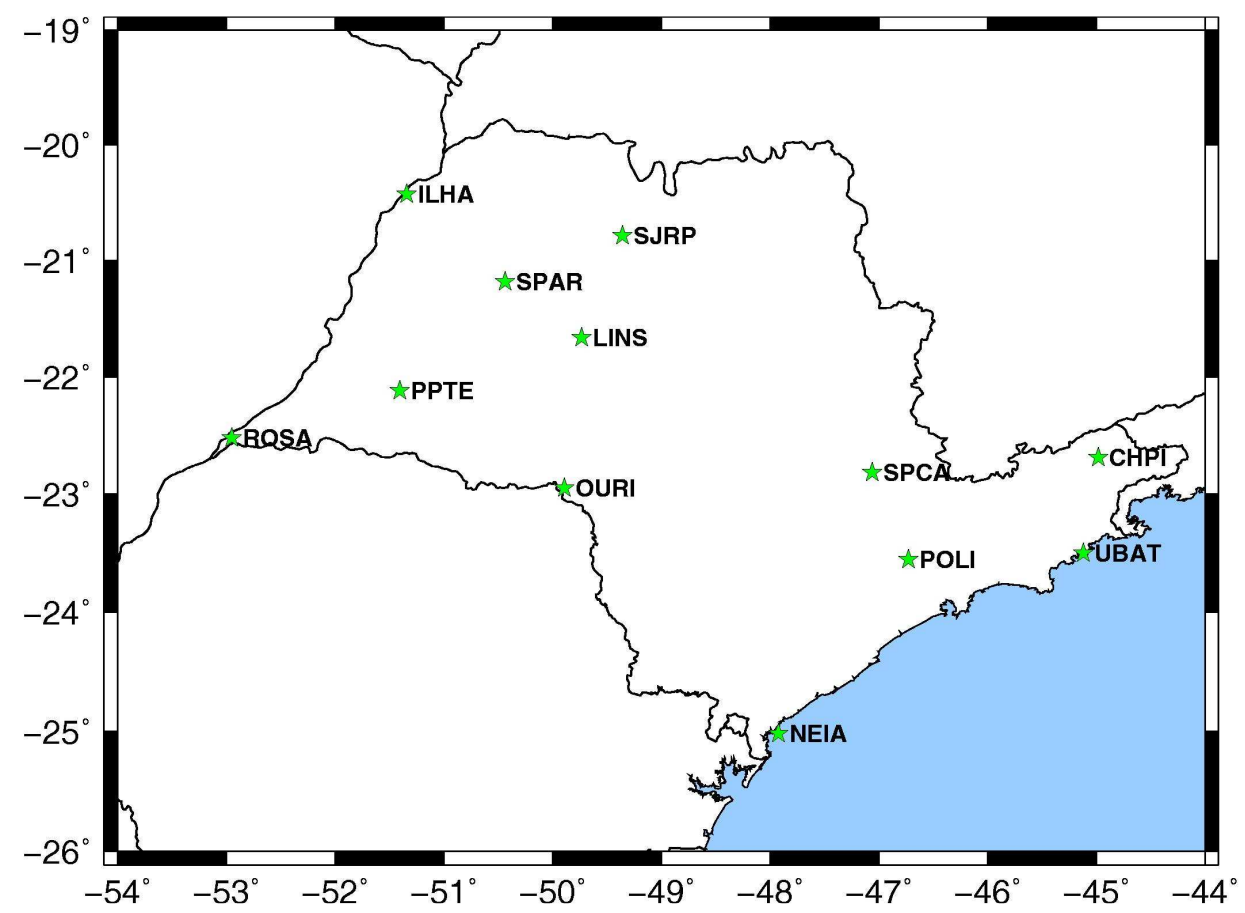

Figura 5.1 - Estações GNSS no estado de São Paulo

\subsubsection{Posicionamento Preciso por Ponto}

Durante muito tempo habituou-se à ideia de que o posicionamento absoluto oferecia resultados pouco precisos e acurados no que diz respeito às aplicações geodésicas. Entretanto, o desenvolvimento científico ocorrido nos últimos 15 anos, aproximadamente, alterou essa perspectiva.

\footnotetext{
${ }^{2}$ http://www.ibge.gov.br/home/geociencias/download/tela_inicial.php?tipo=8
} 
O posicionamento absoluto também conhecido como posicionamento por ponto refere-se à determinação da posição de um ponto com base em observações de pseudodistância, derivadas do código civil, fixando-se a órbita e demais parâmetros dos satélites aos valores calculados com base nas mensagens de navegação (efemérides transmitidas) (MONICO, 2008). Na literatura inglesa, essa técnica é denominada de point positioning. Dessa nomenclatura deriva a expressão precise point positioning, aqui traduzido como Posicionamento Preciso por Ponto (PPP), onde o termo "preciso" é empregado para qualificar o termo "posicionamento" e também para distinguir da técnica de posicionamento convencional por ponto. No PPP utiliza-se a fase da onda portadora empregando efemérides precisas. O PPP surgiu na década de 90 quando predominava o uso do posicionamento relativo. $O$ impulso no uso dessa técnica se deve à disponibilidade de efemérides precisas (dados das órbitas e correções dos relógios dos satélites) e às recomendações do IERS (Internacional Earth Rotation and Reference Systems Service) em relação aos modelos de adequação da Terra elástica a um referencial de equilíbrio o que levou aos modelos de marés terrestres, de cargas oceânicas e atmosféricas. Isto resulta em uma precisão do PPP a níveis compatíveis, dependendo das circunstâncias, ao posicionamento relativo. Outra vantagem apresentada por esse método de posicionamento é o emprego de apenas um receptor, eliminando o rastreio simultâneo com uma estação de referência. Finalmente, o custo efetivo da técnica é outro fator que deve ser levado em consideração.

As observáveis GPS estão sujeitas a diversos erros provenientes de várias fontes (e.g. MONICO, 2008). Outras variações decorrentes de efeitos geodinâmicos podem ocorrer no período da coleta das observações e são capazes de afetar o resultado. Esses fenômenos não podem ser classificados como erros e sim como correções que devem ser aplicadas. Incluem-se os efeitos de marés terrestres, carga dos oceanos, carga da atmosfera e movimento do polo. Esses efeitos devem seguir as convenções do IERS (IERS, 2003).

\subsubsection{Serviços disponíveis do PPP}

Os softwares comerciais ainda não estão estruturados com ferramentas que possibilitem realizar o processamento por meio do PPP. É necessário fazer uso de 
programas on-line desenvolvidos por universidades e instituições governamentais e que se encontram disponíveis na internet. O GAPS ${ }^{3}$ (GPS Analysis and Positioning Software) v1.1 - Online PPP, da Universidade de New Brunswick, no Canadá; o CSRS - PPP (Canadian Spatial Reference System - Precise Point Positioning), do NRCan (Natural Resources Canada); o Automated GIPSY ${ }^{4}$ Analysis, do JPL (Jet Propulsion Laboratory), nos Estados Unidos e recentemente o IBGE $^{5}$, são alguns exemplos desse serviço. Um estudo prévio entre os programas GAPS e CSRS foi realizado para identificar qual deles pudesse apresentar resultados melhores e assim elegê-lo para executar todo o processamento.

Após serem processadas algumas semanas de dados utilizando os dois serviços, os valores obtidos pelo CSRS se mostraram mais estáveis do que o GAPS. Em suma, os arquivos de 24 horas de dados ou próximos a esse período quando processados pelo CRSR convergiram de forma mais eficiente do que em relação ao GAPS. Logo, foi escolhido o serviço do NRCan.

O programa permite ao usuário submeter arquivos de simples ou dupla frequência, no modo estático ou cinemático. No caso, foram enviados arquivos de dupla frequência a serem processados no modo estático. O processamento é realizado utilizando arquivos de órbita precisa e de correção do relógio, fornecidos pelo IGS (International GNSS Service). Caso não existam efemérides precisas disponíveis são utilizadas as rápidas ou ultra-rápidas. Além disso, o serviço fornece os resultados em dois sistemas de referência, o canadense NAD83 (North American Datum 1983) ou o ITRF (International Terrestrial Reference Frame) (época do dado). As coordenadas fornecidas pelo serviço são livres de maré. De acordo com o Geodetic Survey Division (2009), a qualidade dos resultados depende do tipo de equipamento utilizado pelo usuário, da dinâmica atmosférica e da duração da sessão observada.

A compressão dos arquivos enviados pode ser no formato Hatanaka, .Z, .ZIP e .GZ e o programa GPSPACE desenvolvido pelo próprio NRCan é o utilizado no processamento.

\footnotetext{
${ }^{3}$ http://gaps.gge.unb.ca/

${ }^{4} \mathrm{http}: / /$ milhouse.jpl.nasa.gov/ag/

${ }^{5} \mathrm{http}: / /$ www.ibge.gov.br/home/geociencias/geodesia/ppp/default.shtm
} 
O modo de como devem ser enviados os dados é descrito abaixo:

- acessar a página do CSRS-PPP, disponível no endereço <http://www.geod.nrcan.gr.ca/online_data_e.php>, efetuar um cadastro informando o nome de usuário e a senha com o endereço eletrônico para onde serão enviados os resultados. Feito isso pode-se acessar o serviço;

- inserir um arquivo RINEX no campo explicitado;

- selecionar o modo de processamento: estático ou cinemático;

- especificar o tipo do sistema de referência: NAD83 ou ITRF2005;

- acionar o "start" e aguardar o processamento. Ao final, uma mensagem será exibida notificando se houve sucesso no processamento ou não.

Após essa mensagem, os dados são enviados em poucos segundos para 0 endereço eletrônico informado. As coordenadas calculadas, bem como os respectivos desvios padrões, são apresentadas diretamente no corpo do endereço eletrônico. Além disso, um link é disponibilizado para que seja possível realizar o download do relatório completo, que possui 4 arquivos de saída. O primeiro fornece um resumo do processamento (.sum); o segundo os parâmetros estimados das estações para cada época observada (.pos); o terceiro relata as estimativas dos resíduos e a ambiguidade dos satélites (.res); por fim, o quarto arquivo (.ses) contém as informações mais relevantes e elucida os seguintes elementos:

- o nome do arquivo que foi processado;

- a data e a hora de início e fim do processamento;

- tipo de observação, frequência e modo processado;

- máscara de elevação e o número de épocas rejeitadas;

- coordenadas geodésicas calculadas no sistema de referência escolhido para a época atual e os respectivos desvios padrão;

- parâmetros estimados: atraso troposférico, deriva do relógio da estação, resíduo da fase do código e das ambiguidades para cada satélite;

- correções realizadas para cada época. 


\subsubsection{Resultados das Estações NEIA e UBAT}

Realizou-se a análise da estabilidade das estações e do movimento da crosta terrestre por meio dos resultados obtidos no processamento diário. A avaliação foi procedida comparando as coordenadas do serviço do CSRS-PPP com as consideradas verdadeiras e fornecidas pelo IBGE por meio do Relatório da Estação Geodésica $(\varphi, \lambda$ e $h$ - coordenadas geodésicas referenciadas ao SIRGAS2000, época 2000,4), disponível no sítio da instituição.

Os arquivos inferiores a um período de 10 horas de dados foram descartados, uma vez que, com base nos estudos realizados pelo próprio serviço, (Geodetic Survey Division, 2009) resultados com duração menores que esse apresentam valores insatisfatórios em relação à acurácia. Foram processados dados de $1^{\circ}$ de janeiro de 2006 a 31 de agosto de 2009, para ambas as estações.

\subsubsection{Estação NEIA}

A estação ${ }^{6}$ está localizada na base Dr. João Paiva de Carvalho no Instituto Oceanográfico da USP no município de Cananeia, litoral sul do estado. O marco principal é um pilar de concreto com formato cilíndrico, medindo $5,80 \mathrm{~m}$ de altura e com $0,80 \mathrm{~m}$ de diâmetro. Está assentado em um bloco de rocha medindo $1,80 \mathrm{~m} \mathrm{x}$ $1,20 \mathrm{~m}$ e com 0,30 $\mathrm{m}$ de altura. Possui no topo um dispositivo de centragem forçada padrão USP. A Tabela 5.1 apresenta as coordenadas da estação.

Tabela 5.1 - Coordenadas da estação NEIA

\begin{tabular}{lccl}
\hline \multicolumn{4}{c}{ Coordenadas Geodésicas } \\
\hline Latitude & $25^{\circ}$ 01' $12,8615^{\prime \prime}$ & Sigma: & $0,001 \mathrm{~m}$ \\
Longitude & $47^{\circ}$ 55' $29,8867^{\prime \prime}$ & Sigma: & $0,001 \mathrm{~m}$ \\
Alt. Geodésica & $6,06 \mathrm{~m}$ & Sigma: & $0,004 \mathrm{~m}$ \\
Alt. Ortométrica ${ }^{7}$ & $7,79 \mathrm{~m}$ & & \\
\hline
\end{tabular}

Fonte: (Adaptado do IBGE, 2006)

\footnotetext{
${ }^{6} \mathrm{http}: / /$ www.ibge.gov.br/home/geociencias/geodesia/rbmc/rbmc_est.shtm

${ }^{7}$ Altitude ortométrica determinada a partir de nivelamento em trabalho realizado pela UNICAMP.
} 
As Figuras 5.2, 5.3 e 5.4 apresentam as diferenças diárias entre as coordenadas processadas e as consideradas verdadeiras do IBGE, respectivamente, para as coordenadas $\varphi, \lambda$ e $h$. As linhas de tendência presentes em cada caso foram calculadas a partir do método de regressão linear.

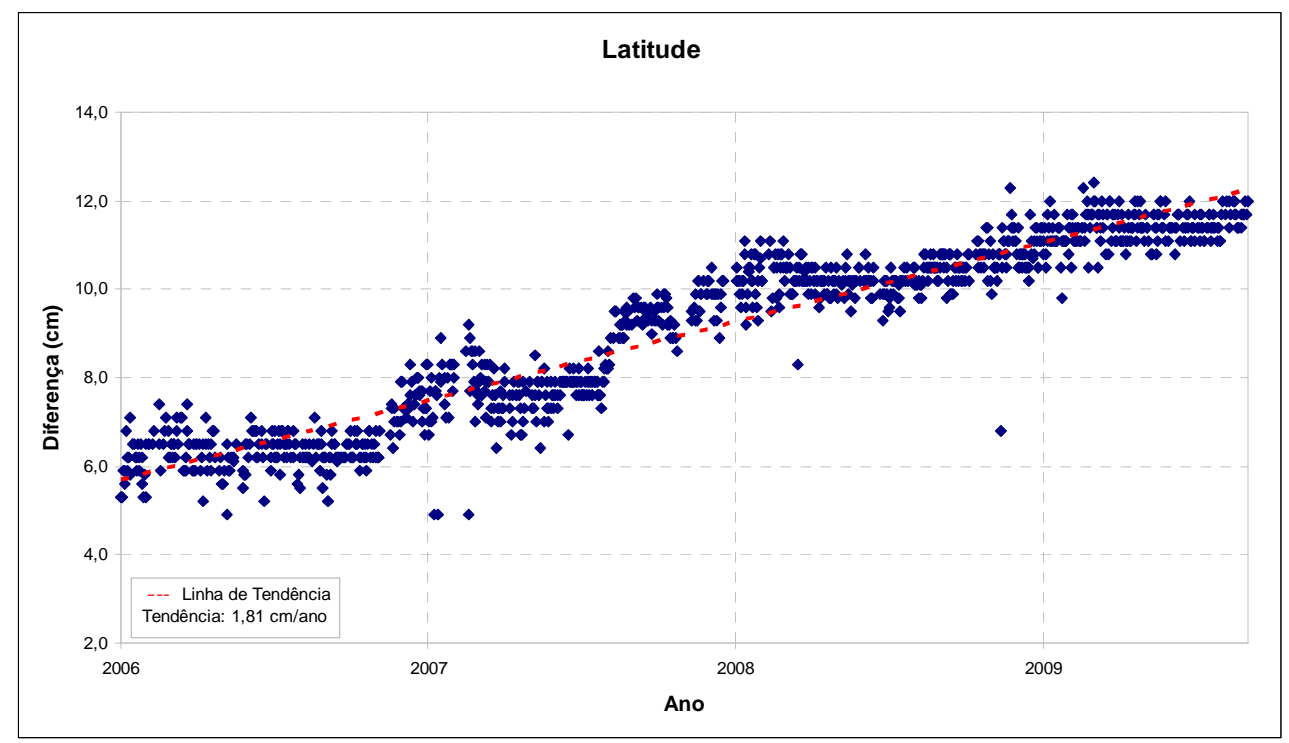

Figura 5.2 - Latitude (estação NEIA)

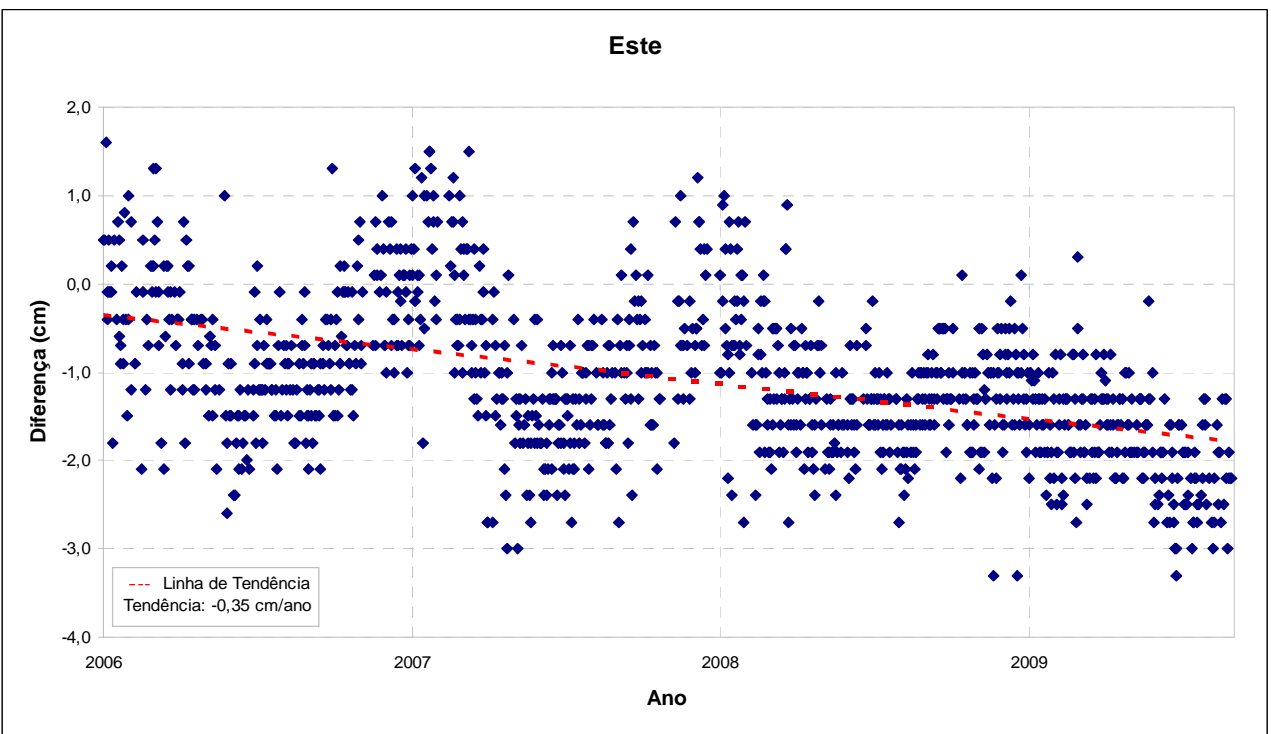

Figura 5.3 - Longitude (estação NEIA) 


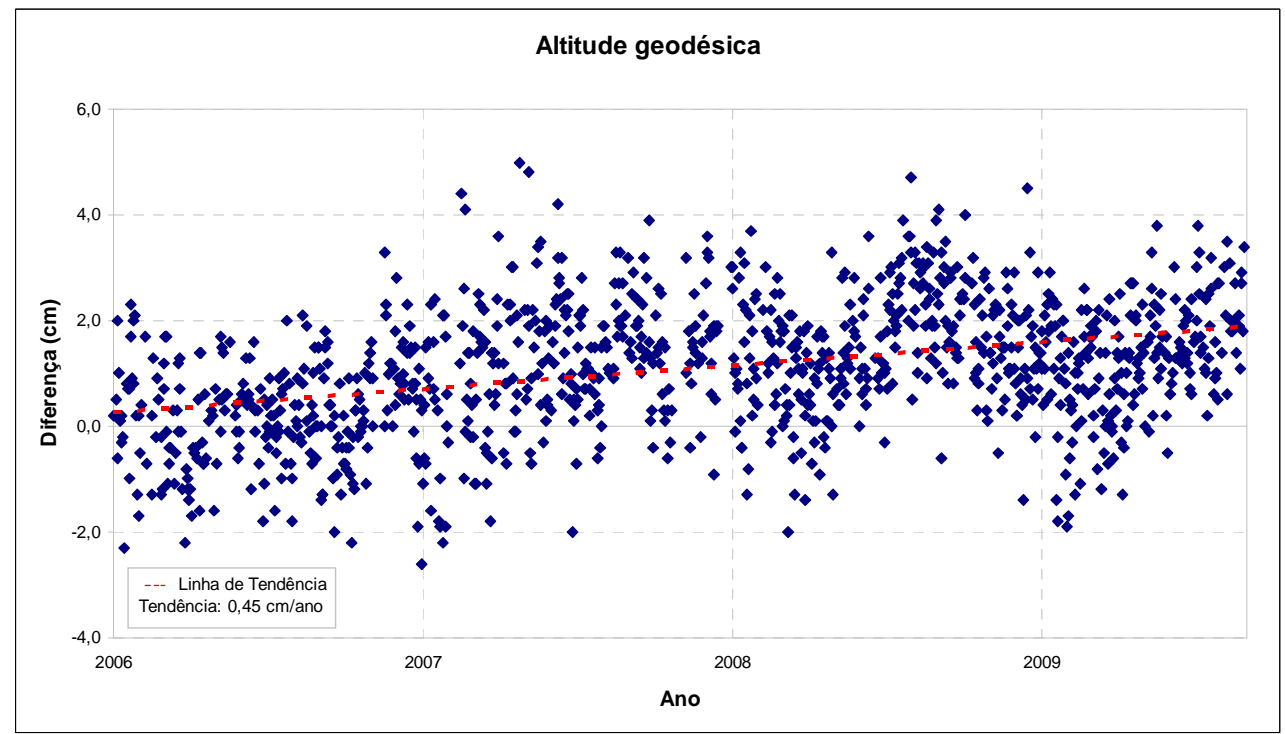

Figura 5.4 - Altitude geodésica (estação NEIA)

A coordenada latitude (Figura 5.2) apresentou um padrão de crescimento entre 6 e $12 \mathrm{~cm}$, com um deslocamento anual de 1,81 cm. Esse acréscimo é constatado pela linha de tendência. A presença de um ciclo anual foi detectada nos dois primeiros anos da série da coordenada longitude (Figura 5.3). Além disso, possuiu um decréscimo variando de 1 a $-3 \mathrm{~cm}$ e um deslocamento de -0,35 cm/ano. Com relação à componente altimétrica (Figura 5.4), foi possível visualizar um comportamento aleatório, variando de -2 a $4 \mathrm{~cm}$. Com o intuito de melhorar a visualização desta componente, a tendência presente na série foi removida e aplicou-se uma média móvel. (Figura 5.5).

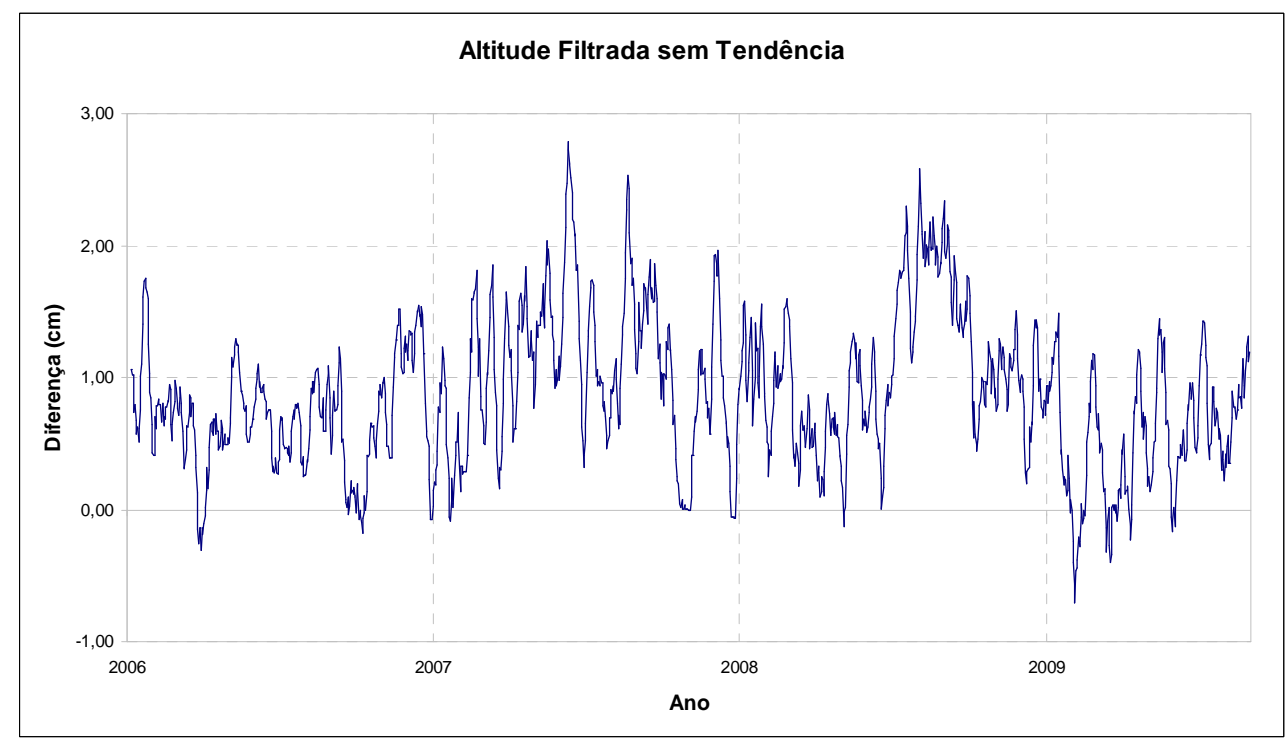

Figura 5.5 - Altitude filtrada e sem tendência (estação NEIA) 
Baseado no estudo da componente planimétrica é possível afirmar que a estação NEIA está sob efeito de uma variação em suas coordenadas, resultado do deslocamento da placa sul-americana. Constata-se que a estação possui um deslocamento de 1,84 cm/ano na direção noroeste (Figura 5.6).

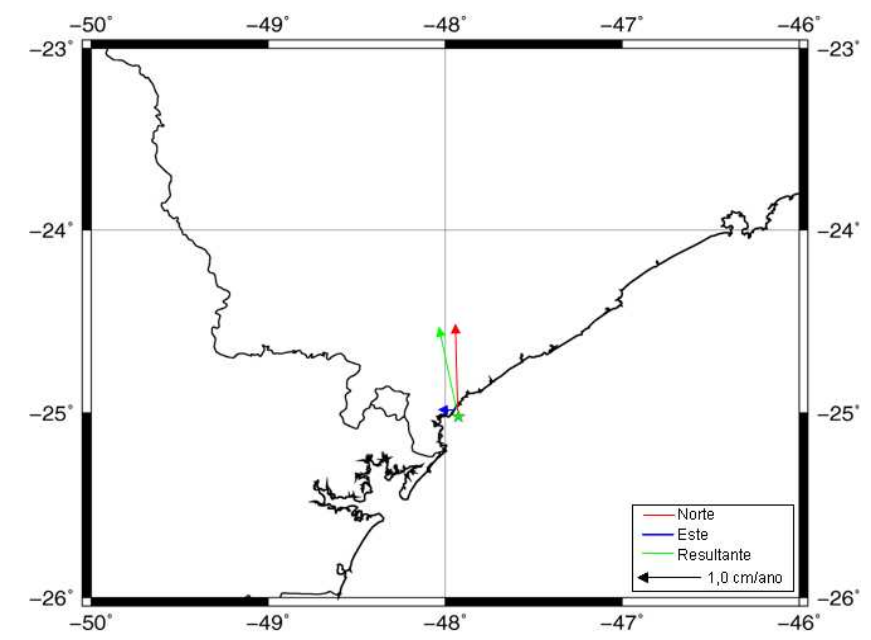

Figura 5.6 - Deslocamento planimétrico da estação NEIA

O IBGE produz uma solução semanalmente de dezenas de estações que compõem a rede SIRGAS2000 (Sistema de Referência Geocêntrico para as Américas). Os dados são processados no modo relativo utilizando estações IGS e o software científico Bernese 5.0. Uma comparação com o processamento do IBGE (Figura 5.7) foi realizada com objetivo de analisar os dois métodos de processamento.

\section{IBGE NEIA - Velocidade Planimetrica $0.01249 \pm 1 \mathrm{e}-04 \mathrm{~m}$ Vano}
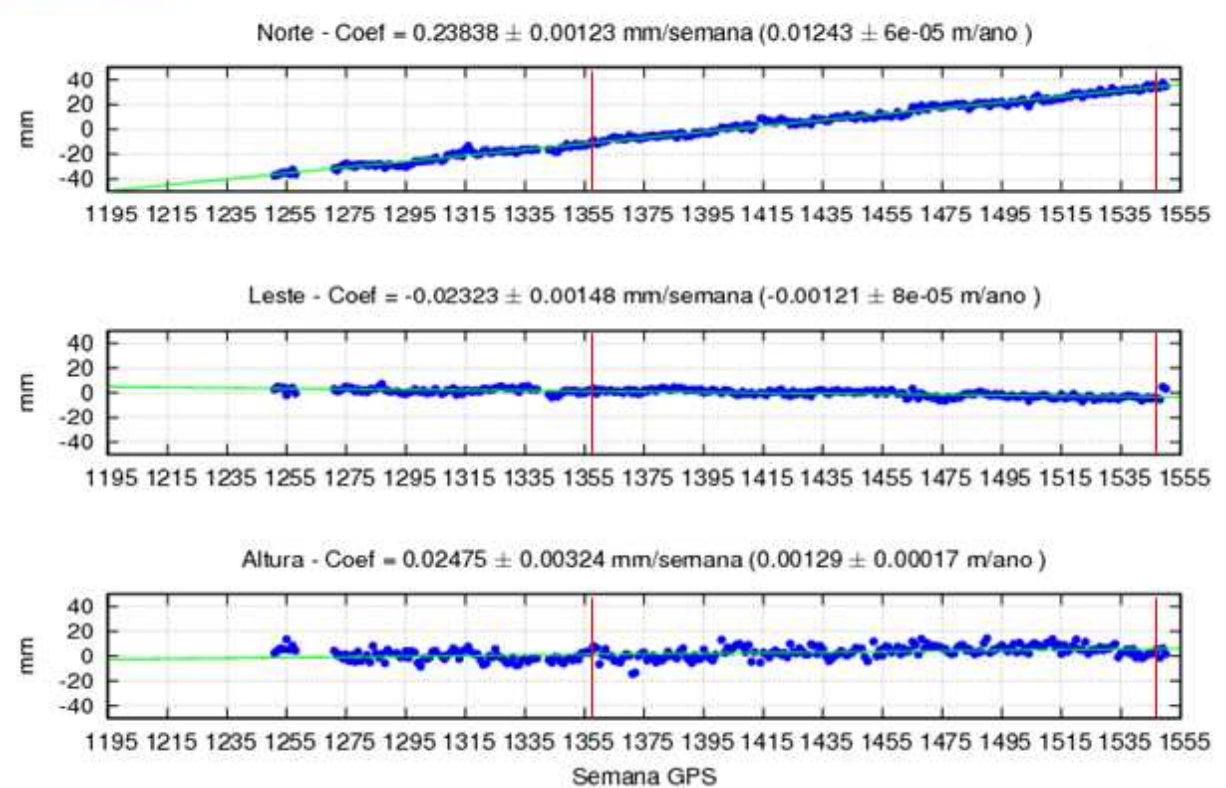

Figura 5.7 - Coordenadas da estação NEIA processadas pelo IBGE (Fonte: IBGE, 2009) 
Na Figura 5.7 as linhas em vermelho indicam o período entre $1^{\circ}$ de janeiro de 2006 a 31 de agosto de 2009. Verifica-se que as 3 componentes processadas pelo IBGE possuem o mesmo comportamento em relação ao PPP. Existe uma diferença que diz respeito à precisão dos processamentos. Enquanto no processamento relativo a precisão é milimétrica, no PPP a precisão é centimétrica. Isso refletirá no vetor resultante das componentes planimétricas; o PPP possui um deslocamento de 1,84 $\mathrm{cm} / \mathrm{ano}$ e o relativo de $1,20 \mathrm{~cm} / \mathrm{ano}$.

\subsubsection{Estação UBAT}

Localizada no litoral norte de São Paulo, a estação ${ }^{8}$ Ubatuba encontra-se na base "Clarimundo de Jesus" do Instituto Oceanográfico da USP. O marco principal é um pilar de concreto com formato cilíndrico, medindo 3,14 $\mathrm{m}$ de altura e com 0,40 $\mathrm{m}$ de diâmetro. A Tabela 5.2 apresenta as coordenadas desta estação.

Tabela 5.2 - Coordenadas da estação UBAT

\begin{tabular}{lrrl}
\hline \multicolumn{4}{c}{ Coordenadas Geodésicas } \\
\hline Latitude & $23^{\circ} 30^{\prime} 00,6375^{\prime \prime}$ & Sigma: & $0,001 \mathrm{~m}$ \\
Longitude & $45^{\circ} 07^{\prime} 08,0467^{\prime \prime}$ & Sigma: & $0,001 \mathrm{~m}$ \\
Alt. Geodésica & $6,07 \mathrm{~m}$ & Sigma: & $0,004 \mathrm{~m}$ \\
Alt. Ortométrica9 & $10,60 \mathrm{~m}$ & & \\
\hline
\end{tabular}

Fonte: (Adaptado do IBGE, 2006)

Na estação UBAT realizou-se um estudo similar à estação NEIA. As Figuras 5.8, 5.9 e 5.10 mostram as diferenças diárias entre as coordenadas processadas e as consideradas verdadeiras do IBGE.

\footnotetext{
${ }^{8} \mathrm{http}: / /$ www.ibge.gov.br/home/geociencias/geodesia/rbmc/rbmc_est.shtm

${ }^{9}$ Altitude ortométrica determinada a partir de nivelamento em trabalho realizado pela UNICAMP.
} 


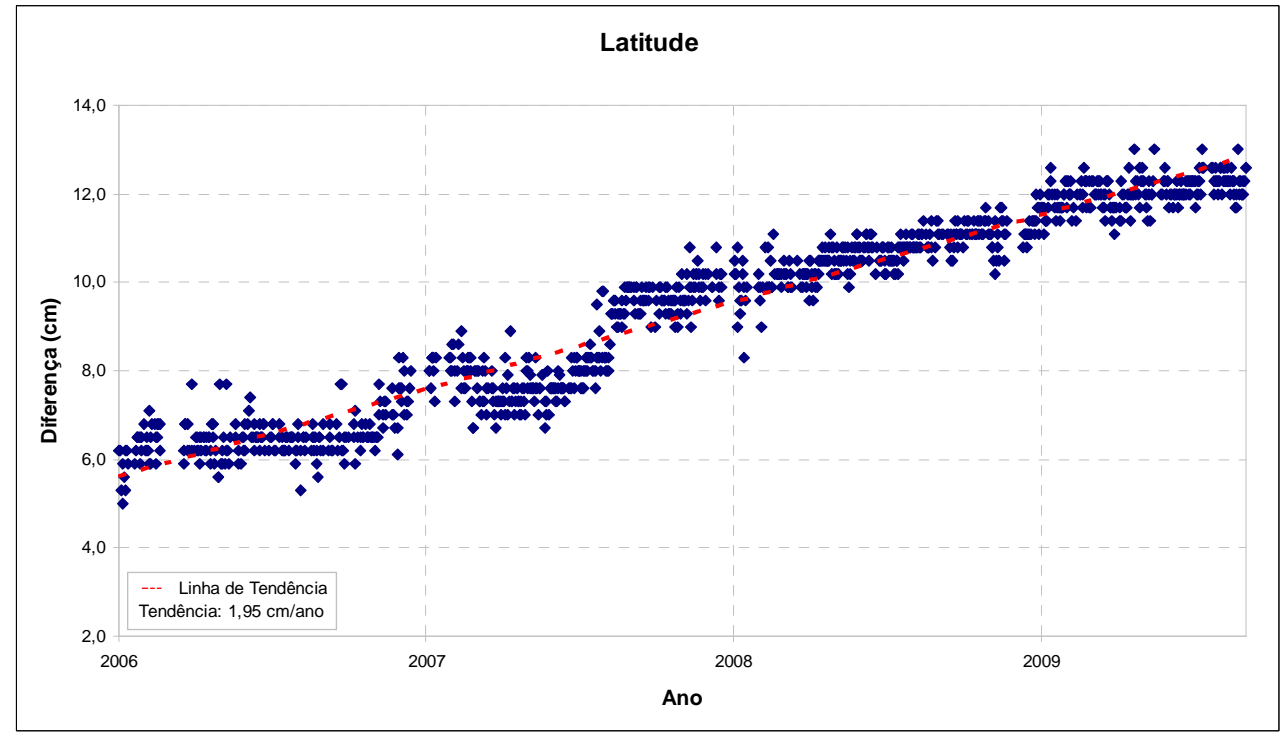

Figura 5.8 - Latitude (estação UBAT)

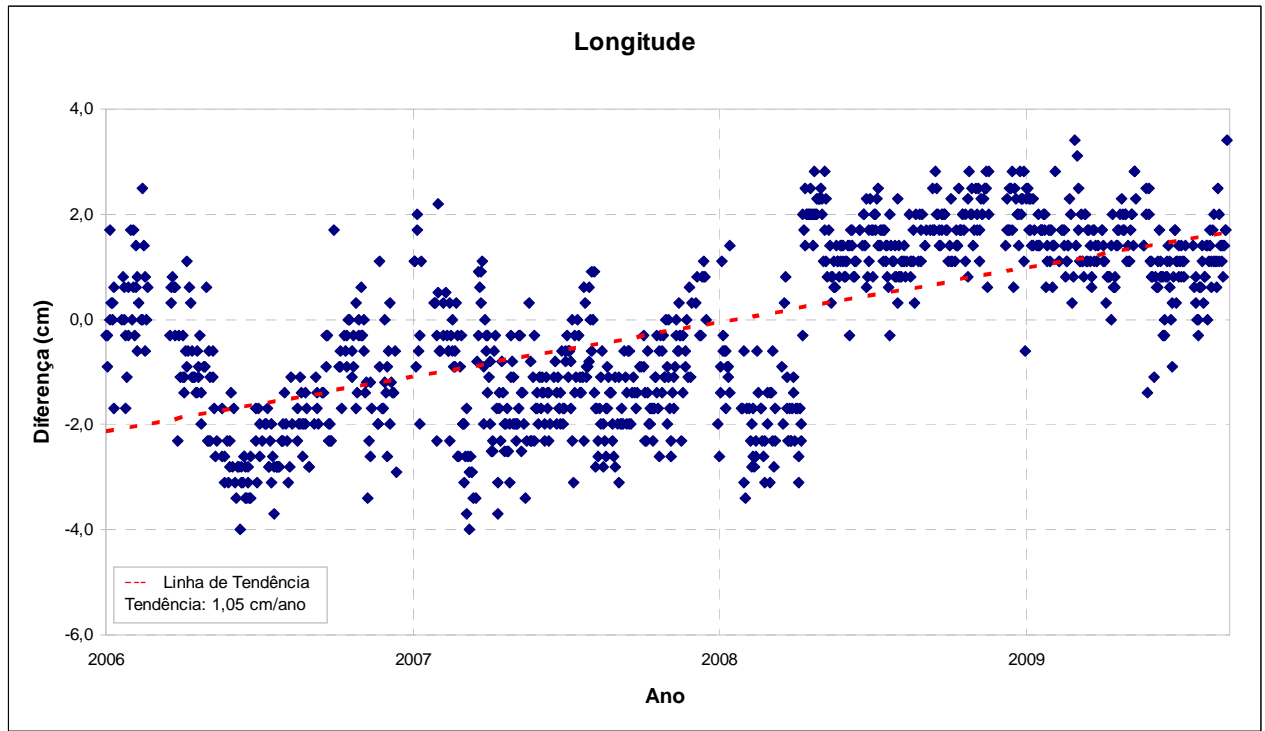

Figura 5.9 - Longitude (estação UBAT)

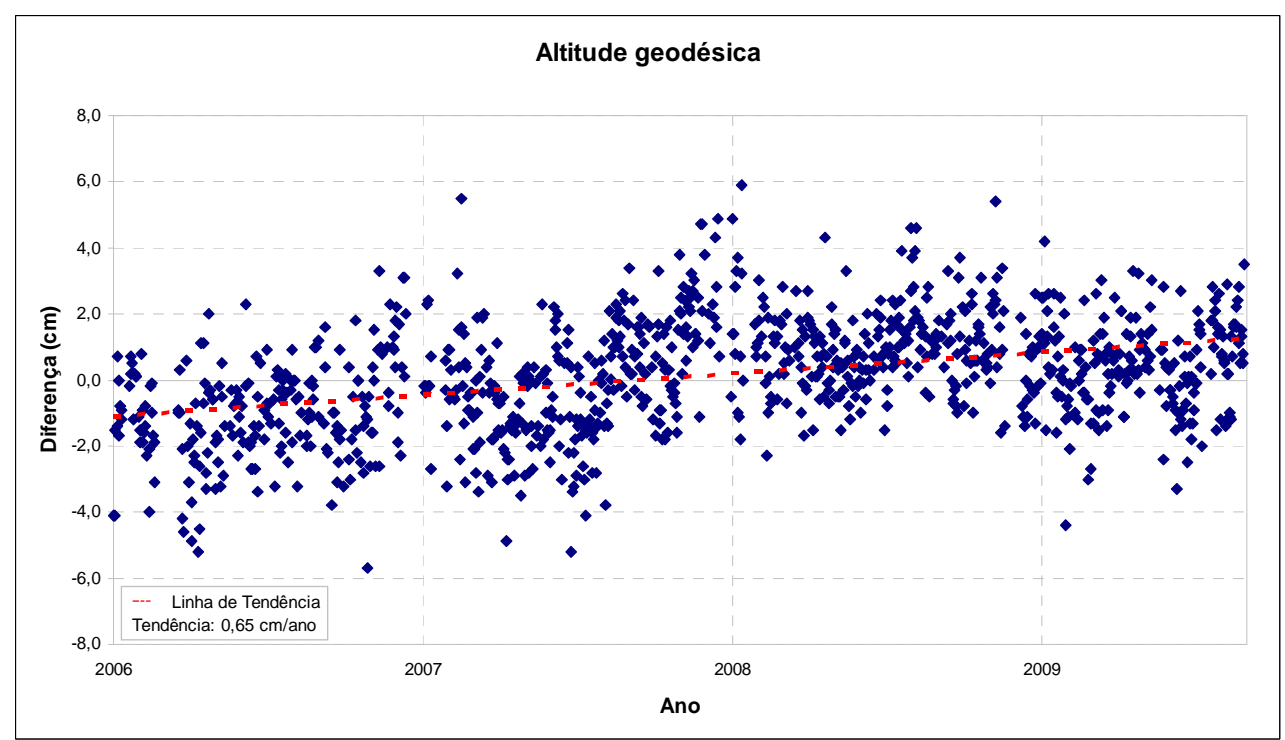

Figura 5.10 - Altitude geodésica (estação UBAT) 
A latitude (Figura 5.8) apresenta um padrão crescente na série, variando de 6 a 12 $\mathrm{cm}$ e com deslocamento de 1,95 cm/ano. Um salto na série temporal da longitude é constatado (Figura 5.9). Tal fato ocorreu no mês de abril de 2008, semana GPS 1476. Não se conseguiu até o momento encontrar o motivo de apenas uma das componentes ter se deslocar. Coincidentemente, no mesmo período houve um terremoto de 5,2 graus na escala Richter, com epicentro a aproximadamente $230 \mathrm{~km}$ de Ubatuba. O fato da coincidência do ocorrido não é o suficiente para justificar o deslocamento dessa coordenada. Com relação à altitude geodésica, (Figura 5.10) ela possui um comportamento aleatório com alta variação $(-6$ a $6 \mathrm{~cm})$. No caso da estação UBAT foi realizado o mesmo procedimento de remoção da tendência e aplicação de uma média móvel (Figura 5.11). O estudo do movimento da estação UBAT é verificado na Figura 5.12. A estação possui um deslocamento no sentido nordeste $(1,55 \mathrm{~cm} / \mathrm{ano})$.

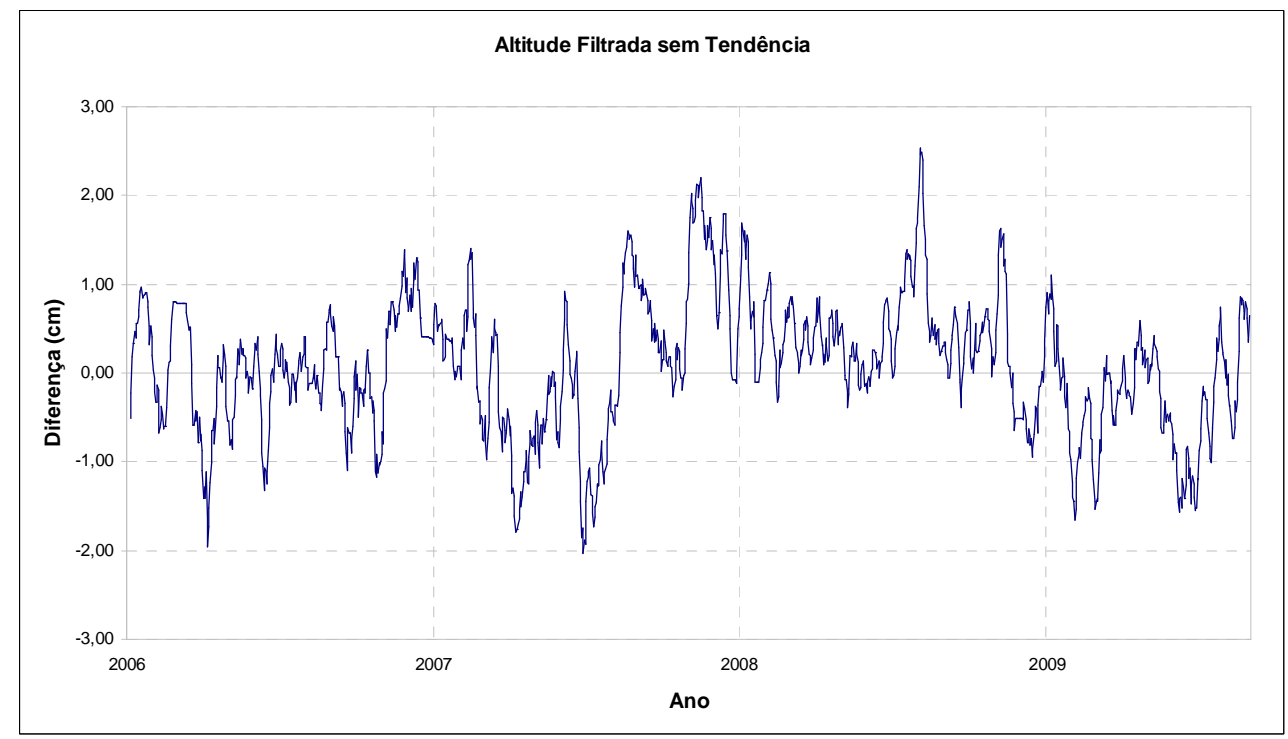

Figura 5.11 - Altitude filtrada e sem tendência (estação UBAT) 


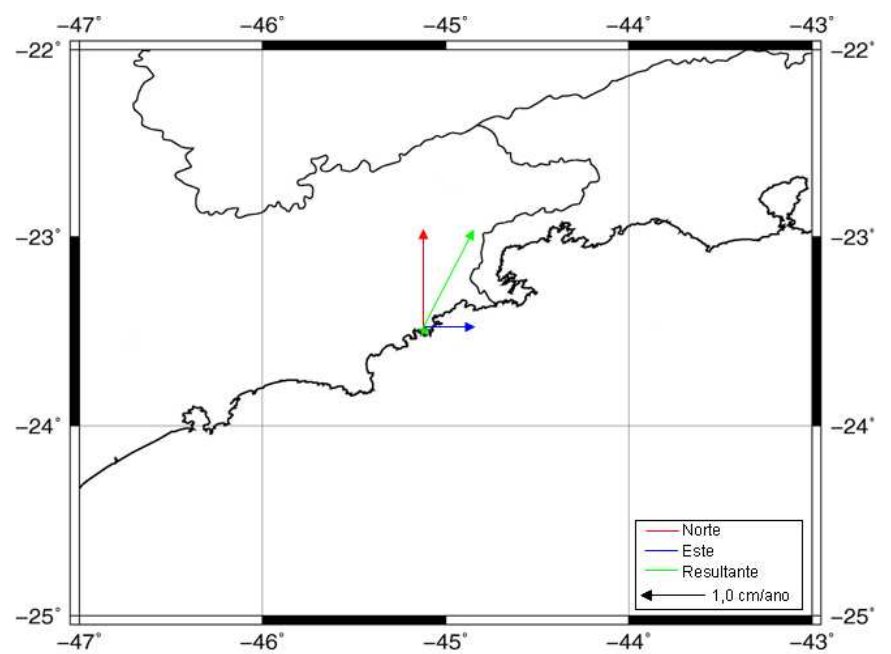

Figura 5.12 - Deslocamento planimétrico da estação UBAT

A comparação com o processamento do IBGE também foi realizada (Figura 5.13). O PPP detectou o mesmo comportamento com relação ao processamento do IBGE para as 3 componentes. O salto ocorrido na longitude também é evidente. O vetor da resultante das componentes planimétricas pelo PPP é de 2,21 cm/ano e do IBGE de $1,54 \mathrm{~cm} / \mathrm{ano}$.

\section{9) UBAT - Velocidade Planimetrica $0.01588 \pm 0.00042 \mathrm{~m} / \mathrm{ano}$}
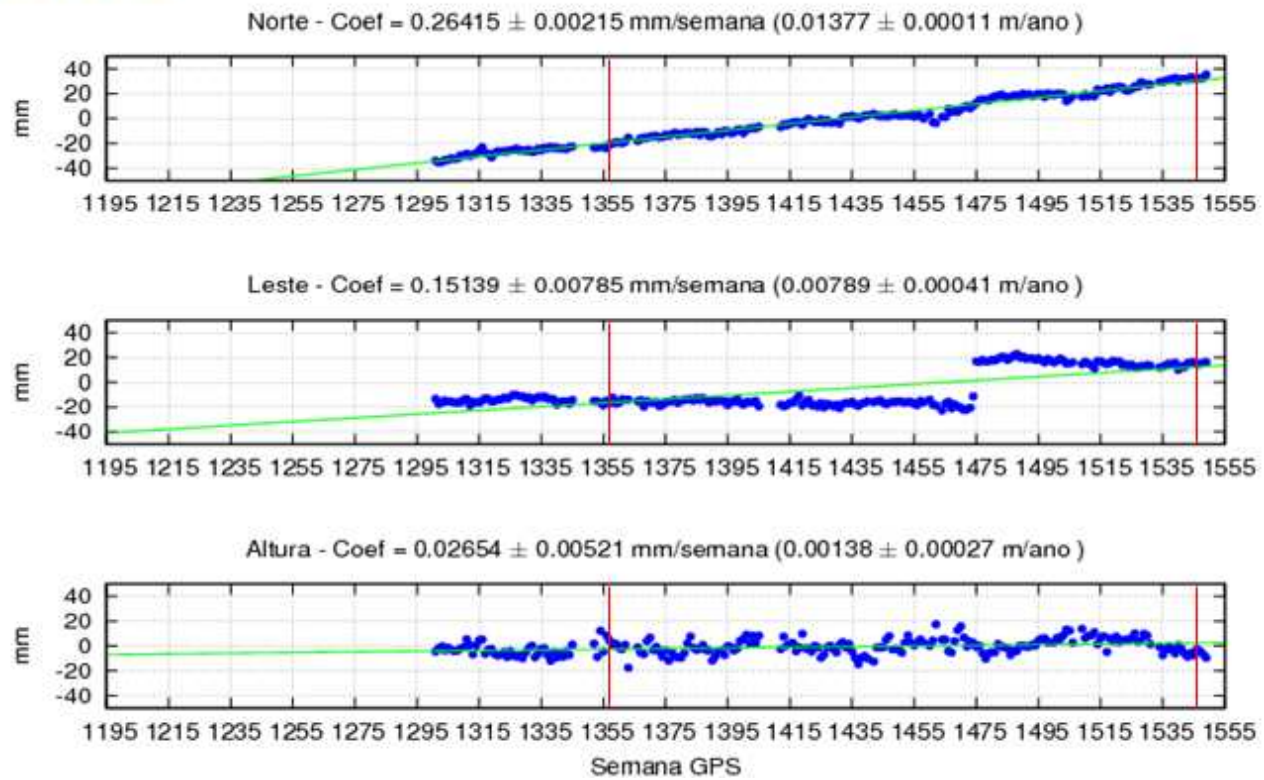

Figura 5.13 - Coordenadas da estação UBAT processadas pelo IBGE (Fonte: IBGE, 2009) 


\subsection{Comparação do Nivelamento com o Nível Médio do Mar}

As bases do Instituto Oceanográfico da USP utilizadas no item 5.2, além de receptores GNSS, também possuem marégrafos. Com isso é possível determinar uma posição de equilíbrio do mar a partir das médias de um longo período de observações daquela região. Na base de Cananeia existem dois maregráfos, um tradicional e outro calisto (Figura 5.14), enquanto em Ubatuba um tradicional.

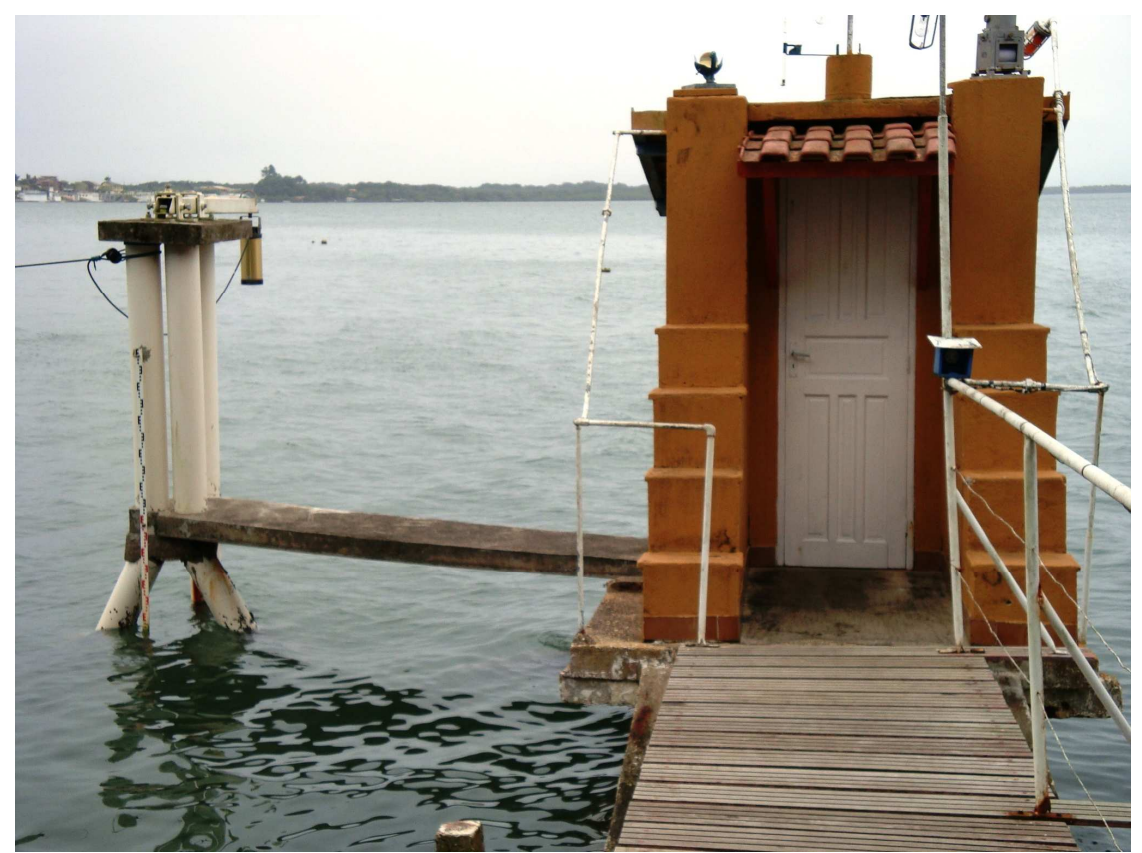

Figura 5.14 - Maregráfos da base Dr. João Paiva de Carvalho

A RAAP iniciada em Imbituba ("altitude zero" do país) se estendeu até os municípios de Cananeia (RN IBGE 2813D) e Ubatuba (RNX 1979D). Através do nivelamento ${ }^{10}$ partindo dessas RNs foi possível obter a altitude no topo da régua referente a cada maregráfo, permitindo avaliar a discrepância entre o nivelamento geométrico proveniente do marégrafo de Imbituba com o nível médio do mar de Cananeia e Ubatuba.

Para o maregráfo ${ }^{11}$ de Cananeia calculou-se o NMM para um período de 16 anos (1990 a 2006). O cálculo foi realizado a partir das médias anuais. Para Ubatuba o nível médio do mar adotado é referente a 1978 (MESQUITA; HARARI, 1983).

\footnotetext{
${ }^{10}$ Nivelamento realizado em trabalho da UNICAMP

${ }^{11}$ Dados disponíveis em: ftp://mar8.io.usp.br/pub/TG/cananeia/
} 
Uma importante questão a ser considerada está relacionada à época em que as observações maregráficas foram tomadas. A não homogeneidade desse período poderá refletir e comprometer o resultado da comparação. O ideal é que as observações dos maregráfos envolvidos no estudo estivessem no mesmo período.

Foi possível por meio do cálculo do NMM saber exatamente onde este coincide com um valor de leitura da régua. Sabendo-se o comprimento de cada régua foi possível calcular a distância do NMM até o topo da régua. Com isso, calculou-se a diferença entre a altitude ortométrica (nivelamento) no topo da régua e a distância do NMM ao topo da régua. O resultado dessa subtração foi a diferença do nivelamento geométrico de Imbituba com os NNMs de Cananeia e Ubatuba (Figura 5.15).

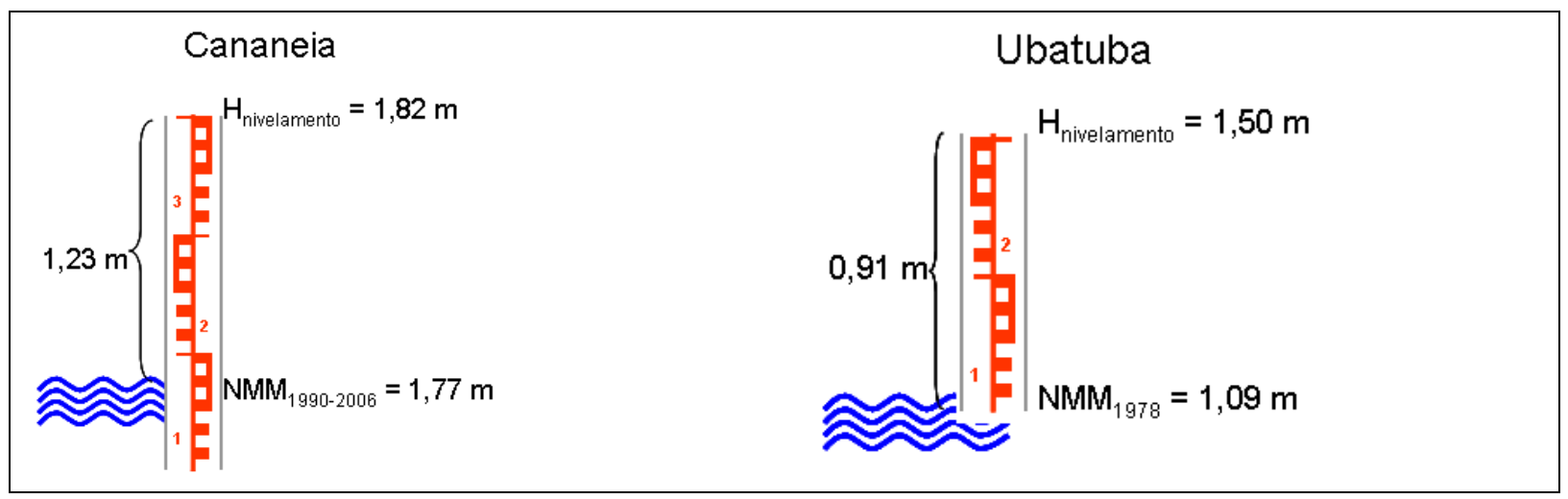

Figura 5.15 - Comparação NMM

O valor encontrado tanto para o maregráfo de Cananeia quanto para o de Ubatuba foi de $0,59 \mathrm{~m}$. Esses resultados não sofreram nenhum tipo de correção, sendo considerados valores "brutos". Para um estudo minucioso é necessário levar em consideração correções referentes à TSO, o movimento da crosta terrestre e o erro proveniente do nivelamento. Uma primeira aproximação considerando a correção da TSO e do erro do nivelamento foi realizada. A TSO na região de Imbituba é de -0,20 m, enquanto para a região de Cananeia e Ubatuba é de zero (LASKOWSKI, 1983). O IBGE está trabalhando para o ajustamento da RAAP e em algumas regiões do país a rede já foi ajustada. Para a região do litoral de São Paulo o desvio padrão da altitude ajustada é de cerca de 0,06 m (Figura 5.16) (PINHEIRO et al., 2007). O resultado obtido após a correção da TSO e do erro do nivelamento foi de $0,33 \mathrm{~cm}$. Vale ressaltar que a correção do efeito da crosta terrestre não foi efetuada, pois, para tanto, é necessário um aprofundamento do tema no que diz respeito ao estudo da carga oceânica, carga atmosférica e marés terrestre, oceânica e atmosférica. 


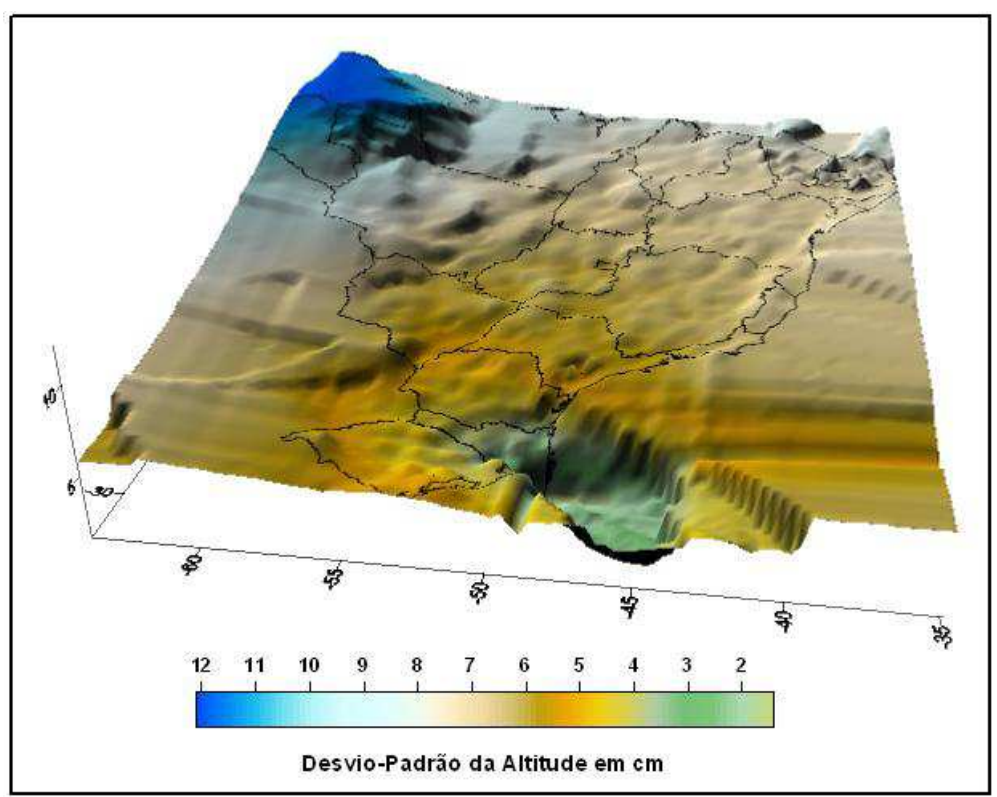

Figura 5.16 - Desvio padrão da altitude ajustada (Pinheiro et al., 2007)

\subsection{Comparação entre GPS/RN e GGMs}

As observações GPS/RN permitem determinar a ondulação geoidal para um determinado ponto, a partir da altitude geodésica derivada do GPS e da altitude ortométrica obtida pelo nivelamento. As ondulações geoidais podem ser comparadas com as anomalias de altura. Para essa avaliação foram utilizadas 199 estações GPS/RN (Figura 5.17) distribuídas no estado de São Paulo. As instituições que colaboraram com os dados foram: IBGE, EPUSP, UNICAMP e IAG-USP (Instituto de Astronomia, Geofísica e Ciências Atmosféricas). 


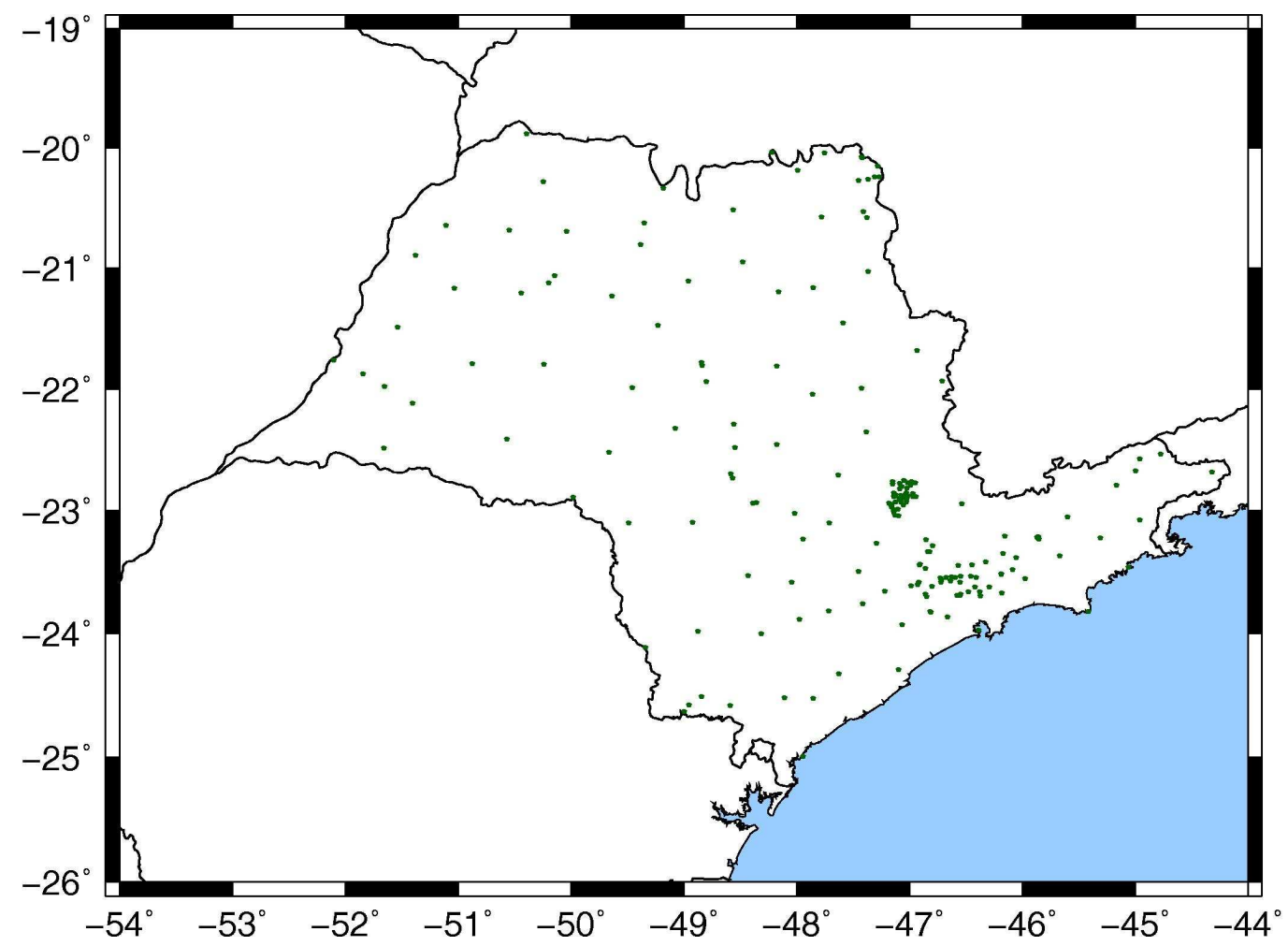

Figura 5.17 - Estações GPS/RN

Com o objetivo de realizar essa tarefa, 3 modelos foram empregados: EIGEN-GL04, EIGEN-5C e EGM08. Foram validados os modelos EIGEN-GL04S (grau e ordem 150), EIGEN-GL04C (grau e ordem 150 e 360), EIGEN-05C (grau e ordem 150, 180, 360) e EGM08 (grau e ordem 150, 180, 360, 2160).

\subsubsection{EIGEN-GL04}

Foram utilizados dois tipos do modelo EIGEN-GL04: o EIGEN-GL04C que foi obtido a partir de dados de satélites e dados terrestres e o EIGEN-GL04S que envolve somente dados de satélites. Os resultados em termos de histogramas e da distribuição normal são visualizados na Figura 5.18 e em termos gráficos na Figura 5.19. 

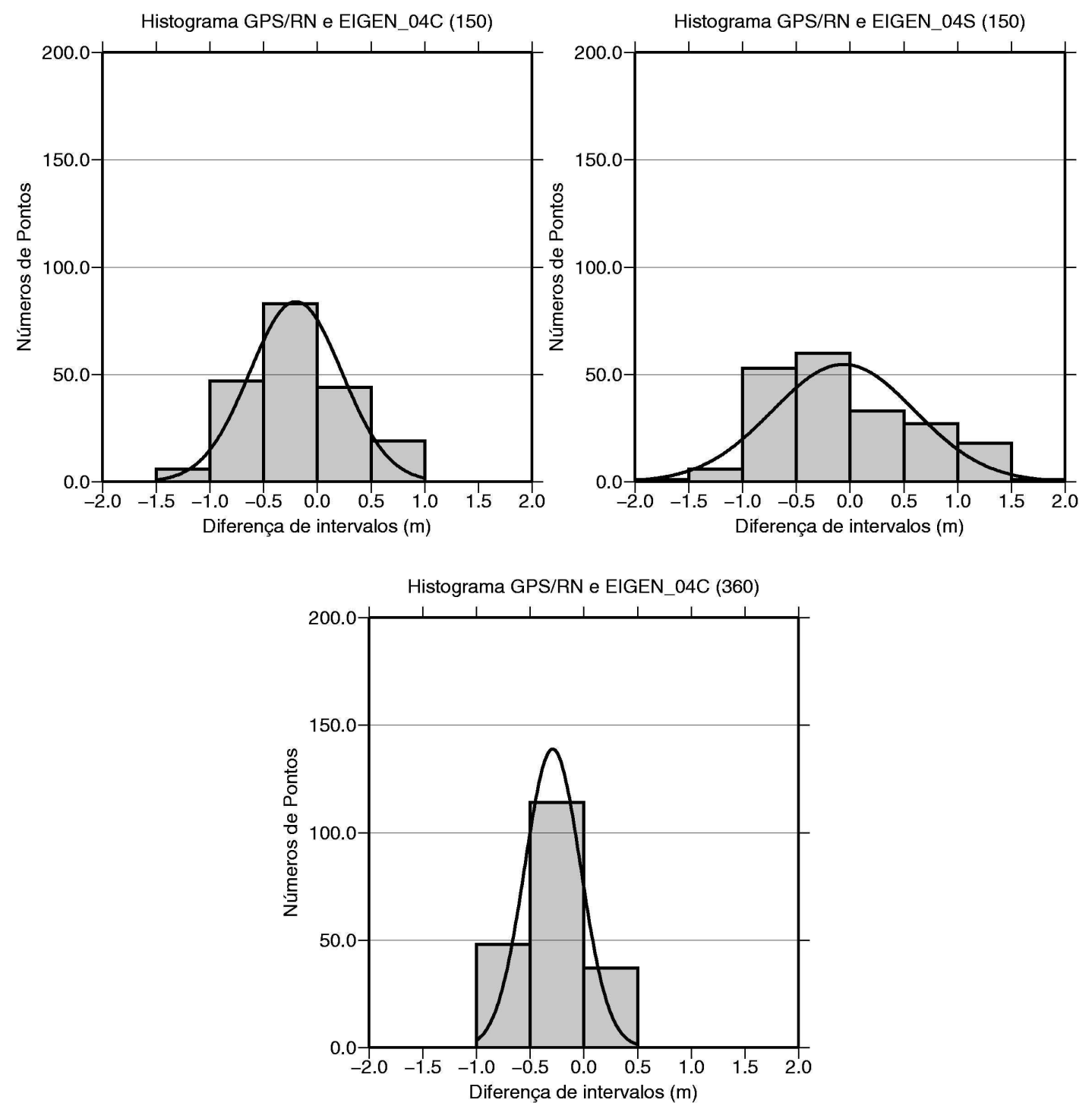

Figura 5.18 - Discrepâncias entre GPS/RN e GGMs - EIGEN-GL04

Verifica-se na Figura 5.18 que o modelo EIGEN-GL04C grau e ordem 360 foi o que apresentou melhor consistência com os dados GPS/RN. Nota-se que a curva da distribuição normal possui um comportamento leptocúrtica, apresenta um alto grau de afilamento superior ao da normal. Além disso, a curva possui um padrão próximo ao do simétrico. O modelo EIGEN-GL04C e EIGEN-GL04S (grau e ordem 150) não apresentaram consistência na comparação. 

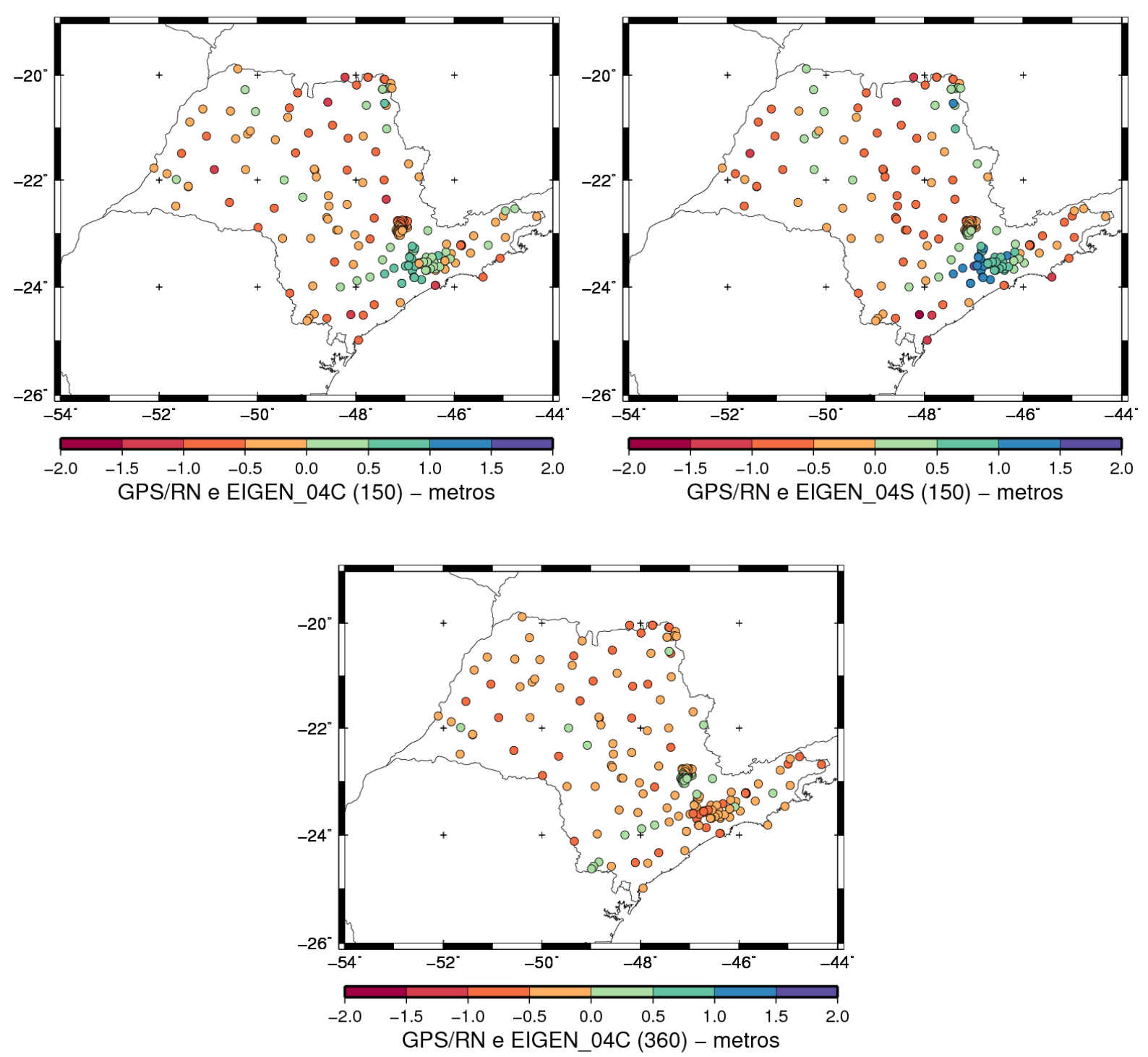

Figura 5.19 - Diferença entre GPS/RN e GGMs - EIGEN-GL04

De acordo com a Figura 5.19, o modelo que se originou somente de dados de satélites (EIGEN-GL04S) apresentou uma diferença entre as anomalias de altura e as ondulações geoidais de aproximadamente $\pm 1,50 \mathrm{~m}$. Para o modelo grau e ordem 360 as diferenças em relação à média variaram entre -1 a 0,5 m.

A Tabela 5.3 indica os resultados em termos de valores médios, diferença média quadrática, assimetria, curtose e valores máximos e mínimos entre as anomalias de altura do modelo EIGEN-GL04 para os diversos grau e ordem e as ondulações geoidais. 
Tabela 5.3 - Estatística entre GPS/RN e GGMs - EIGEN-GL04

\begin{tabular}{ccccccc}
\hline MG & Média & RMSD & Assimetria & Curtose & Máx. & Mín. \\
\cline { 2 - 7 } & \multicolumn{7}{c}{ metros } \\
\hline EIGEN-GL04C (150) & $-0,20$ & 0,44 & 0,32 & $-0,16$ & 0,99 & $-1,34$ \\
EIGEN-GL04S (150) & $-0,06$ & 0,66 & 0,39 & $-0,77$ & 1,51 & $-1,55$ \\
EIGEN-GL04C (360) & $-0,29$ & 0,26 & $-0,08$ & $-0,57$ & 0,37 & $-0,97$ \\
\hline
\end{tabular}

A Tabela 5.3 mostra que em termos da média da diferença em relação às duas grandezas o modelo completo até grau e ordem 150 somente com dados de satélites apresentou o menor valor. Por outro lado, a diferença média quadrática $(\text { RMSD })^{12}$ do modelo até grau e ordem 360 teve o menor valor em comparação aos demais GGMs.

\subsubsection{EIGEN-5C}

Para o modelo do geopotencial mais recente da missão GRACE disponibilizado pelo GFZ a comparação foi realizada para os graus e ordens 150, 180 e 360. O EIGEN5C é um modelo combinado, constituído de dados de satélites e dados terrestres. Os resultados em termos de histogramas e da distribuição normal são visualizados na Figura 5.20 e em termos gráficos na Figura 5.21.

\footnotetext{
${ }^{12}$ Em inglês designado por Root Mean Square Difference - RMSD
} 

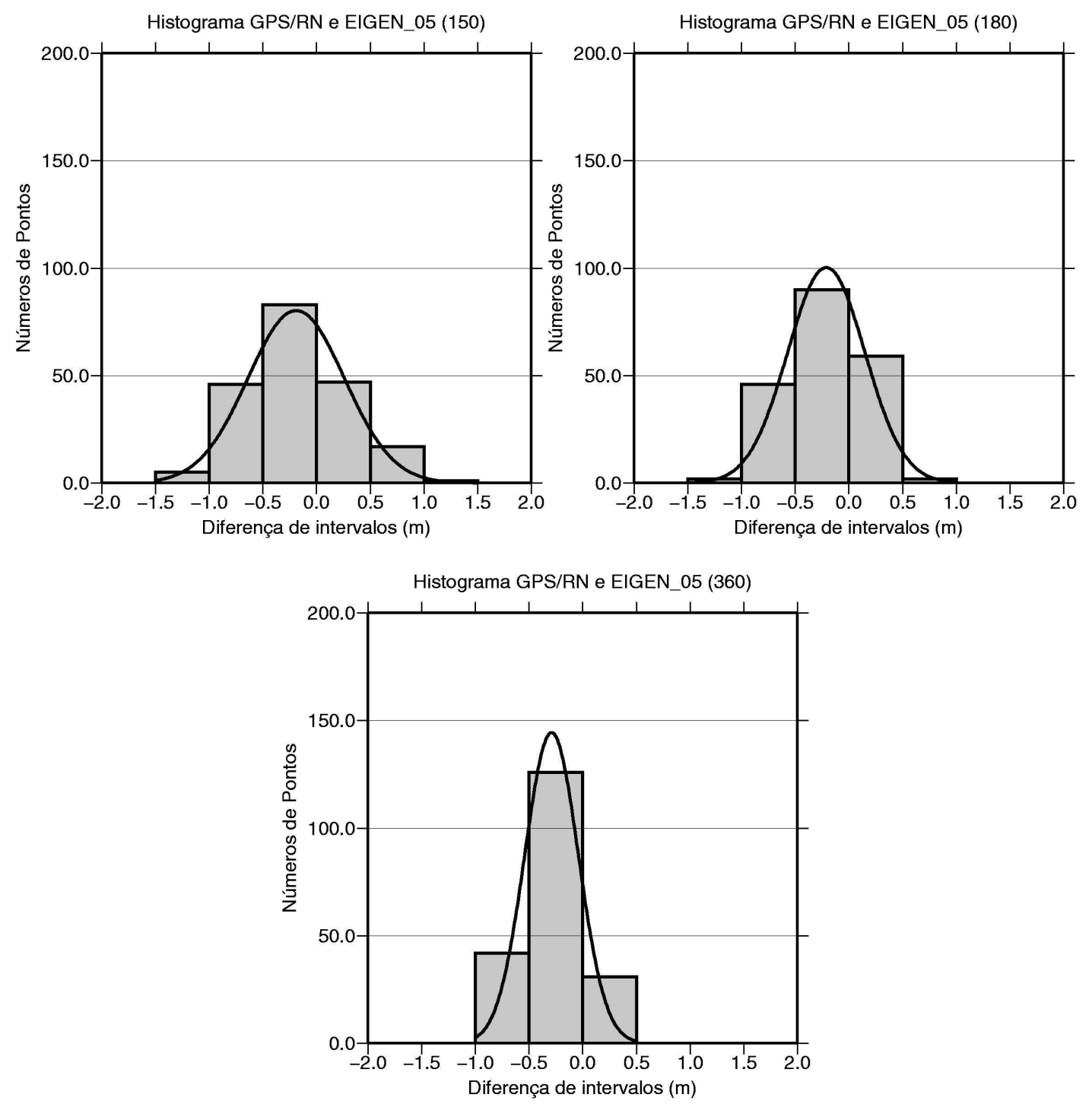

Figura 5.20 - Discrepâncias entre GPS/RN e GGMs - EIGEN-5C

Nota-se na Figura 5.20 que o modelo EIGEN-5C grau e ordem 360 foi o que apresentou melhor comportamento com relação aos dados GPS/RN. Verifica-se também que o resultado em termos da distribuição normal foi semelhante ao modelo EIGEN-GL04C (Figura 5.18) para mesmo grau e ordem. Os valores obtidos para grau e ordem 150 e 180 variaram de $-1,5$ a 1,0 m. 

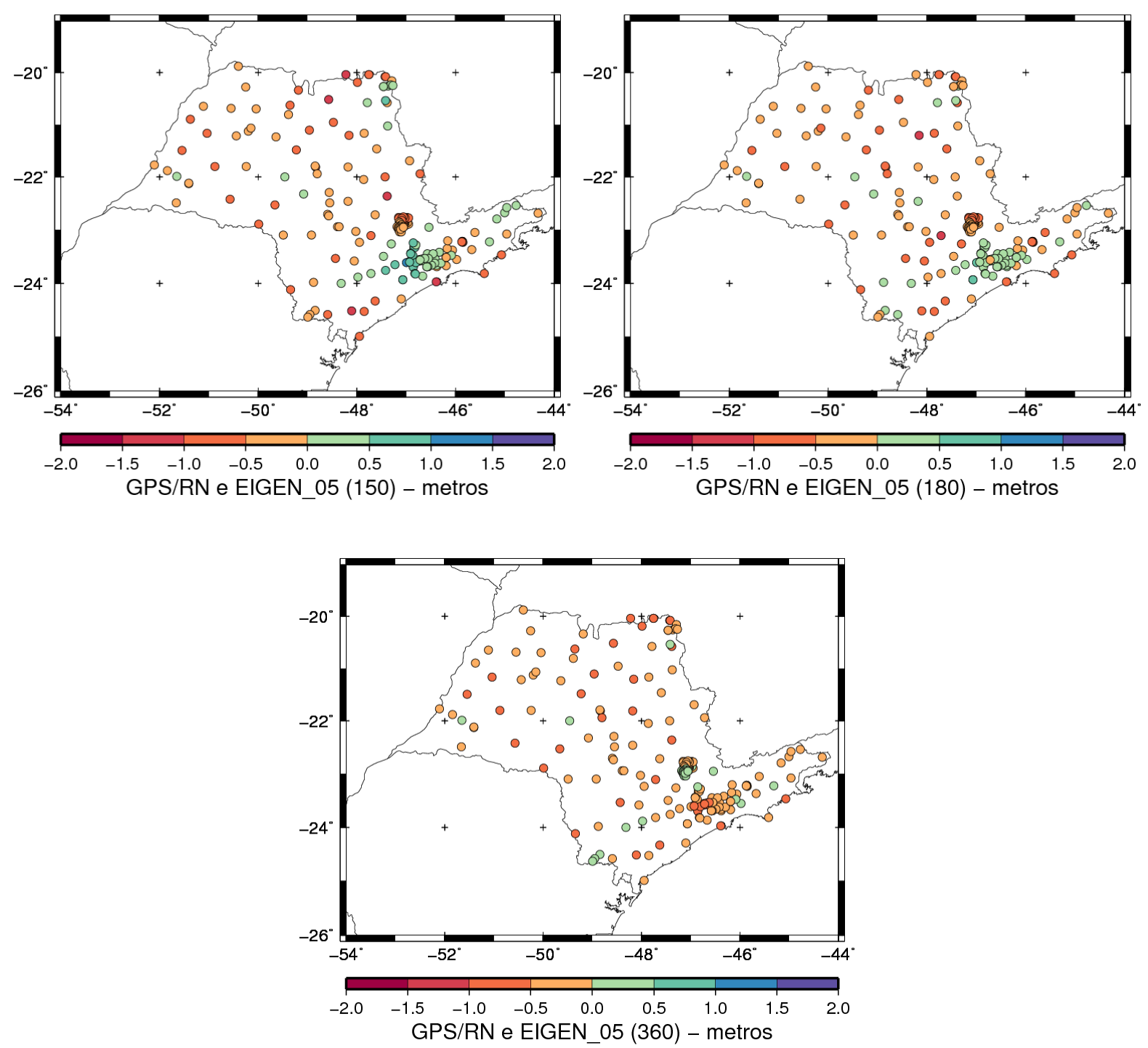

Figura 5.21 - Diferença entre GPS/RN e GGMs - EIGEN-5C

A Tabela 5.4 indica os resultados em termos estatísticos para os 3 valores de grau e ordem utilizados para o modelo EIGEN-5C.

Tabela 5.4 - Estatística entre GPS/RN e GGMs - EIGEN-5C

\begin{tabular}{ccccccc}
\hline \multirow{2}{*}{ MG } & Média & RMSD & Assimetria & Curtose & Máx. & Mín. \\
\cline { 2 - 7 } & \multicolumn{7}{c}{ metros } \\
\hline EIGEN-5C (150) & $-0,19$ & 0,45 & 0,35 & $-0,30$ & 1,03 & $-1,31$ \\
EIGEN-5C (180) & $-0,21$ & 0,37 & 0,20 & $-1,02$ & 0,60 & $-1,05$ \\
EIGEN-5C (360) & $-0,29$ & 0,25 & $-0,12$ & $-0,33$ & 0,40 & $-0,99$ \\
\hline
\end{tabular}

Em relação à média, o modelo até grau e ordem 150 apresentou menor valor estatístico $(-0,19 \mathrm{~m})$. No que tange ao RMSD, o menor valor foi encontrado para o modelo até grau e ordem 360 . 


\subsubsection{EGM08}

Para o mais recente modelo do geopotencial, as anomalias de altura foram calculadas utilizando o programa hsynth_WGS84.f desenvolvido por Holmes e Pavlis (2008). É importante mencionar que o coeficiente harmônico zonal de grau $2\left\{\bar{C}_{20}\right\}$ está expresso no sistema de maré zero. A correção de $-41 \mathrm{~cm}$, resultado da diferença entre o elipsoide vinculado ao modelo do geopotencial e o elipsoide de referência não foi utilizada (HOLMES e PAVLIS, 2008). Os resultados em termos de histogramas e da distribuição normal são visualizados na Figura 5.22 e em termos gráficos na Figura 5.23.
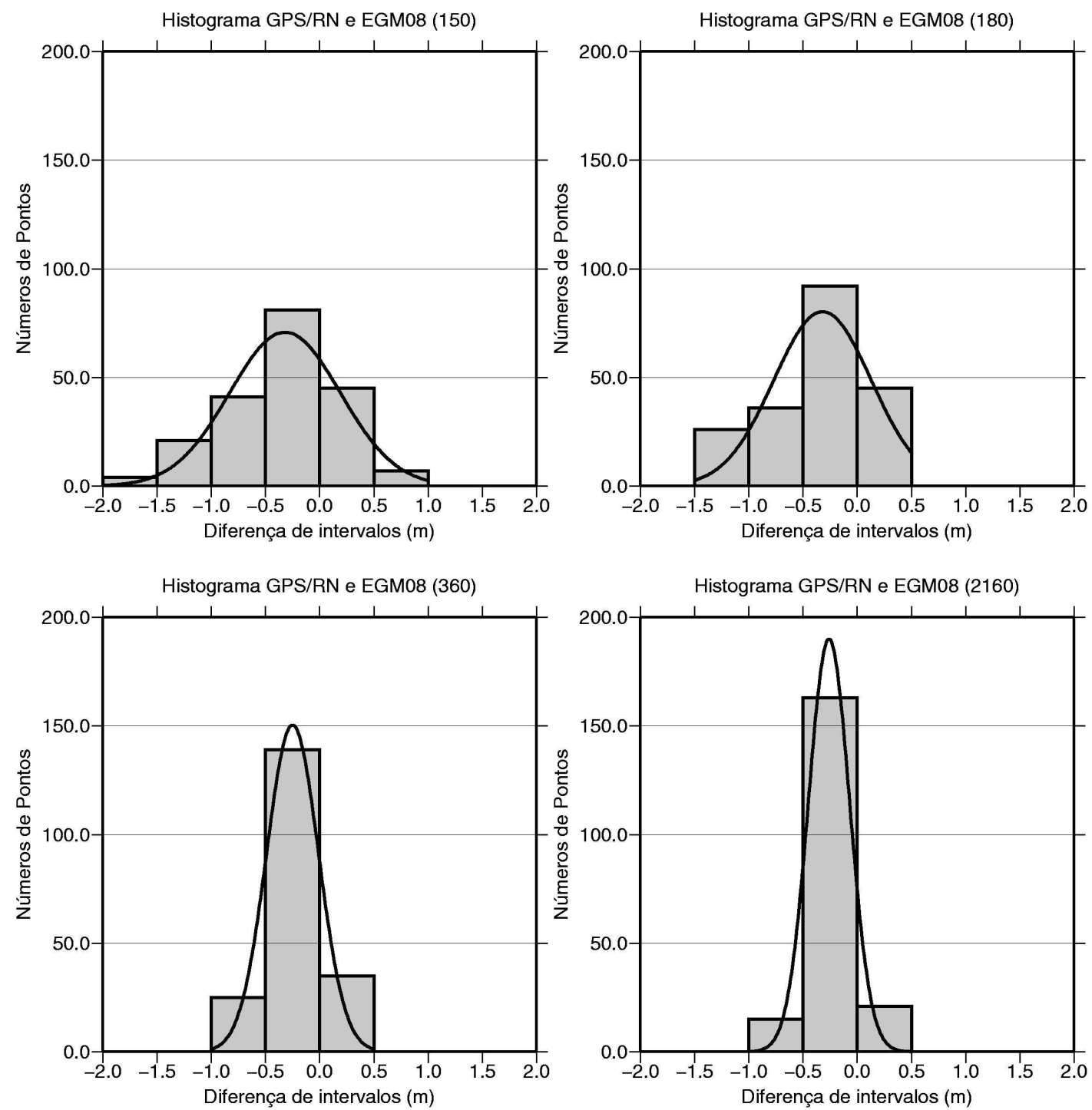

Figura 5.22 - Discrepâncias entre GPS/RN e GGMs - EGM08 
Observa-se na Figura 5.22 que a comparação envolvendo grau e ordem 360 e 2160 apresentaram valores consistentes em relação aos dados GPS/RN. Os valores se comportaram entre -1,0 e 0,5 m. Já o grau e ordem 150 e 180, estes não possuem consistência com os dados GPS/RN.
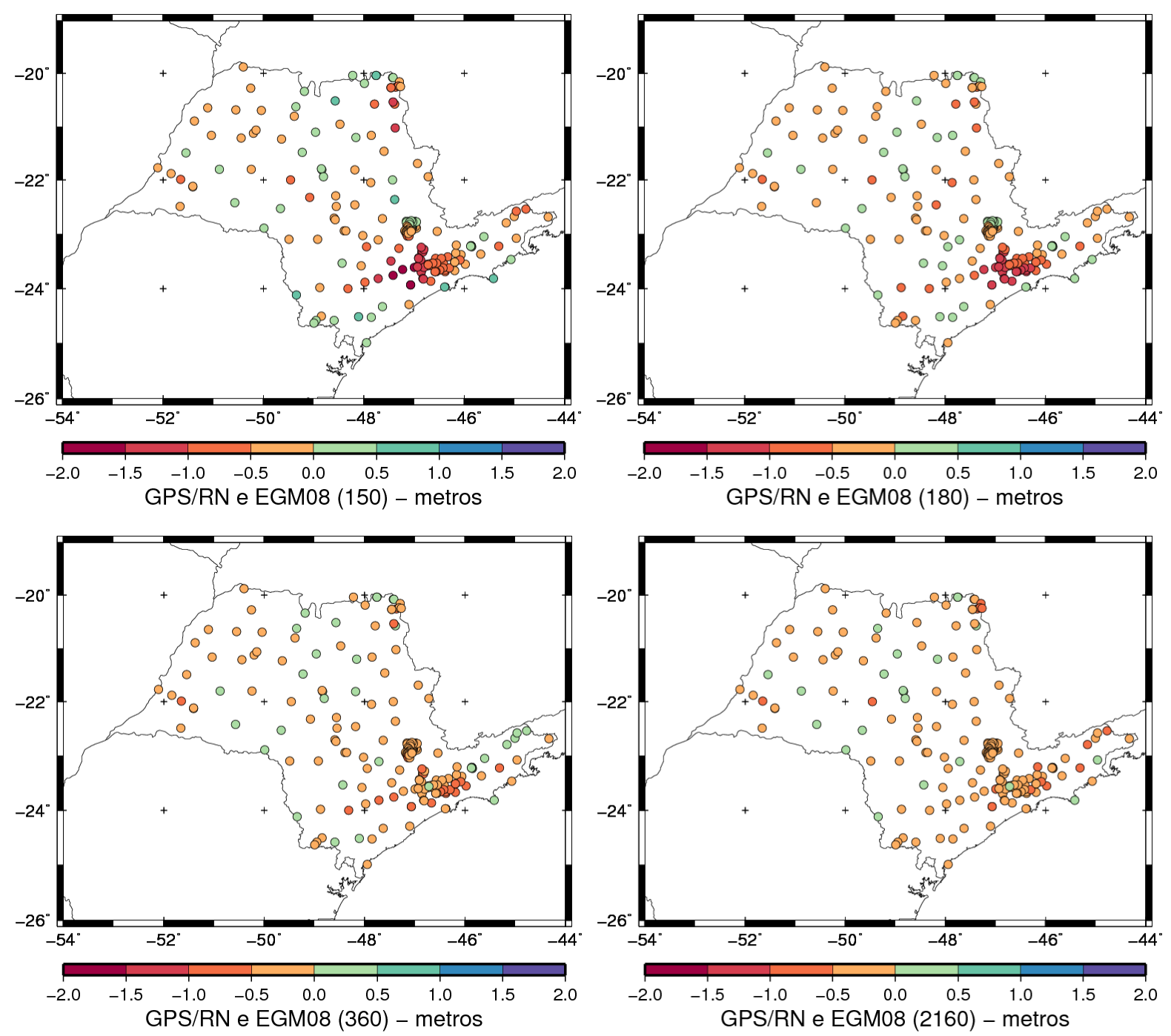

Figura 5.23 - Diferença entre GPS/RN e GGMs - EGM08

Com relação à Figura 5.23, verifica-se o comportamento semelhante entre o grau e ordem 360 e 2160. Para o grau e ordem 150 e 180 as maiores diferenças encontram-se na região do município de São Paulo. A Tabela 5.5 mostra os resultados em termos de valores médios, diferença média quadrática, assimetria, curtose e valores máximos e mínimos. 
Tabela 5.5 - Estatística entre GPS/RN e GGMs - EGM08

\begin{tabular}{ccccccc}
\hline \multirow{2}{*}{ MG } & Média & RMSD & Assimetria & Curtose & Máx. & Mín. \\
\cline { 2 - 7 } & \multicolumn{7}{c}{ metros } \\
\hline EGM08 (150) & $-0,33$ & 0,51 & $-0,55$ & $-0,07$ & 0,83 & $-1,79$ \\
EGM08 (180) & $-0,33$ & 0,46 & $-0,50$ & $-0,83$ & 0,47 & $-1,43$ \\
EGM08 (360) & $-0,25$ & 0,25 & 0,12 & 0,05 & 0,42 & $-0,93$ \\
EGM08 (2160) & $-0,26$ & 0,19 & 0,82 & 1,00 & 0,35 & $-0,74$ \\
\hline
\end{tabular}

Verifica-se na Tabela 5.5 que o EGM08 quando processado com grau e ordem 150 apresentou, em relação à média e ao RMSD, maiores valores. O uso do grau e ordem 360 apresentou menor média, enquanto o valor de 2160 possui a menor diferença média quadrática.

\subsection{Modelo Geoidal do Estado de São Paulo}

O estado de São Paulo possui no momento 6753 estações gravimétricas. Elas são derivadas de levantamentos passados e de novas medições como parte do Projeto Temático (seção 1.3, parágrafo $2^{\circ}$ ). A Figura 5.24 apresenta a distribuição dos dados existentes, em azul (1914 estações) referente ao projeto mencionado e em vermelho (4839 estações) os dados de campanhas anteriores provenientes de empresas públicas e privadas que realizam levantamentos gravimétricos no país, tais como, PETROBRAS, Observatório Nacional, além da contribuição do IAG-USP. 


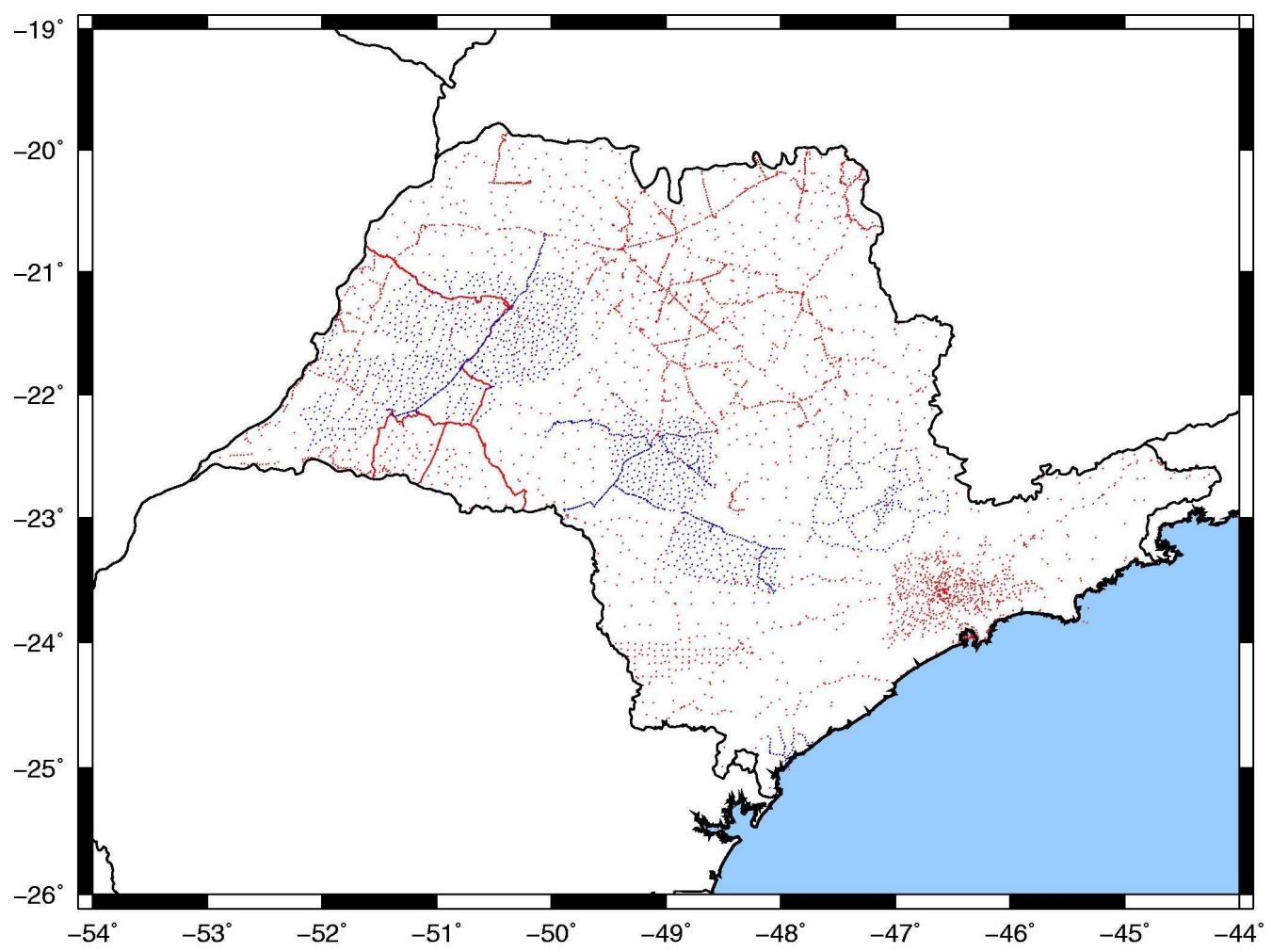

Figura 5.24 - Distribuição dos dados gravimétricos no estado de São Paulo

O software SHGEO desenvolvido pela Universidade de New Brunswick, no Canadá, foi utilizado para o cálculo das anomalias de gravidade Helmert. A anomalia de Bouguer foi calculada a priori para um modelo digital de 1'x 1' por meio do método de interpolação pelo inverso da distância. Em seguida criou-se um modelo digital de 5' x 5' a partir da média simples dos valores do modelo digital de 1' x 1'. O modelo digital do terreno utilizado foi o SAM3s_v2 para um modelo digital de 3" x 3". Este consiste no uso do SRTM3 (FARR et al., 2007), porém as ondulações geoidais do EGM96 utilizadas no mesmo foram substituídas pelo EIGENGL04C. Os vazios foram preenchidos a partir de mapas digitalizados e do DTM2002 (SALEH; PAVLIS, 2002) e (BLITZKOW et al., 2007). A malha das anomalias médias de gravidade ar-livre foi determinada em um modelo digital de 5' x 5' derivada de dados terrestres. Os blocos sem informação gravimétrica foram preenchidos pelo modelo do geopotencial EGM08. A anomalia de gravidade ar-livre sobre os oceanos foi obtida a partir do modelo do Danish National Space Center (DNSC08-GRA) com resolução de 1' x 1' (ANDERSEN et al., 2008). A anomalia Helmert (Figura 5.25) referida à superfície da Terra foi determinada pela soma da anomalia ar-livre, efeitos topográficos direto e indireto secundário, efeito atmosférico direto e a correção geoide/quase-geoide. 


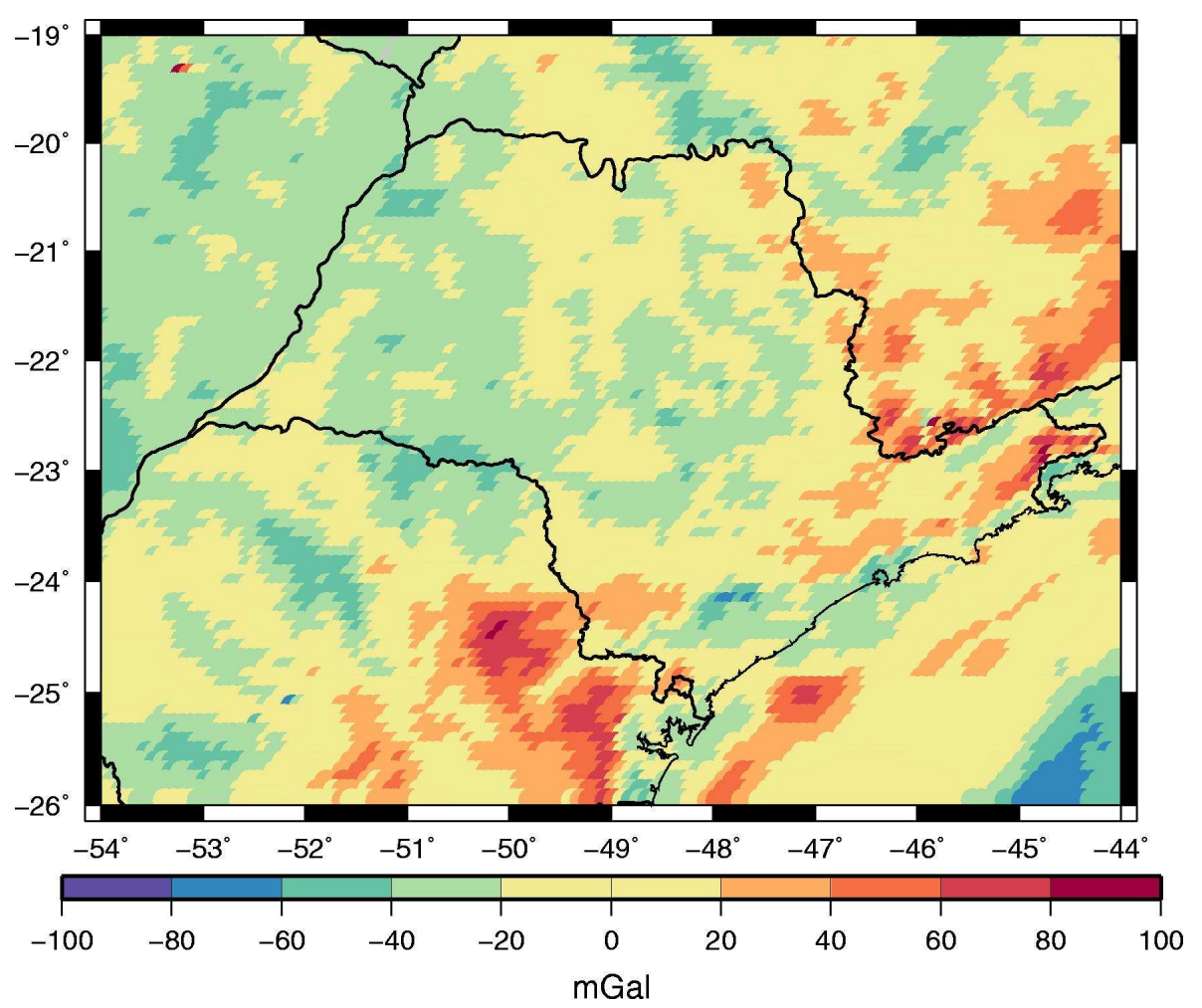

Figura 5.25 - Anomalia de gravidade de Helmert

A técnica "remove-calcula-restaura" foi empregada no cálculo das ondulações geoidais. Ela consiste em remover das anomalias médias de gravidade a componente de longo comprimento de onda fornecida pelo EGM08 (grau e ordem 150). Calculou-se a integral de Stokes estendendo-se a uma vizinhança $\psi_{0}=1,5^{\circ}$. Em seguida restaurou-se na ondulação geoidal a componente de longo comprimento de onda do EGM08 usando o mesmo grau e ordem. O cálculo da integral foi realizado através da técnica da FFT (seção 4.3) com auxílio do programa FFTMOD (LI; SIDERIS, 1993) onde a modificação do núcleo de Stokes é proposta por (FEATHERSTONE; EVANS; OLLIVER, 1998). O modelo geoidal GEOIDSP2010 é apresentado pela Figura 5.26. No modelo calculado não foi adicionado o termo de ordem zero. 


\section{GEOIDSP2010}

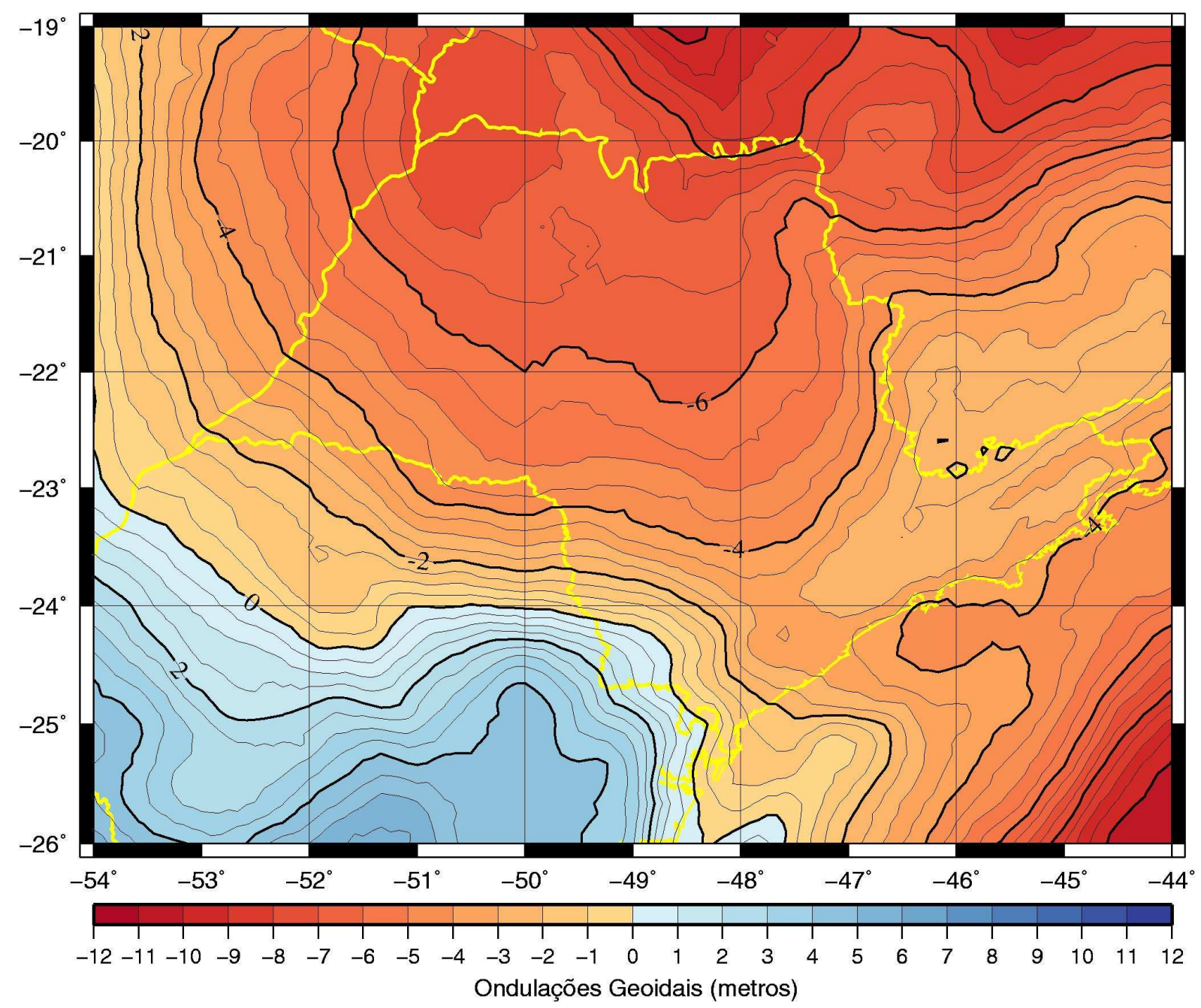

Figura 5.26 - Modelo geoidal do estado de São Paulo

\subsubsection{Validação do Modelo Geoidal}

Com o intuito de verificar a consistência do modelo geoidal a partir do GGM e dos dados GPS/RN uma validação do GEOIDSP2010 foi realizada. Várias instituições que calculam modelos geoidais utilizam a comparação entre essas duas grandezas como forma de avaliar o geoide. Deve-se levar em consideração que erros provenientes do GPS e do nivelamento podem afetar o resultado da comparação. No estado de São Paulo o nivelamento foi executado pelo IBGE e pelo antigo IGG e a implantação da rede altimétrica do IGG, em particular, não passou por um processo de ajustamento, o que pode ocasionar em uma heterogeneidade nos 
valores das altitudes ortométricas. Além disso, essa mesma rede serviu de apoio para outras redes, como a da Emplasa.

A comparação entre estas duas grandezas foi realizada em termos de diferença média quadrática (root mean square difference), uma vez que nenhuma das variáveis pode ser considerada verdadeira ou estimada. $\mathrm{Na}$ estatística utiliza-se a terminologia erro médio quadrático (root mean square error) quando se compara uma grandeza considerada verdadeira com outra observada. No caso do desvio médio quadrático (root mean square deviation) a comparação é realizada a partir de valores estimados ou preditos por um modelo e a grandeza observada. Duas análises foram realizadas: a primeira compara pontualmente a ondulação geoidal obtida pelo GPS/RN e a fornecida pelo GEOIDSP2010. Para esse caso utilizou-se o termo "diferença absoluta" (seção 5.4.1.1). A segunda compara pares de pontos a partir da diferença de $\Delta N$ do GPS/RN e do modelo geoidal relacionados à distância que separa as estações. Nesse caso utilizou-se a expressão "diferença relativa" (seção 5.4.1.2).

\subsubsection{Comparação GPS/RN e GEOIDSP2010 absoluta}

Para a verificação da diferença absoluta foram utilizadas 199 estações GPS/RN. A Figura 5.27 apresenta a discrepância entre o GEOIDSP2010 e GPS/RN em termos de histograma, enquanto a 5.28 as diferenças em termos gráficos. A Tabela 5.6 mostra a estatística da comparação. 


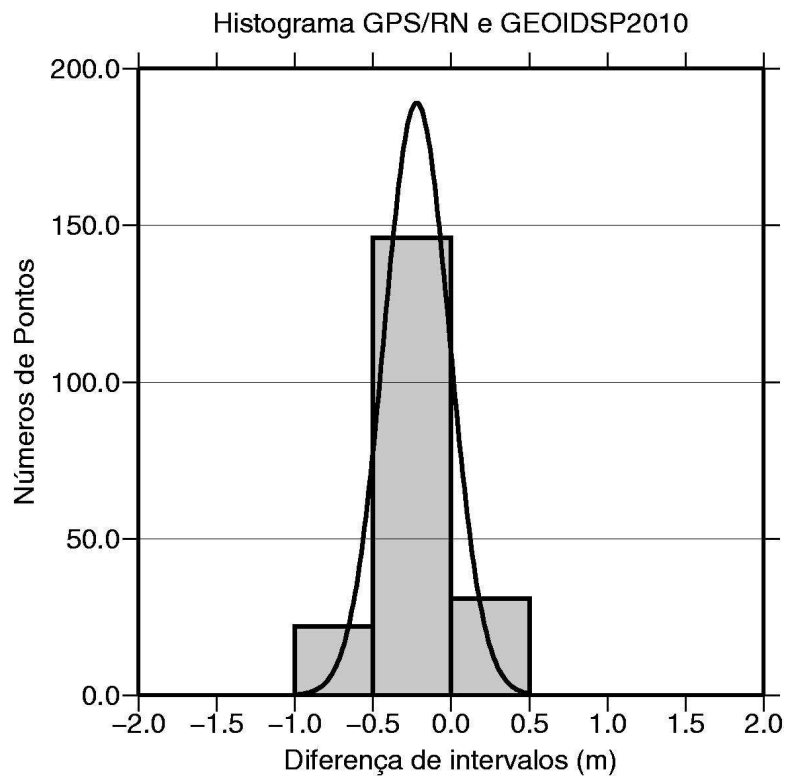

Figura 5.27 - Discrepância entre GPS/RN e GEOIDSP2010

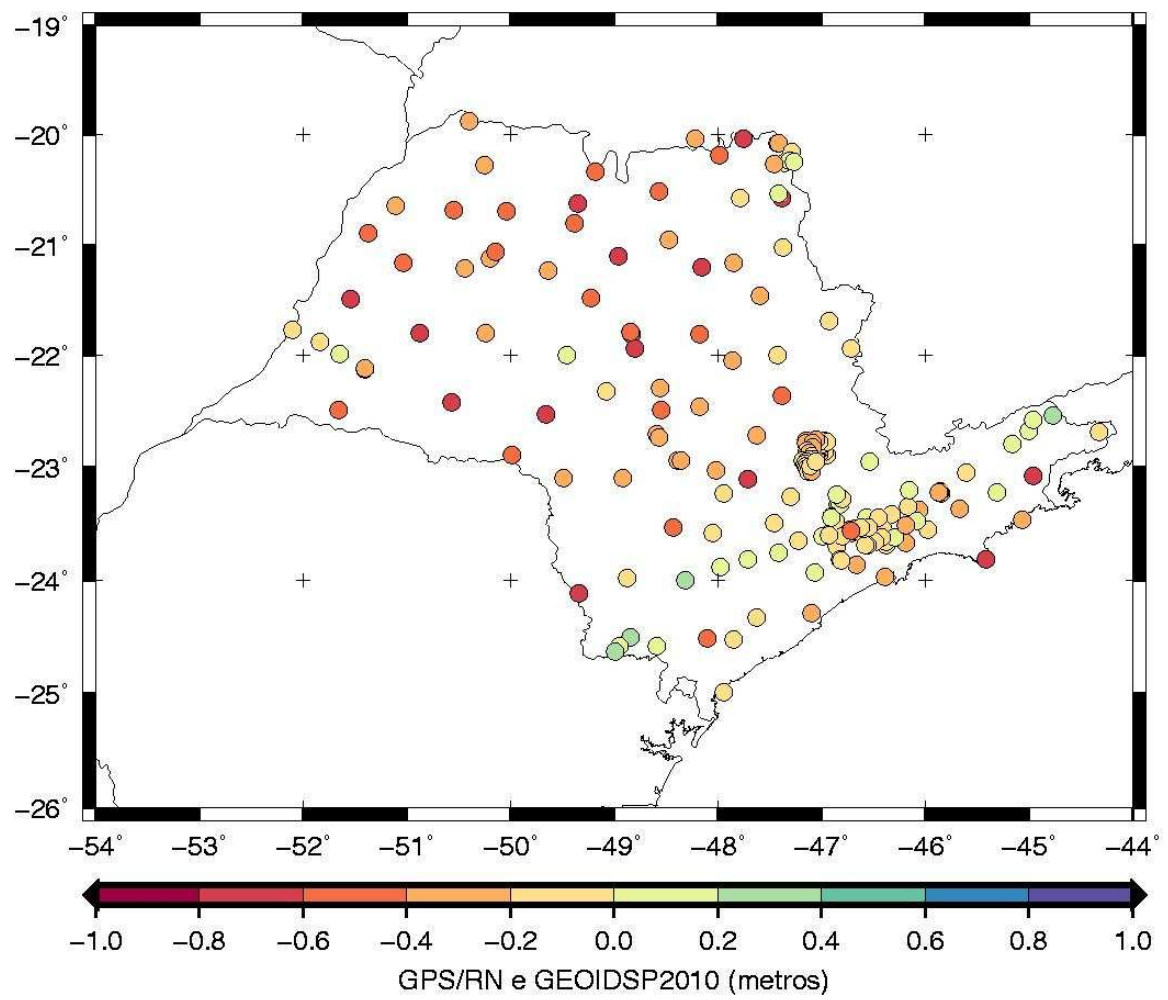

Figura 5.28 - Diferença absoluta entre o GPS/RN e GEOIDSP2010

Tabela 5.6 - Estatística da diferença absoluta

Média RMSD Assimetria Curtose Máx. Mín.

metros

$\begin{array}{lllllll}\text { GEOIDSP2010 } & -0,22 & 0,21 & -0,37 & -0,02 & 0,23 & -0,80\end{array}$


Verifica-se na Tabela 5.6 que a média foi de $-0,22 \mathrm{~m}$ e a diferença média quadrática de 0,21 m. Esperava-se um valor diferente de zero para a média dessa grandeza, uma vez que o termo de ordem zero não foi adicionado no modelo geoidal. Sendo assim, o elipsoide do GGM possui uma diferença sistemática com relação ao GRS80 que é vinculado ao GPS.

Com intuito de delimitar as áreas de maior e menor diferença dos pontos GPS/RN, foi realizada a partir desses pontos uma interpolação em um modelo digital de 30' x 30' para determinar as isolinhas (Figura 5.29). As cores mais claras representam as menores diferenças.

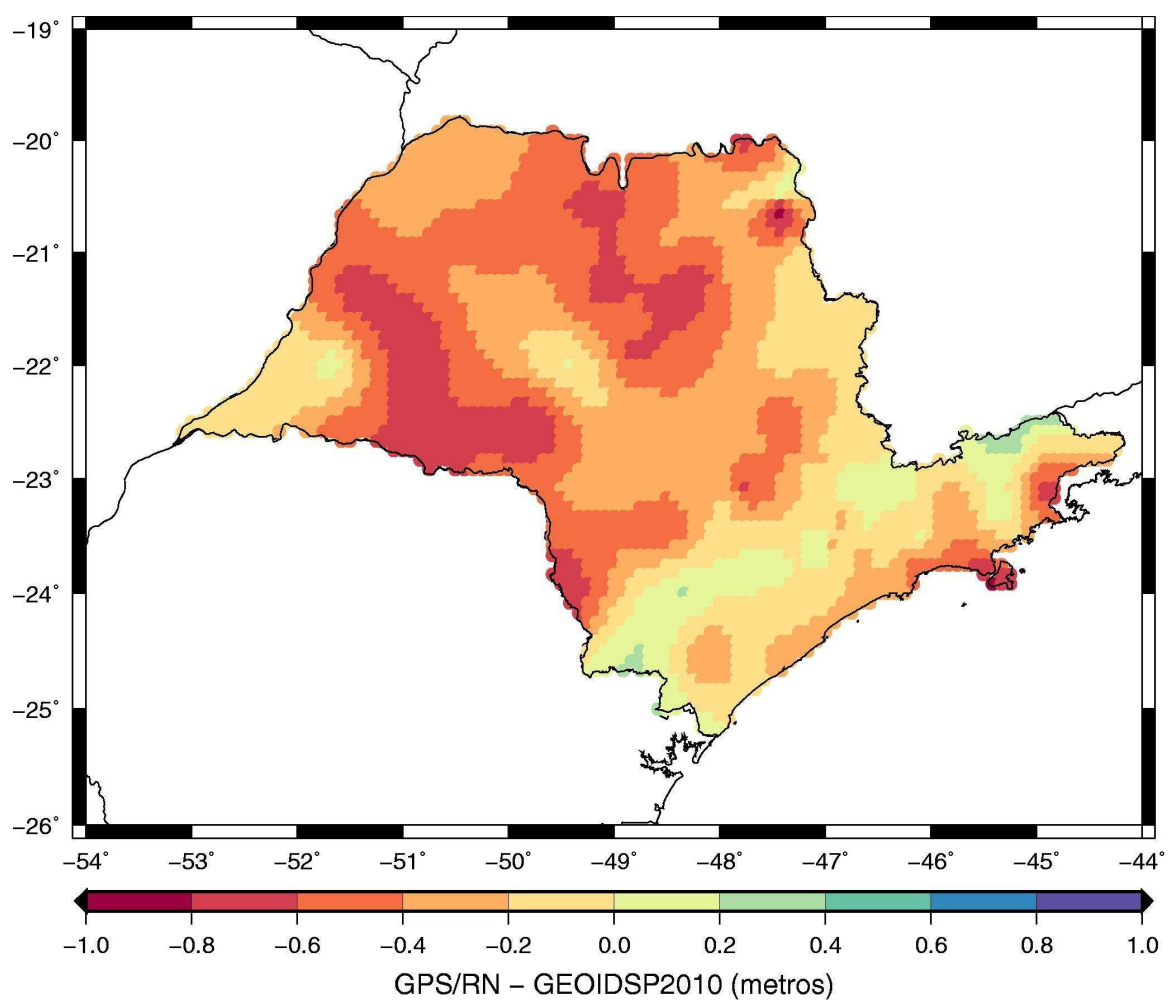

Figura $\mathbf{5 . 2 9}$ - Interpolação da diferença entre o GPS/RN e o GEOIDSP2010

\subsubsection{Comparação GPS/RN e GEOIDSP2010 relativa}

$\mathrm{Na}$ verificação da diferença relativa, um programa foi desenvolvido para escolher pares de pontos espaçados entre $20-50 \mathrm{~km}$. Um total de 72 pares foi selecionado, totalizando 144 pontos. A Figura 5.30 ilustra os pares de pontos selecionados pelo programa. 


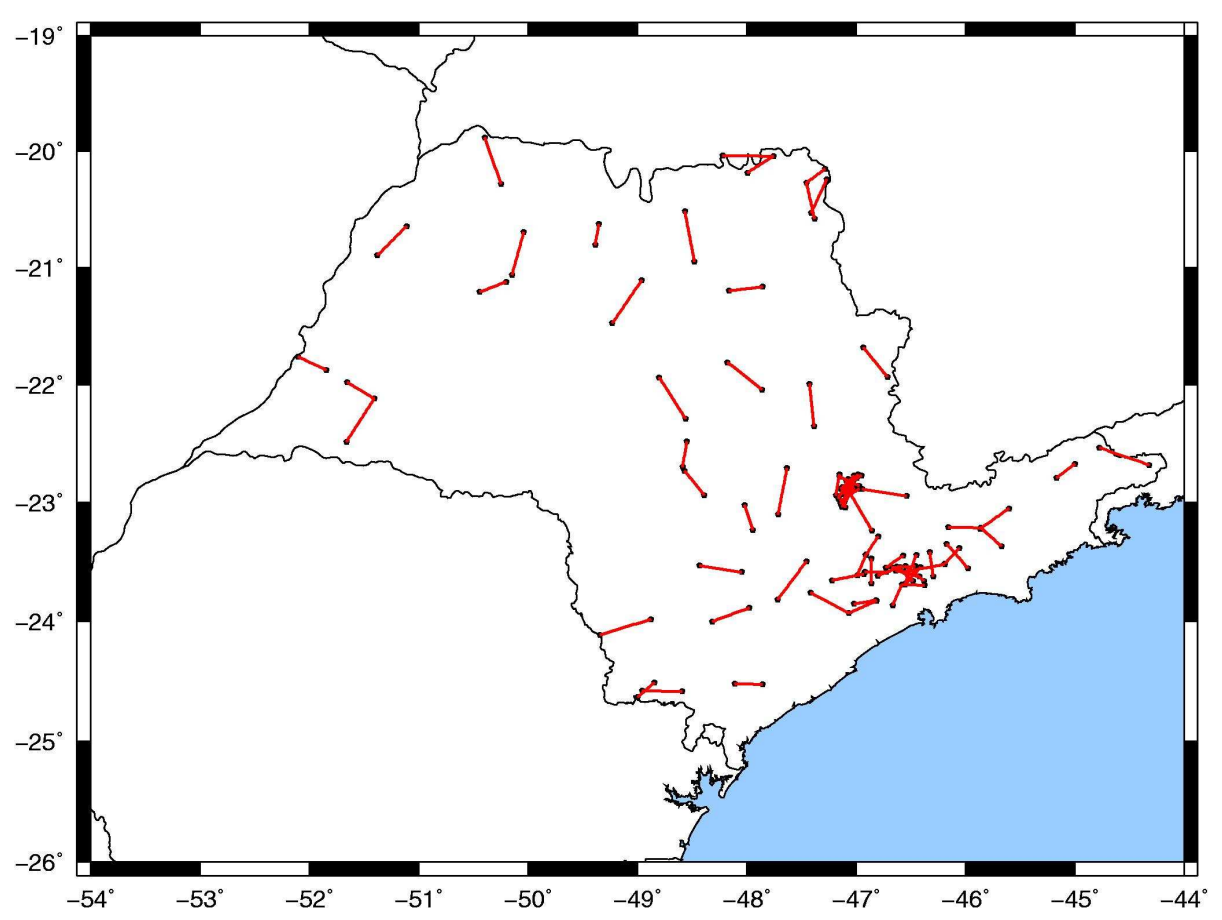

Figura $\mathbf{5 . 3 0}$ - Pares de pontos selecionados

A partir das seguintes expressões é possível calcular a diferença relativa:

$$
\begin{gathered}
N_{G P S 1}-N_{G P S 2}=\Delta N_{G P S} \\
N_{G E O I D E 1}-N_{G E O I D E 2}=\Delta N_{G E O I D E}
\end{gathered}
$$

que é dado por:

$$
\text { difrel }=\left(\Delta N_{\text {GEOIDE }}-\Delta N_{\text {GPS }}\right) / \text { Dist }
$$

O valor final da diferença padrão foi definido como o valor médio resultante de todas as bases. A análise estatística gráfica é vista na Figura 5.31. As cores mais claras representam os menores erros. A Tabela 5.7 mostra as estatísticas do cálculo da diferença relativa. 


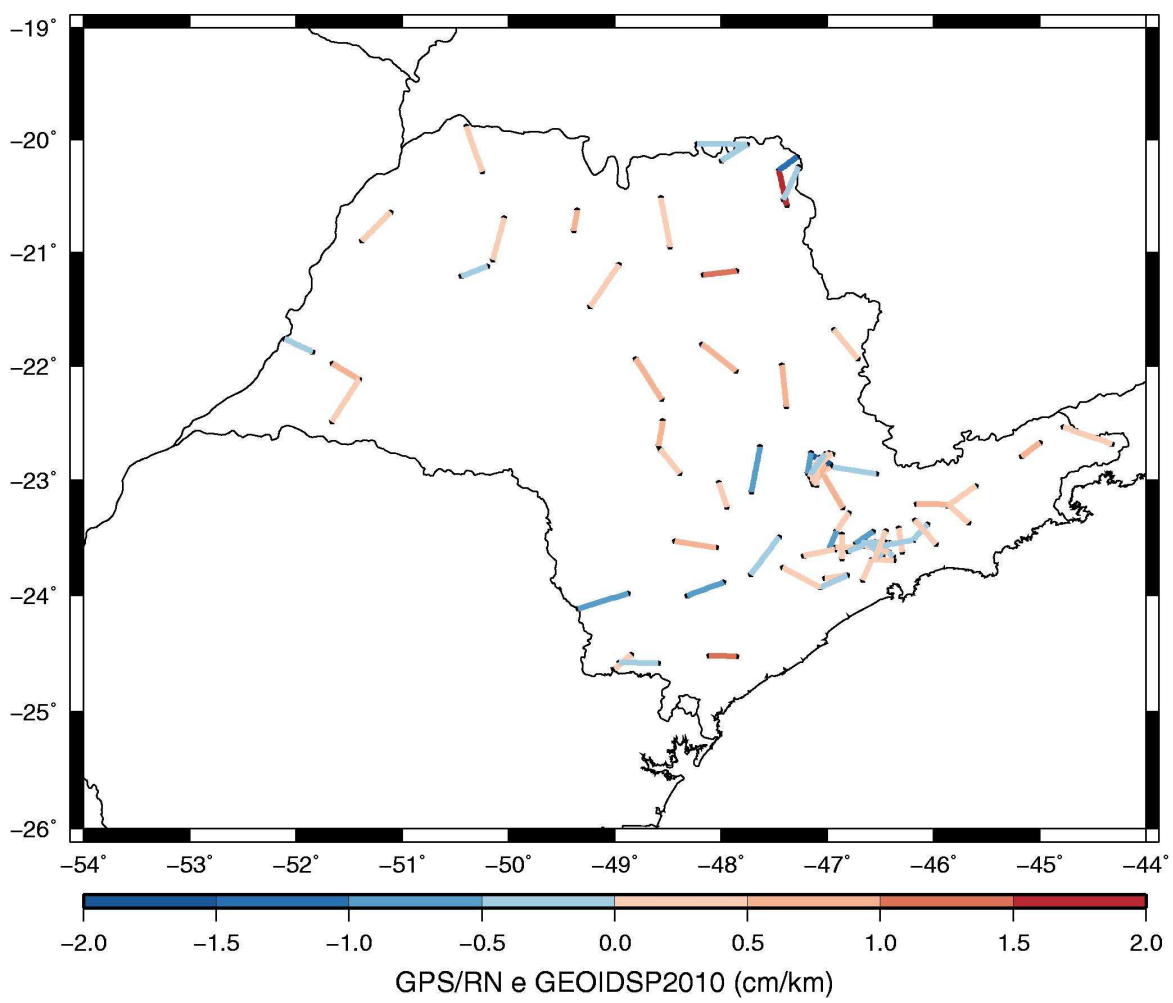

Figura 5.31 - Diferença relativa entre o GPS/RN e GEOIDSP2010

Tabela 5.7 - Estatística da diferença relativa

\begin{tabular}{cccc} 
Média (cm) & Dif. Padrão (cm/km) & Máximo (cm) & Mínimo (cm) \\
\hline 0,15 & 0,58 & 1,87 & $-1,51$ \\
\hline
\end{tabular}




\section{CONCLUSÕES E RECOMENDAÇÕES}

A determinação do campo de gravidade externo às massas, bem como a superfície limitante constitui o problema da Geodésia. Duas formulações foram propostas para a solução do mesmo. Enquanto na primeira (Stokes) existe a dificuldade de se tratar de um problema interno às massas e requerer o conhecimento ao menos teórico de um modelo de distribuição de densidade no interior da crosta, a segunda (Molodenskii) utiliza uma superfície não equipotencial como limite. Várias versões do PVCG (livre, escalar livre, fixo e gravimétrico fixo) foram formuladas, além de novas versões a partir da combinação dos dados "clássicos" com os dados de satélite. A determinação do terno geodésico na superfície física com auxílio da era espacial faz com que o PVCG fixo caminhe para ser o mais empregado nos trabalhos geodésicos. Além disso, o PVCG gravimétrico fixo também evolui na sua utilização graças à altimetria por radar sobre os oceanos. A formulação do PVCG a ser utilizada dependerá da possibilidade de escolha dos dados.

O estabelecimento de um referencial altimétrico está associado à escolha de uma superfície de referência adequada e de um sistema de altitude. A opção por um sistema que não considere o campo de gravidade poderá ocasionar problemas na execução de trabalhos que envolvam água. A definição de conceitos presentes na Geodésia é possível de ser realizada. A escolha de sistemas de referência implica em geral numa definição, sempre possível de ser viabilizada. O número geopotencial pode ser definido sem maiores dificuldades, bem como a altitude ortométrica. No entanto, a materialização dessas grandezas tem implicado numa dificuldade. Materializar um referencial altimétrico ou o NMM de uma região não é uma tarefa simples. O que se busca em um estudo que envolva alguns conceitos da altimetria, tais como, a análise do movimento da crosta terrestre, o estudo do NMM na região, as comparações entre GPS/RN e modelos do geopotencial e a determinação de um modelo geoidal, é verificar se todos estes possuem consistência, convergência e compatibilidade. É necessário averiguar se o modelo geoidal está consistente e compatível com a rede de nivelamento e se o mesmo converge quando comparado a outros modelos. É fundamental que exista uma distinção envolvendo o movimento da crosta terrestre e a variação do NMM. 
Com relação aos estudos realizados:

1) As análises das séries realizadas nas duas estações da RBMC (NEIA e UBAT) comprovam a potencialidade do posicionamento preciso por ponto. Em ambos os processamentos os resultados obtidos se comportaram próximos aos resultados alcançados pelo processamento relativo do IBGE. Vale salientar que a precisão para um conjunto diário de observações utilizando o PPP varia de 1 a $2 \mathrm{~cm}$. Foi possível detectar o comportamento da crosta terrestre, bem como a velocidade planimétrica e a direção, em cada uma das estações. O fato da estação UBAT (direção nordeste) não apresentar deslocamento no mesmo padrão da placa sul-americana (direção noroeste) pode ter sido função da descontinuidade ocorrida na componente Este, o que pode não ser realista. Observou-se que a estação NEIA possui o mesmo padrão de deslocamento que a referida placa. Com relação à componente altimétrica, a remoção da tendência e aplicação da média móvel permitiu detectar ciclos mensais em ambas as estações. Os mesmos podem estar relacionados ao movimento de marés. A perda de dados em alguns períodos de ambas as séries não comprometeu a análise, porém na alternativa de utilização da transformada em ondaleta, por exemplo, o resultado poderá ficar comprometido. Recomenda-se a continuidade do processamento por meio do PPP em ambas as estações. Desta maneira, um período maior de observações poderá evidenciar melhor o comportamento da crosta.

2) A avaliação preliminar do nivelamento advindo de Imbituba e do NMM de Cananeia e Ubatuba permitiu avaliar as discrepâncias. É necessário que sejam realizadas todas as considerações no que diz respeito à correção da TSO, do erro proveniente do nivelamento e também da crosta terrestre. Além disso, a homogeneidade do período de coleta dos dados maregráficos também é de suma importância para que não haja inconsistências na comparação. $\mathrm{O}$ valor de $0,34 \mathrm{~m}$ mesmo não corrigido dos efeitos da crosta terrestre nos conduz a um indicativo de que existe uma diferença entre o nivelamento proveniente de Imbituba e o NMM no litoral paulista. Recomenda-se que seja realizado um estudo mais aprofundado incluindo a correção dos efeitos da crosta terrestre, além dos demais, para se chegar a uma conclusão mais embasada sobre essa diferença. A integração do GNSS com os marégrafos e o gravímetro auxiliará nos estudos relacionados à crosta terrestre e à carga oceânica. 
3) A comparação das anomalias de altura fornecidas pelos GGMs com as ondulações geoidais derivadas de GPS/RN é uma maneira de avaliar a consistência entre essas duas grandezas. O modelo EIGEN-GL04 grau e ordem 360 se adaptou melhor aos dados GPS/RN (Tabela 5.3). Com relação ao modelo EIGEN-5C grau e ordem 360, este foi o que melhor se adaptou (Tabela 5.4) Finalmente, o modelo EGM08 grau e ordem 2160 foi o que obteve melhor adaptação sobre os dados GPS/RN (Tabela 5.5). Além disso, esse último apresentou melhor consistência com relação aos demais modelos do geopotencial utilizados. Conclui-se que a similaridade dos valores da média e da RMSD entre os modelos EIGEN-GL04 e EIGEN-5C comprova a igualdade em termos de Brasil, pois o modelo EIGEN-5C não sofreu nenhuma atualização em relação ao EIGEN-GL04 no que se refere aos dados no território brasileiro.

4) Os esforços advindos das campanhas gravimétricas do Projeto Temático colaboraram de forma substancial para o cálculo do modelo geoidal no estado de São Paulo. Ao todo 1914 medições foram adicionadas até o momento em função do projeto. Na comparação GPS/RN deve-se levar em consideração que tanto o GPS quanto o nivelamento são plausíveis de erros provenientes do levantamento. Além disso, a rede de nivelamento do IGG não sofreu um processo de ajustamento o que pode ter comprometido a qualidade das altitudes ortométricas e, consequentemente, a comparação. Apesar disso, a consistência do modelo geoidal GEOIDSP2010 em relação aos dados GPS/RN foi de 0,21 m. Conclui-se que a determinação do modelo geoidal no estado de São Paulo consistente com a altimetria foi uma importante contribuição. O preenchimento das áreas desprovidas de medidas gravimétricas (principalmente nas regiões serranas) é de suma importância para aprimorar a qualidade do modelo geoidal. É importante que exista uma cooperação entre as instituições produtoras de dados gravimétricos de modo que não haja sobreposição. Recomenda-se que o cálculo do modelo geoidal seja atualizado a partir do momento em que se tenha mais medições oriundas do Projeto Temático e de outros levantamentos. 


\section{REFERÊNCIAS}

ALENCAR, J.C.M. Datum altimétrico brasileiro. Cadernos de Geociências, Rio de Janeiro, 5 v. $1990.5 \mathrm{p}$.

ALMEIDA FILHO, F.G.V. Variação temporal do campo gravitacional detectado pelo satélite GRACE: aplicação na bacia Amazônica. 2009. 146p. Tese (Doutorado) - Escola Politécnica, Universidade de São Paulo, São Paulo, 2009.

ANDERLE, R. Geodetic parameter set NWL-5E-6 based on Doppler satellite observations. In: $2^{\text {nd }}$ INTERNATIONAL SYMPOSIUM GEODETIC USE OF SATELLITES, 1966, Atenas. Proceedings... G. Veis, 179-220p. 1966.

ANDERLE, R.; SMITH, S. NWL-8 Geodetic parameters based on Doppler satellite observations. NWL Technical Report n. 2106. Dahlgren. 1967.

ANDERSEN, O.B. et al. The DNSC08 ocean wide altimetry derived gravity field. In: EUROPEAN GEOSCIENCES UNION 2008 MEETING, 2008, Vienna, Austria, Proceedings... 2009.

BARBOSA, L.G. Proposta de unificação do sistema altimétrico da Grande São Paulo. 1996. 148p. Dissertação (Mestrado) - Escola Politécnica, Universidade de São Paulo, São Paulo, 1996.

BIANCALE, R. 1ère Ecole d'Eté du GRGS. Forcalquier: France, 2002. (Notas de curso de verão, CNES/GRGS).

BLITZKOW, D. Função de transferência de modulação: aplicação ao estudo do desempenho dos sistemas aerofotográficos. 1973. 103p. Dissertação (Mestrado), Universidade Federal do Paraná, Curitiba, 1973.

- O problema do valor de contorno da geodésia: resultados práticos para a América do Sul. 1996. 81p. Tese (Livre Docência) - Escola Politécnica, Universidade de São Paulo, São Paulo, 1996.

Sistemas de altitudes e a determinação do geóide. Curso proferido no Instituto Oceanográfico da Armada (INOCAR). Quaiaquil, Equador: 2003.

BLITZKOW, D.; CAMPOS, I. de O.; FREITAS, S.R.C. Altitude: o que interessa e como equacionar? Laboratório de Topografia e Geodésia - Escola Politécnica, Universidade de São Paulo, São Paulo, 2007. (Notas de aula Informações Espaciais II).

BLITZKOW, D.; CINTRA, J.P.; FORTES, L.P.S. A contribution to the geoid determination. In: RECENT GEODETIC AND GRAVIMETRIC RESEARCH IN LATIN AMERICA. Proceedings International Association of Geodesy Symposia: Symposium, 111. Edited by W. Torge, Springer-Verlag. Berlin, 1991. 
BLITZKOW, D.; et al., An attempt for an Amazon geoid model using Helmert gravity anomaly. Earth: our changing planet, IAG General Assembly at IUGG XXIV, Perugia Italia, July 2-13. 2007.

BURŠA, M. Primary and derived parameters of common relevance of astronomy, geodesy and geodynamics. Earth, Moon and Planets, v. 69, n. 1, p. 51-63, 1995.

CAMPOS, I. de O. Referencial altimétrico para a bacia do Rio Amazonas. 2004. 110p. Tese (Doutorado) - Escola Politécnica, Universidade de São Paulo, São Paulo, 2004.

CASTRO, C.A.C. Jr. Contribuição ao estabelecimento de um sistema gravimétrico para a América do Sul. 2005. 151p. Dissertação (Mestrado) - Escola Politécnica, Universidade de São Paulo, São Paulo, 2005.

CHELTON, D.B.; et al. Satellite altimetry and earth sciences, A handbook of techniques and applications: Satellite altimetry. In: FU, L.L.; CAZENAVE, A. (Ed.). San Diego: Academic Press, p. 1-122, 2001.

DREWES, H.; et al. Documento técnico sobre o sistema de referência vertical para a América do Sul. SIRGAS, Boletim Informativo n. 6, p. 23-3, 2002a.

. Scientific foundations of the SIRGAS vertical reference system. In: Vertical Reference Systems (International Association of Geodesy). Berlin: SpringerVerlag, v. 124, p. 297-301, 2002b.

FARR, T.G.; et al. The Shuttle Radar Topography Mission, Reviews of Geophysics, v.45, n 2, p. 21-35, 2007.

FEATHERSTONE, W.E. A comparison of gravimetric geoid models over Western Australia, computed using modified forms of Stokes's integral. Journal of the Royal Society of Western Australia, v.82, p. 137-145, 1999.

. Expected contributions of dedicated satellite gravity field missions to regional geoid computations, Journal of Geospatial Engineering, v. 4, n. 1, p. 2-19, 2002.

FEATHERSTONE, W.; EVANS, J.; OLLIVER, J. A Meissl-modified Vaníček and Kleusberg kernel to reduce the truncation error in gravimetric geoid computations. Journal of Geodesy, v.72, p. 154-160, 1998.

FEATHERSTONE, W.E.; KUHN, M. Height systems and vertical datums: a review in the Australian context. Journal of the Spatial Science. v. 51, n. 1, p. 21-41, 2006.

FORSBERG, R.; KENYON, S. Gravity and geoid in the Arctic region - The northern gap now filled. In: $2^{\text {ND }}$ WORKSHOP GOCE. ESA Publication Division, Noordwijk, 2004. 1 CD-ROM. 
FÖRSTE, C.; et al. A mean global gravity field model from the combination of satellite mission and altimetry/gravimetry surface data - EIGEN-GL04C. Geophysical Research Abstracts, v. 8, 2006.

FREITAS, S.R.C.; BLITZKOW, D. Altitudes e Geopotencial. IGeS Bulletin N.9 International Geoid Service. Junho 1999, Milão, p. 47-62, 1999.

GEMAEL, C. Introdução a Geodésia Física. Curitiba: Editora UFPR, 1999.

GEODETIC SURVEY DIVISION. Disponível em: http://webapp.csrs.nrcan.gc.ca/field/Scripts/CSRS_PPP_main_e.pl. Acesso em: 25 de ago. 2009.

GUIER, W.H.; NEWTON, R.R. The Earth's gravity field deduced from the Doppler tracking of five satellites. Journal of Geophysical Research, v. 70, p. 4613-4626, 1965.

HECK, B. The non-linear geodetic boundary value problem in quadratic approximation. Manuscripta Geodaetica, v. 13, p. 337-348, 1988.

A contribution to the scalar free boundary value problem of physical geodesy. Manuscripta Geodaetica, v.14, p. 87-99, 1989a.

. On the non-linear geodetic boundary value problem for a fixed boundary surface. Bulletin Géodésique, v.63, p. 57-67, 1989b.

On the linearized boundary value problems of physical geodesy. Ohio $\overline{\text { State }}$ University, Report 407. Columbus, 1991.

Formulation and linearization of boundary value problems: from observables to a mathematical model. In: SANSÒ, F.; RUMMEL, R. (Eds.). Geodetic boundary value problems in view of the one centimeter geoid. Berlin: Springer, p. 121-160, 1997. (Lectures Notes in Earth Sciences, v.65).

HEISKANEN, W.A.; MORITZ, H. Physical geodesy. San Francisco: Freeman and Co., 1967.

HIRVONEN, R.A. New theory of gravimetric geodesy. Publications of the Isostatic Institute of the International Association of Geodesy, Helsinki, v. 32, 1960.

. The reformation of geodesy. Journal of Geophysical Research, v. 66, p. 1471-1478, 1961.

HOFMANN-WELLENHOF, B.; MORITZ, H. Physical geodesy. $2^{\text {nd }}$ Edition, New York: Springer. 2005.

HOLMES, S.; PAVLIS, N. Earth Gravitational Model 2008 (EGM2008). Disponível em: http://earthinfo. nga.mil/GandG/wgs84/gravitymod/egm2008/first_release.html. Acesso em: 30 de out. 2009. 
IAG. IAG Resolution 16, Geodesists Handbook, Bulletin Géodésique, v. 58, n. 3, p. 324, 1984.

IGG (Instituto Geográfico e Geológico do Estado de São Paulo) Nivelamento de precisão. Secretaria da Agricultura IGG, Boletim n. 30, p. 47-71,1943.

Nivelamento Geral do Estado de São Paulo: altitudes de precisão. Secretaria da Agricultura IGG, Boletim N³6, p. $101,1962$.

INSTITUTO BRASILEIRO DE GEOGRAFIA E ESTATISTICA. Geociência:

Rede gravimétrica. 2004.2 Disponível em: <http://www.ibge.gov.br/home/geociencias/geodesia/rmpg/default_rmpg_int.shtm?c= 10>. Acesso em: 26 de mar. 2009a.

Geociência: Rede altimétrica. 2009 Disponível em: < ftp://geoftp.ibge.gov.br/documentos/geodesia/altitotal.pdf>. Acesso em: 01 de out. 2009b.

JEKELI, C. Heights, the geopotential, and vertical datums. The Ohio State University, Columbus, USA: Department of Geodetic Science, (Report 459). 34 p. 2001.

KAULA, W.M. Tests and combinations of satellite determinations of the gravity field with gravimetry. Journal of Geophysical Research. v. 71, p. 5303-5314, 1966.

KÖHNLEIN, W. The Earth's gravitational field as derived from a combination of satellite data with gravity data. Presented at 14th General Assembly, IUGG, Lucerne, Switzerland, 1967.

LEMOINE, F.G.; et al. New high-resolution model developed for Earth' gravitational field, Earth Observing System. Transactions. AGU, n. 113, p. 117-118. 1998a.

The development of the joint NASA GSFC and the National Imagery and Mapping Agency (NIMA) geopotential model EGM96, NASA/TP-1998-206861. Maryland, USA: National Aeronautics and Space Administration, 1998b.

LI, Y.; SIDERIS, M. Estimation and minimization of geoid undulation errors, In: International Association of Geodesy General Meeting. Beijing, China, 1993.

LOBIANCO, M.C.B. Determinação das alturas do geoide no Brasil. 2005. 165p. Tese (Doutorado) - Escola Politécnica da Universidade de São Paulo, São Paulo, 2005.

LUNDQUIST, C.A.; VEIS G. Geodetic parameters for a 1966 Smithsonian Institution Standard Earth. Special Report, Cambridge, Massachusetts, EUA, v. 1, n. 200, 1966.

LUZ, R.T.; GUIMARÃES, V.M. Realidade e Perspectivas da Rede Altimétrica de Alta Precisão do Sistema Geodésico Brasileiro. In: Anais do II Colóquio Brasileiro de Ciências Geodésicas (CD-ROM), Curitiba, 2001. 
Dez Anos de Monitoramento do Nível do Mar no IBGE. In: Anais do III Colóquio Brasileiro de Ciências Geodésicas (CD-ROM), Curitiba, 2003.

LUZ, R.T.; et al. Brazilian first order levelling network. In: Vertical Reference Systems (International Association of Geodesy). Ed. Springer-Verlag, v. 124, p. 20-22, 2002.

LUZ, R.T. Estratégias para a modernização da componente vertical do Sistema Geodésico Brasileiro e sua integração ao SIRGAS. Tese (Doutorado), Universidade Federal do Paraná, Curitiba, 2008.

McCARTHY, D.D.; PETIT, G.; EDS. IERS Conventions (2003). IERS Technical Note 32, Frankfurt am Main: Verlag des Bundesamts für Kartographie und Geodäsie, 2004.

MEISSL, P. Preparations for the numerical evaluation of second-order Molodenskii-type formulas. Columbus, Dep. of Geodetic Science and Surveying. Ohio State University, Report 163, 1971.

MESQUITA, A.R.; HARARI, J. Tides and tide gauges of Cananéia and Ubatuba Brazil. Relatório Interno. Instituto Oceanográfico Universidade de São Paulo. São Paulo. 1983.

MOLODENSKII, M.S.; EREMEV, V.F.; YURKINA, M.I. Methods for study of the external gravity field and figure of the earth. Israel Jerusalém Scientific Translations, Jerusalém, 1962.

MONICO, J.F.G. Posicionamento pelo GNSS: Descrição, fundamentos e aplicações. 2.ed, São Paulo: Ed. UNESP, 2008.

PAUL, M.K. A method of evaluating the truncation error coefficients for geoidal height. Bulletin Geodesique, Berlin, n. 47 p. 413-425, 1973.

PAVLIS, N.K.; et al. An Earth gravitational model to degree 2160: EGM2008. presented at the 2008 General Assembly of the European Geosciences Union, Vienna, Austria, April 13-18, 2008.

PINHEIRO, R.R.; et al. Situação atual do ajustamento da rede altimétrica de alta precisão - RAAP do SGB, utilizando o sistema GHOST. In: XXII Congresso Brasileiro de Cartografia, Rio de Janeiro, 21-24 de outubro de 2007.

PUGH, D. Tides, surges tides and mean sea-level: A Handbook for Engineers and Scientists. Manchester, United Kingdom: John Wiley and Sons, 1987.

RAPP, R.H.; et al. Consideration of permanent tidal deformation in the orbit deformation and data analysis for the TOPEX/Poseidon mission, NASA Technical Memo 100775. Goddard Space Flight Center, Greenbelt, USA, 1991. 
RAPP, R.H. Past and future developments in geopotential modeling, geodesy on the move. Forsberg, Feissel, Dietrich (eds), Springer-Verlag Berlin. New York, p. $58-78,1998$.

RUMMEL, R.; et al. Dedicated gravity field missions - principles and aims, Journal of Geodynamics. n. 1-2, v. 33, p. 3-20, 2002.

SÁ, N.C.; et al. Rede GPS no estado de São Paulo: aprimoramento de modelos geoidais e apoio básico local. Relatório científico final - FAPESP (Processo $\mathrm{n}^{\circ}$ 99/012691-9). São Paulo, 2006.

SACERDOTE, F.; SANSÒ, F. The scalar boundary value problem of physical geodesy. Manuscripta Geodaetica, v. 11, p. 15-28, 1986.

SALEH, J.; PAVLIS, N.K. The development and evaluation of the global digital terrain model DTM2002. In: $3^{\text {rd }}$ Meeting of the International Gravity and Geoid Commission. Thessaloniki, Greece, 2002.

SCHWARZ, K.P.; SIDERIS, M.G.; FORSBERG, R. The use of FFT techniques in physical geodesy. Geophysical Journal. v. 100, p. 485-514, 1990.

SIDERIS, M. The gravity field in surveying and Geodesy. Calgary, Canada, 1993.

TORGE, W. Geodesy. 3ed New York, USA: Ed. Walter de Gruyter, 2001.

VANÍČEK, P.; KRAKIWSKY, E. Geodesy: the concepts. Holland: NorthHolland,1986.

VANÍČEK, P.; et al. The Canadian geoid. Department of Geodesy and Geomatics Engineering - University of New Brunswick. Fredericton, Canada, 1987.

VANÍČEK, P.; FEATHERSTONE, W.E. Performance of three types of Stoke's kernel in the combined solution for the geoid. Journal of Geodesy, Berlin v. 71, n. 12, p. 684-697, 1998.

WONG, L.; GORE, R. Accuracy of geoid heights from modified Stokes Kernels. Geophysical Journal Research, New York, vol. 18, n. 1, p. 81-91, 1969. 